\title{
Channel Transmission Loss Studies During Ephemeral Flow Events: ER-5-3 Channel and Cambric Ditch, Nevada Test Site, Nye County, Nevada
}

\author{
prepared by \\ Julianne J. Miller, Steve A. Mizell, Richard H. French, Darren G. Meadows, \\ and Michael H. Young
}

submitted to

Nevada Site Office

National Nuclear Security Administration

U.S. Department of Energy

Las Vegas, Nevada

September 2005

Publication No. 45213 
Reference herein to any specific commercial product, process, or service by trade name, trademark, manufacturer, or otherwise, does not necessarily constitute or imply its endorsement, recommendation, or favoring by the United States Government or any agency thereof or its contractors or subcontractors. The views and opinions of authors expressed herein do not necessarily state or reflect those of the United States Government or any agency thereof.

This report has been reproduced directly from the best available copy.

Available for sale to the public, in paper, from:

U.S. Department of Commerce

National Technical Information Service

5285 Port Royal Rd.

Springfield, VA 22161

phone: 800.553 .6847

fax: 703.605 .6900

email: order@ntis.gov

online ordering: http://www.osti.gov/ordering.htm

Available electronically at http://www.doe.gov/bridge

Available for a processing fee to the U.S. Department of Energy and its contractors, in paper, from:

U.S. Department of Energy

Office of Scientific and Technical Information

P.O. Box 62

Oak Ridge, TN 37831-0062

phone: 865.576 .8401

fax: 865.576.5728

email: reports@adonis.osti.gov 


\title{
Channel Transmission Loss Studies During Ephemeral Flow Events:
}

\section{ER-5-3 Channel and Cambric Ditch, Nevada Test Site, Nye County, Nevada}

\author{
prepared by \\ Julianne J. Miller ${ }^{1}$, Steve A. Mizell ${ }^{1}$, Richard H. French ${ }^{2}$, Darren G. Meadows ${ }^{1}$, \\ and Michael H. Young ${ }^{1}$ \\ ${ }^{1}$ Division of Hydrologic Sciences, Desert Research Institute, 755 East Flamingo Road, \\ Las Vegas, Nevada 89119 \\ ${ }^{2}$ Department of Civil and Environmental Engineering, University of Texas \\ at San Antonio, 6900 North Loop 1604 West, San Antonio, TX 78249
}

Publication No. 45213

submitted to

Nevada Site Office

National Nuclear Security Administration

U.S. Department of Energy

Las Vegas, Nevada

SEPTEMBER 2005

The work upon which this report is based was supported by the U.S. Department of Energy under Contract \#DE-AC52-00NV13609. Approved for public release; further dissemination unlimited. 
THIS PAGE INTENTIONALLY LEFT BLANK 


\section{EXECUTIVE SUMMARY}

Transmission losses along ephemeral channels are an important, yet poorly understood, aspect of rainfall-runoff prediction. Losses occur as flow infiltrates channel bed, banks, and floodplains. Channel transmission loss research has been conducted at the U.S. Department of Energy/National Nuclear Security Administration's Nevada Test Site (NTS), where two transmission loss field experiments have been completed using water discharged from unrelated drilling activities. This research was designed to improve understanding of the impact of transmission loss on ephemeral flood modeling and compare various methodologies for predicting runoff from rainfall events. Various applications of this research to DOE projects include more site-specific accuracy in runoff prediction; possible reduction in size of flood mitigation structures at the NTS; and a better understanding of expected infiltration from runoff losses into landfill covers.

Two channel transmission loss field experiments were performed on the NTS between 2001 and 2003: the first was conducted in the ER-5-3 channel (Miller et al., 2003), and the second was conducted in the Cambric Ditch (Mizell et al., 2005). Both studies quantified transmission losses using water discharged from unrelated drilling activities during well development and aquifer pump tests. Discharge measurements at several flumes located along the channels were used to directly measure transmission losses. Flume locations were chosen in relation to geomorphic surface types and ages, vegetative cover and types, subsurface indurated layers (calcrete), channel slopes, etc. At some of the flumes, instrument arrays, consisting of water content reflectometers (WCR), heat dissipation sensors (HDS), and thermocouples were installed in the subsurface to collect additional data for loss quantification analyses.

Transmission losses are quantified using three different analysis methods. Method 1 uses Lane's Method (Lane, 1983) for estimating flood magnitude in ephemeral channels. Method 2 uses heat as a subsurface tracer for infiltration. Numerical modeling, using HYDRUS-2D (Simunek et al., 1999), a finite-element-based flow and transport code, was applied to estimate infiltration from soil temperature data. Method 3 uses hydraulic gradient and water content in a Darcy's Law Approach (Freeze and Cherry, 1979) to calculate one-dimensional flow rates. Heat dissipation and water content data were collected for this analysis.

In the ER-5-3 channel experiment, using the discharge measurements from the flumes, up to 70 percent of the flow was lost in reaches of 1,000 to 2,000 $\mathrm{m}(3,300$ to $6,600 \mathrm{ft}$ ). In Cambric Ditch, approximately 40 percent of the initial upstream flow was lost throughout the $1,000 \mathrm{~m}(3,300 \mathrm{ft})$ experimental channel. The timing of flow events at each subsequent downstream flume location within these experimental channels suggested transmission losses were occurring in the intervening reach. Loss of flow volume between the upstream and downstream flumes of each reach confirmed transmission losses. The greatest losses were measured in the reaches with the youngest soils, characterized by unconsolidated sands, no calcrete, and no indication of long term stability. Losses were less in the reaches where geomorphic surface ages were older and calcrete present. However, study results have since suggested that within the lower reach of Cambric Ditch, which is 
closer to the playa, an increased amount of fine material has been thoroughly intermixed with the sandy soil either by shoreline movement or eolian transport.

Thermocouples were used to determine temperature changes associated with infiltration. Temperature changes clearly indicated the beginning and end of each flow event. Thermal gradients corresponded well with channel and surficial geomorphology and measured losses. Larger thermal gradients were measured on older geomorphic surfaces with buried calcrete, suggesting heat transfer by conduction, and thus lower infiltration rates. Smaller thermal gradients, suggesting advection-dominated heat transfer and higher infiltration rates, were observed in reaches on younger geomorphic surfaces.

The WCR probes were used to measure water content in the soil. The WCR measured an abrupt, large magnitude change in moisture content with the arrival of flow in the channel. The HDS probes were used to evaluate soil water tension. All HDS probes reflected the diurnal atmospheric temperature variations, as well as measuring the lowest water tension in the wettest conditions. However, HDS sensor sensitivity is quite poor for the range of soil wetness typically found in arid environments; thus, readings may have not represented actual soil conditions.

The transmission losses were quantified using three different analysis methods, the first being Lane's Method (Lane, 1983) for estimating flood magnitude in ephemeral channels, which compensates for transmission losses. As inflow-outflow data for each reach within the experimental channels was known from flume measurements, Lane's Method was used to predict outflow volumes that could then be compared with the measured flume data. However, the conditions of the NTS transmission loss experiments may not have been sufficiently similar temporally or spatially to the conditions underlying the data Lane used in deriving his method. Therefore, only two reaches, ER-5-3 reach 3 (between ER-5-3 stations 3 and 4) and Cambric reach 2 (between Cambric stations 2 and 3), produced an intercept and slope for the Lane's Method estimating equation that satisfied the constraints of the method.

For both the ER-5-3 reach 3 and Cambric reach 2, Lane's Method slightly over-estimates the measured outflow for each reach in two of the three flow events; however, the percent error of the over-estimated outflow only ranges between 1.3 to 5.1 percent. For the remaining flow event in each reach, the method under-estimates the measured outflow, but again the percent error is relatively small, ranging between 2.5 to 6.0 percent. These results suggest that the Lane's Method is a good estimator of discharge from a reach when the regression equation coefficients are within proper constraints.

The HYDRUS-2D (Simunek et al., 1999) finite-element-based flow and transport code was used to model the measured temperature data from the experimental channels. The model was able to fit the measured temperature and water content data for ER-5-3 stations 1 and 4 relatively well; however, there were some inconsistencies between the measured water content and the modeled predictions at depth. These inconsistencies were most likely the result of increasing heterogeneity as the flowpath lengthens, and with the water travel time to the deeper probes. The models for the Cambric Ditch were produced based upon the fit to the temperature data alone, as there were no hydraulic physical 
property data on the in-situ soils to support the parameters used in the model. Again, the model was able to fit the measured temperature data for Cambric Ditch stations 1, 2, and 3 relatively well. Models for the two experimental channels produced cumulative infiltration estimates ranging from approximately 3.0 to $740.0 \mathrm{~m}^{3}$ per meter $\left(32.3\right.$ to $7961.2 \mathrm{ft}^{3}$ per foot), with corresponding infiltration flux ranging from 0.3 to $2.0 \mathrm{~m} / \mathrm{d}(1.0$ to $6.6 \mathrm{ft} / \mathrm{d})$, depending upon the geomorphic surface. The HYDRUS-2D (Simunek et al., 1999) analyses indicate that temperature can be used to make relatively good estimates of soil water content, which correlates to infiltration, or in this case, to channel transmission loss estimates.

Darcy's Law (Freeze and Cherry, 1979) was used as the last approach to quantify transmission losses using hydraulic gradient and water content to calculate one-dimensional flow rates. Heat dissipation and water content data collected from ER-5-3 stations 1 and 4 were used for this analysis. As water content data were not collected in Cambric Ditch, no analysis was performed.

The Darcy's Law approach estimate of total infiltration volume over the ER-5-3 reach 3 (upstream of station 4) assumes the infiltration rate calculated at ER-5-3 station 4 is representative of the entire reach. Infiltration estimates, using the Darcy analysis, ranged from 7572.6 to $12420.1 \mathrm{~m}^{3}\left(267,423.8\right.$ to $\left.438,611.7 \mathrm{ft}^{3}\right)$ for the various flow events in this reach of the ER-5-3 channel. These calculated loss estimates are six to eight times greater than the measured losses between ER-5-3 stations 3 and 4 (ER-5-3 reach 3). The difference in the loss estimation is likely due to using saturated hydraulic conductivity in the calculation and assuming that soil characteristics and saturated hydraulic conductivity at ER-5-3 station 4 describe the entire reach. Thus, without more spatially-detailed knowledge of the soil characteristics and hydraulics within a channel, it is unlikely that using Darcy's Law approach to estimate transmission losses is a valid approach.

Although transmission losses measured through the entire length of both experimental channels ranged upwards between 40 and 70 percent, it is clear from the variation of transmission loss volumes measured in shorter reaches of the channels that these losses vary greatly along the length of a channel. The variation in volume of transmission losses in the shorter reaches demonstrates the important roles that geomorphic surface types and ages, vegetative cover and types, subsurface indurated layers (calcrete), channel slopes, soil hydraulic properties, etc. play in runoff prediction.

Although these studies indicate that there may be some validity in applying temperature modeling or Lane's Method (1983) to estimating transmission losses if the necessary detailed, specific, and accurate information regarding geomorphic surfaces, vegetation, subsurface conditions, and soils properties, is available, without this site-specific information, it appears that it would be difficult to consistently estimate accurate transmission losses using any of the three methods evaluated in these studies. Thus, at this time, it is not recommended that DOE/NNSA, or any other entity, attempt to reduce any rainfall-runoff model-generated discharge value to account for transmission losses in any engineering analysis or design. 
THIS PAGE INTENTIONALLY LEFT BLANK 


\section{CONTENTS}

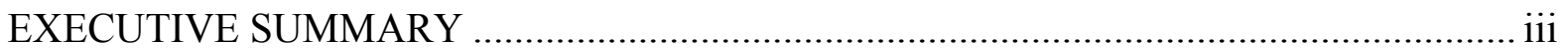

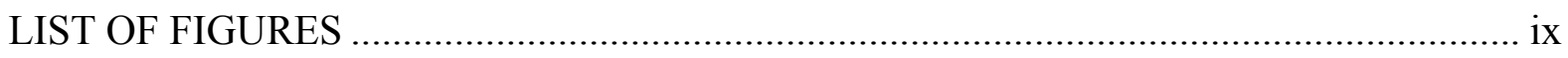

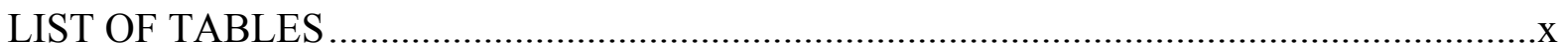

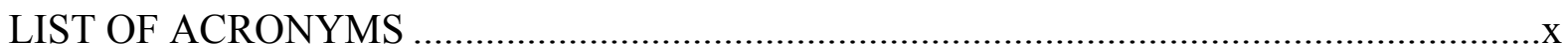

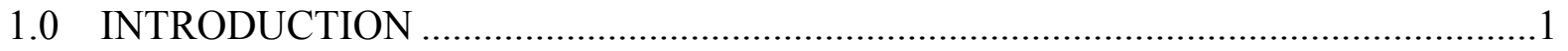

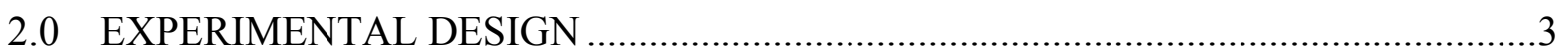

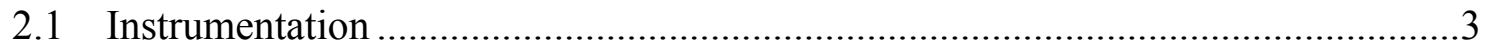

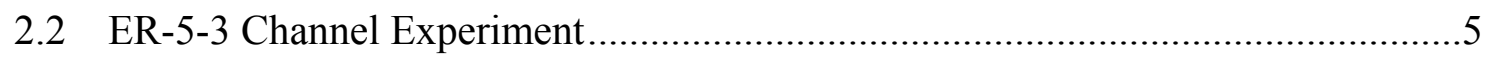

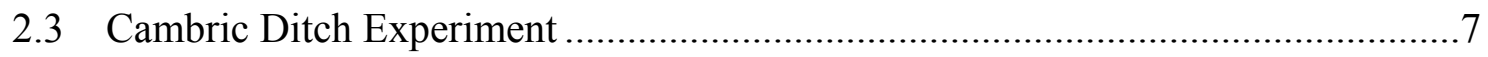

3.0 DIRECT MEASUREMENT RESULTS OF TRANSMISSION LOSS STUDIES .........9

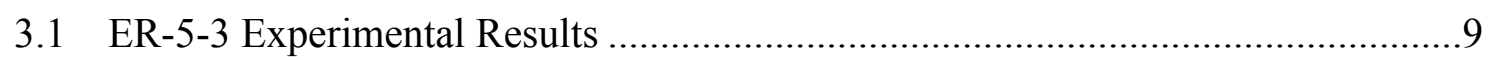

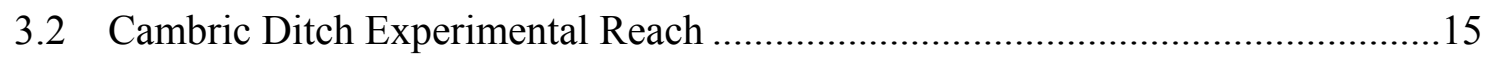

4.0 TRANSMISSION LOSS QUANTIFICATION ANALYSES ..................................25

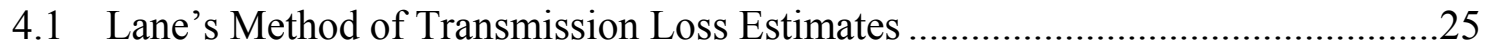

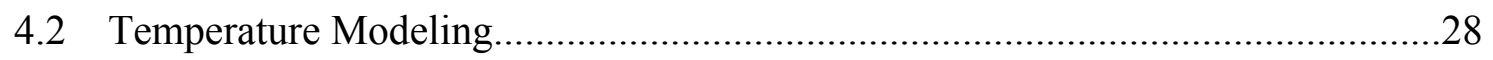

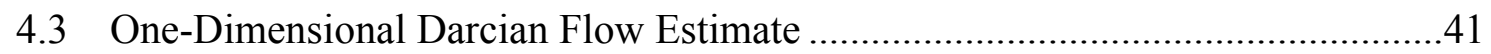

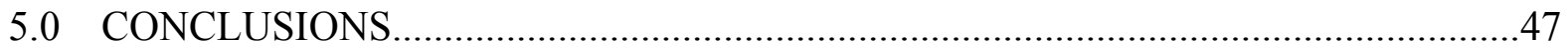

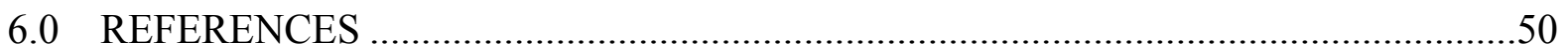

APPENDICES (on CD in pocket of back cover)

A. ER-5-3 Channel and Cambric Ditch Data ........................................................... A-1

Part 1: Full Data Set

Part 2: Reduced Data Set

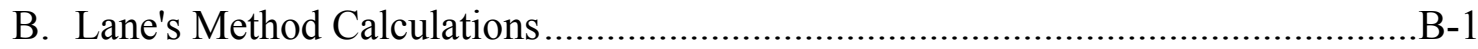

C. HYDRUS-2D Model Input and Output Data........................................................

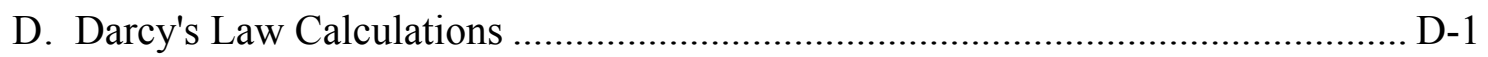


THIS PAGE INTENTIONALLY LEFT BLANK 


\section{LIST OF FIGURES}

2.1 Typical flume and instrumentation station on ER-5-3 Channel. .................................4

2.2 Typical flume and instrumentation station on Cambric Ditch.................................

2.3 A. Aerial photograph showing locations of the flume stations on ER-5-3 Channel.

B. Surficial geomorphic map showing locations of the flume stations on ER-5-3

Channel and the corresponding soils. ..........................................................6

2.4 Aerial photograph showing locations of the flume stations on Cambric Ditch............8

3.1 Hydrographs of channel transmission loss experiment flows at ER-5-3 Channel.......10

3.2 Soil temperature and discharge for ER-5-3 station 1 ...............................................11

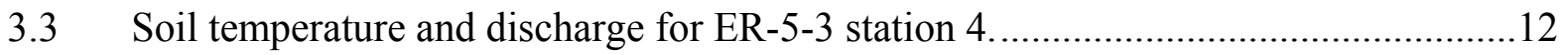

3.4 Moisture content and discharge for ER-5-3 station 1..........................................13

3.5 Moisture content and discharge for ER-5-3 station 4 ........................................ 14

3.6 Soil water tension and discharge for ER-5-3 station 1. ........................................... 14

3.7 Soil water tension and discharge for ER-5-3 station 4. ......................................15

3.8 Hydrographs of channel transmission loss experiment flows at Cambric Ditch........16

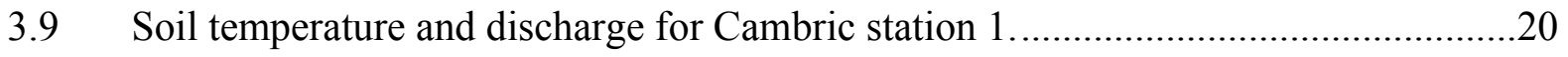

3.10 Detail of soil temperature and discharge for Cambric station 1. ...............................21

3.11 Soil temperature and discharge for Cambric station 2 .......................................21

3.12 Soil temperature and discharge for Cambric station 3 ........................................22

3.13 Soil water content and discharge for Cambric station 2...................................22

3.14 Soil water content and discharge for Cambric station 3......................................23

3.15 Soil water tension and discharge for Cambric station 2. ......................................23

3.16 Soil water tension and discharge for Cambric station 3. ......................................24

4.1 A. Close-up of the model domain showing the finite-element mesh.

B. Extended view of the model domain.

4.2 Comparison of the modeled and field temperature data at ER-5-3 station 1 at A)

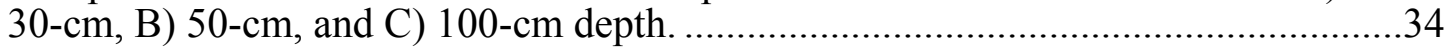

4.3 Comparison of modeled and field temperature data and discharge at ER-5-3 station 1 for the flow period.

4.4 Comparison of the modeled and field temperature data at ER-5-3 station 4 at A)

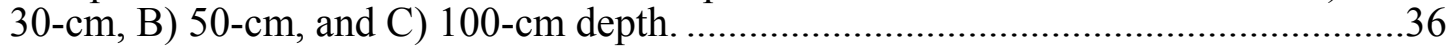

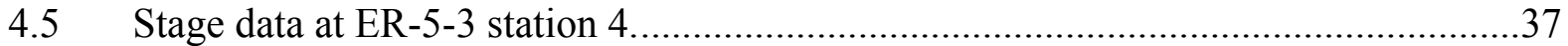

4.6 Comparison of modeled (symbols) and field (solid) temperature data and discharge

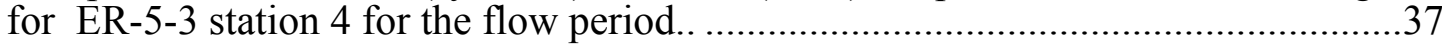

4.7 Comparison of the modeled and field temperature data at Cambric station 1 at A)

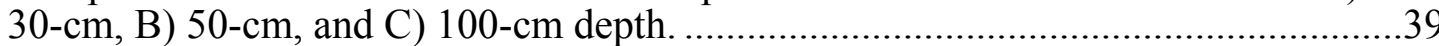

4.8 Comparison of the modeled and field temperature data at Cambric station 2 at $\mathrm{A}$ ) 30-cm, B) 50-cm, and C) 100-cm depth.

4.9 Raw data from the WCR and discharge data collected at Cambric station 2

4.10 Comparison of the modeled and field temperature data at Cambric station 3 at A) 30-cm, B) 50-cm, and C) 100-cm depth.

4.11 Raw data from the WCR and discharge data collected at Cambric station 3............43 


\section{LIST OF TABLES}

2.1 General description of soils and channel bed along ER-5-3 experimental reach. ........5

2.2 ER-5-3 experiment instrumentation and location ............................................6

2.3 Cambric experiment instrumentation and location ............................................

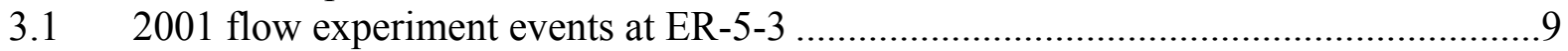

3.2 2003 Cambric Ditch flow experiment event statistics ...........................................17

4.1 Parameters for Lane's Method estimation equation developed by regression of ER-5-3 and Cambric Ditch transmission loss inflow-outflow data..........................27

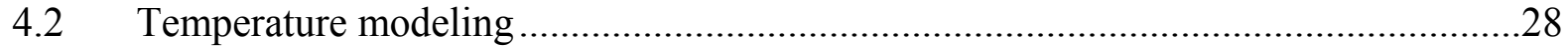

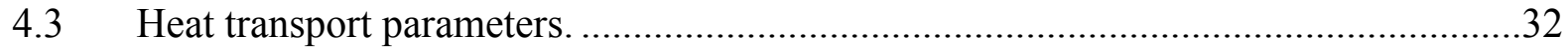

4.4 Unsaturated hydraulic properties used to produce modeled results............................33

4.5 Darcy infiltration rate estimates for ER-5-3 station 1 and station 4 .........................45

4.6 ER-5-3 channel dimensions and infiltration between flumes 3 and 4 for each flow

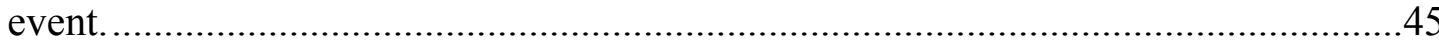

\section{LIST OF ACRONYMS}

DOE/NNSA U.S. Department of Energy/National Nuclear Security Administration

HDS heat dissipation sensor

NTS Nevada Test Site

WCR water content reflectometer 


\section{$1.0 \quad$ INTRODUCTION}

Transmission losses along ephemeral channels are an important, yet poorly understood, aspect of rainfall-runoff prediction. Losses occur as flow infiltrates channel bed, banks, and floodplains. Estimating transmission losses in arid environments is difficult because of the variability of surficial geomorphic characteristics and infiltration capacities of soils and near-surface low-permeability geologic layers (e.g., calcrete). Transmission losses in ephemeral channels are nonlinear functions of discharge and time (Lane, 1972), and vary spatially along the channel reach and with soil antecedent moisture conditions (Sharma and Murthy, 1994).

Rainfall-runoff models used to estimate peak discharge and runoff volume for flood hazard assessment are not designed specifically for ephemeral channels, where transmission loss can be significant because of the available storage volume in channel soils. Accuracy of the flow routing and rainfall-runoff models is dependent on the transmission loss estimate. Transmission loss rate is the most uncertain parameter in flow routing through ephemeral channels.

This research, sponsored by the U.S. Department of Energy, National Nuclear Security Administration (DOE/NNSA) and conducted at the Nevada Test Site (NTS), is designed to improve understanding of the impact of transmission loss on ephemeral flood modeling and compare various methodologies for predicting runoff from rainfall events. Various applications of this research to DOE projects include more site-specific accuracy in runoff prediction; possible reduction in size of flood mitigation structures at the NTS; and a better understanding of expected infiltration from runoff losses into landfill covers. Two channel transmission loss field experiments were performed on the NTS between 2001 and 2003: the first was conducted in the ER-5-3 channel (Miller et al., 2003), between March and June 2001, and the second was conducted in the Cambric Ditch (Mizell et al., 2005), between April and July 2003. Both studies used water discharged from unrelated drilling activities during well development and aquifer pump tests.

Discharge measurements at several flumes located along the channels were used to directly measure transmission losses. Flume locations were chosen in relation to geomorphic surface types and ages, vegetative cover and types, subsurface indurated layers (calcrete), channel slopes, etc. Transmission losses were quantified using three different analysis methods. Method 1 uses Lane's Method (Lane, 1983) for estimating flood magnitude in ephemeral channels. Method 2 uses heat as a subsurface tracer for infiltration. Numerical modeling, using HYDRUS-2D (Simunek et al., 1999), a finite-element-based flow and transport code, was applied to estimate infiltration from soil temperature data. Method 3 uses hydraulic gradient and water content in a Darcy's Law approach (Freeze and Cherry, 1979) to calculate one-dimensional flow rates. Heat dissipation and water content data were collected for this analysis. 
THIS PAGE INTENTIONALLY LEFT BLANK 


\subsection{EXPERIMENTAL DESIGN}

Field experiments were conducted in the ER-5-3 channel and in Cambric Ditch to assess the loss of water via infiltration during transmission of ephemeral flow events in small channels. Conceptually, the experiments were similarly designed. The channels were instrumented to measure flow, soil temperature, soil moisture content, and soil water tension. Water from a controlled source was released into each channel for a specific time period, during which measurements were made at specific locations and recorded using electronic dataloggers. On completion of the experiments, data were analyzed to determine the volume of flow lost to infiltration through each reach of the experimental channels.

\subsection{Instrumentation}

Flumes were installed at each instrumentation station in both channels to measure discharge. Box flumes were used in ER-5-3 (Figure 2.1), whereas 15.0-cm (0.5-ft) Parshall flumes were installed in Cambric Ditch (Figure 2.2). Stage in the flumes was determined using a Sonar depth finder during the ER-5-3 experiment and pressure transducers in attached stilling wells during the Cambric Ditch experiment. Subsurface instrumentation was installed a few meters downstream of some of the flumes. The instrumentation was placed at 30.0-, 50.0-, and 100.0-cm (1.0-, 1.6-, and 3.3-ft) depths, with the exception of the thermocouples, which were also installed at the ground surface $[0.0 \mathrm{~cm}(0.0 \mathrm{ft})]$. The thermocouples, buried in the channel bed to measure soil temperature, were installed in a $2.5-\mathrm{cm}(0.2-\mathrm{ft})$ boring and backfilled with native material. Water content reflectometer (WCR) probes were used to measure soil moisture. Heat dissipation sensors (HDS) were used to estimate soil moisture tension. The WCR and HDS sensors were inserted in the upstream wall of a $1.0-\mathrm{m}(3.0-\mathrm{ft})$ deep pit excavated downstream of selected flume stations. Field instrumentation valves were recorded every five minutes throughout the data collection periods. These data were subsampled at every quarter hour for analysis. The quarter-hour data are reported in Appendix A. Appendix A Part 1: Full Data Set contains data for the entire collection periods. Appendix A Part 2: Reduced Data Set includes only data for the experimental flow periods.

It is necessary to develop calibration equations to estimate soil moisture and soil tension from the WCR and HDS output data, respectively. Calibration equations were developed using soils from the ER-5-3 channel. Calibration data were initially fitted with a second-order polynomial. However, field data from the WCR probes exceeded the range of the calibration data slightly and impinged on the inflection point of the parabola. The polynomial calibration equations for the WCR probes were replaced with log-linear equations to accommodate the ER-5-3 field data.

The ER-5-3 calibration equations were assumed to be applicable to the Cambric Ditch. However, output from both the WCR and HDS sensors collected during the Cambric Ditch experiment were well outside the range of the calibration data and extended well beyond the inflection point of the parabolic equations. Thus, the calibration equations were rendered unusable for the Cambric Ditch experiment. Calibration experiments were not re-run for the Cambric Ditch experiment. As a result, it was not possible to evaluate soil moisture content or soil tension; therefore, WCR and HDS output data are presented as surrogates for moisture content and soil tension, respectively. 


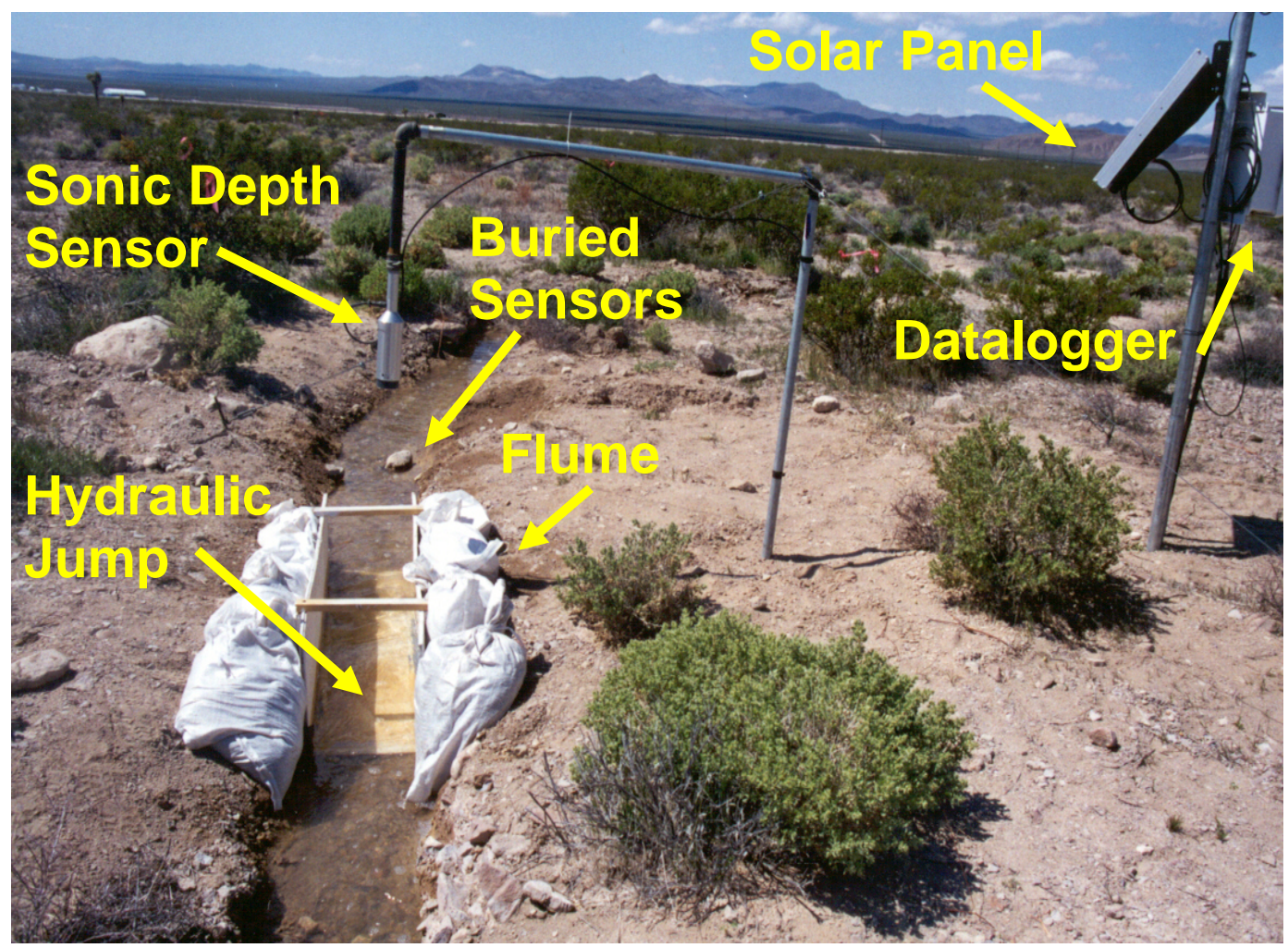

Figure 2.1. Typical flume and instrumentation station on ER-5-3 Channel.

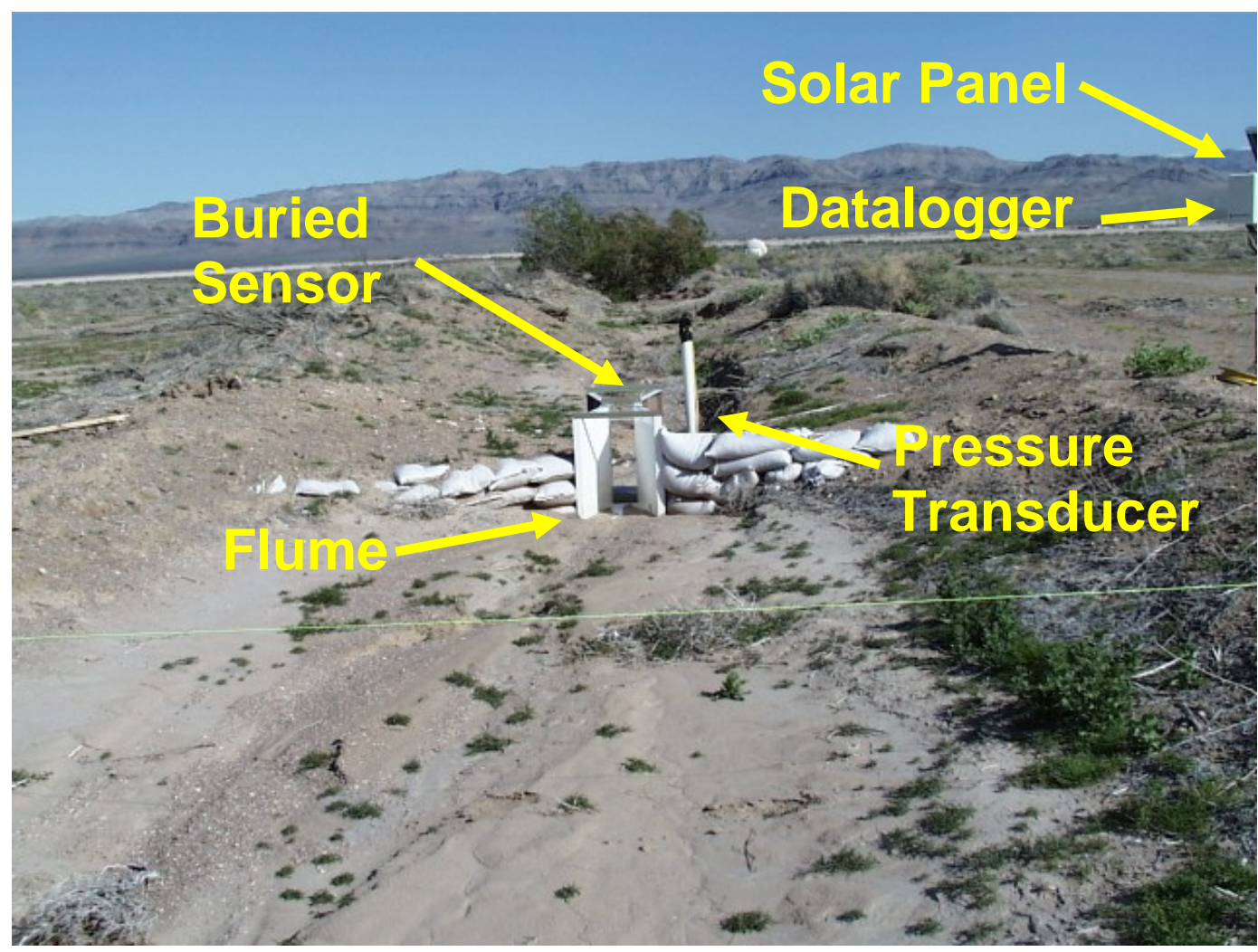

Figure 2.2. Typical flume and instrumentation station on Cambric Ditch. 


\section{$2.2 \quad$ ER-5-3 Channel Experiment}

The ER-5-3 transmission loss experiment was conducted on an ephemeral channel in northern Frenchman Flat. The channel lies near the junction of alluvial fans issuing from Massachusetts Mountain and Nye Canyon to the north and northeast, respectively. The ER-5-3 Channel is an incised, ephemeral channel, largely created by discharge of water during well drilling activities.

Field instruments were installed at four stations. Water pumped during well testing overflowed holding ponds and entered the channel providing flows for the transmission loss experiment. Table 2.1 presents a general description of soils along the experiment reach. Table 2.2 describes the type and distribution of instruments. Figure 2.3 shows the location of the instrumented stations and the surficial soil geomorphology.

The ER-5-3 pumping test was conducted between April 7 and May 4, 2001. Activities supporting the test required the pump to be shut off twice. As a result, there were three periods of flow in the ER-5-3 channel lasting four, six, and nine days. Flow rates, measured at ER-5-3 station 1, were variable during the experiment, ranging from $0.007 \mathrm{~m}^{3} / \mathrm{s}$ to $0.012 \mathrm{~m}^{3} / \mathrm{s}(0.25 \mathrm{cfs}$ to $0.43 \mathrm{cfs}$ ).

Table 2.1. General description of soils* and channel bed along ER-5-3 experimental reach.

\begin{tabular}{|c|c|c|}
\hline Location & Distance & Soil Description \\
\hline Station 1 & $159 \mathrm{~m}$ & $\begin{array}{l}\text { middle Pleistocene fans, terraces, abandoned drainages, colluvial slopes; shrub } \\
\text { and annual vegetation common; animal burrows uncommon; desert pavement } \\
\text { well expressed over large areas; carbonate platelets common; varnish well } \\
\text { expressed; } \mathrm{K}_{\text {sat }}: 0 \text { to } 15 \mathrm{~cm}, 48 \mathrm{~cm} / \mathrm{d} ; 25 \text { to } 40 \mathrm{~cm}, 51 \mathrm{~cm} / \mathrm{d} ; 45 \text { to } 60 \mathrm{~cm} \text {, } \\
15 \mathrm{~cm} / \mathrm{d} ; 85 \text { to } 100 \mathrm{~cm}, 137 \mathrm{~cm} / \mathrm{d} \text {; mapped soil group } 3(\mathrm{~S} 3) 85-100 \mathrm{~cm} \text {, } \\
137 \mathrm{~cm} / \mathrm{d} \text {; mapped soil group } 3 \text { (S3) }\end{array}$ \\
\hline Reach 1 & 159 to $484 \mathrm{~m}$ & $\begin{array}{l}\text { channel bed dominated by fine to coarse sand, fine to medium gravel common, } \\
\text { cobbles present, occasional boulders, caliche present at some cross-sections; no } \\
\text { vegetation }\end{array}$ \\
\hline Station 2 & $484 \mathrm{~m}$ & $\begin{array}{l}\text { late Pleistocene flans, terraces, abandoned drainages, colluvial slopes; shrub and } \\
\text { annual vegetation common; desert pavement well expressed over large areas; } \\
\text { varnish moderately to well expressed; mapped soil group } 4 \text { (S4) }\end{array}$ \\
\hline Reach 2 & 484 to $1,215 \mathrm{~m}$ & $\begin{array}{l}\text { channel bed dominated by fine to coarse sand, coarse sand to medium gravel } \\
\text { common, coarse gravel to cobbles present, rare boulders, no caliche; no } \\
\text { vegetation }\end{array}$ \\
\hline Station 3 & $1,215 \mathrm{~m}$ & $\begin{array}{l}\text { early Holocene fans, terraces, abandoned drainages, colluvial slopes; shrub and } \\
\text { annual vegetation common; animal burrows common; desert pavement } \\
\text { moderately expresses over large areas; varnish incipient; mapped soil group 5a } \\
\text { (S5a) }\end{array}$ \\
\hline Reach 3 & 1,215 to $1,857 \mathrm{~m}$ & $\begin{array}{l}\text { channel bed dominated by fine to coarse sand, coarse sand to medium gravel } \\
\text { common, coarse gravel to cobbles present, no boulders, no caliche; no vegetation }\end{array}$ \\
\hline Station 4 & $1,857 \mathrm{~m}$ & $\begin{array}{l}\text { late Holocene terraces, bars, active drainages, few shrubs, sparse annual } \\
\text { vegetation, no animal burrows; no desert pavement; no varnish; } \mathrm{K}_{\mathrm{sat}}: 0 \text { to } 15 \mathrm{~cm} \text {, } \\
518 \mathrm{~cm} / \mathrm{d} ; 20 \text { to } 35 \mathrm{~cm}, 277 \mathrm{~cm} / \mathrm{d} ; 45 \text { to } 60 \mathrm{~cm}, 35 \mathrm{~cm} / \mathrm{d} ; 90 \text { to } 100 \mathrm{~cm}, 327 \mathrm{~cm} / \mathrm{d} \text {; } \\
\text { mapped soil group } 6 / 7(\mathrm{~S} 6 / 7)\end{array}$ \\
\hline
\end{tabular}

*Soil description abstracted from Bechtel Nevada, 2000; channel bed description based on field observation. 
Table 2.2. ER-5-3 experiment instrumentation and location.

\begin{tabular}{cccc}
\hline Instrumentation & Station & Depth $(\mathrm{cm})$ & Model/Manufacture \\
\hline flume & 1 to 4 & na & constructed on site \\
depth sonar & 1 to 4 & na & SR-50, Campbell Scientific \\
thermocouple wire & 1 to 4 & $0,30,50,100$ & type T, Omega Engineering \\
water content reflectometer & 1 and 4 & $30,50,100$ & CS615, Campbell Scientific \\
heat dissipation sensor & 1 and 4 & $30,50,100$ & 229, Campbell Scientific \\
datalogger & 1 to 4 & na & CR-23X, Campbell Scientific \\
\hline
\end{tabular}
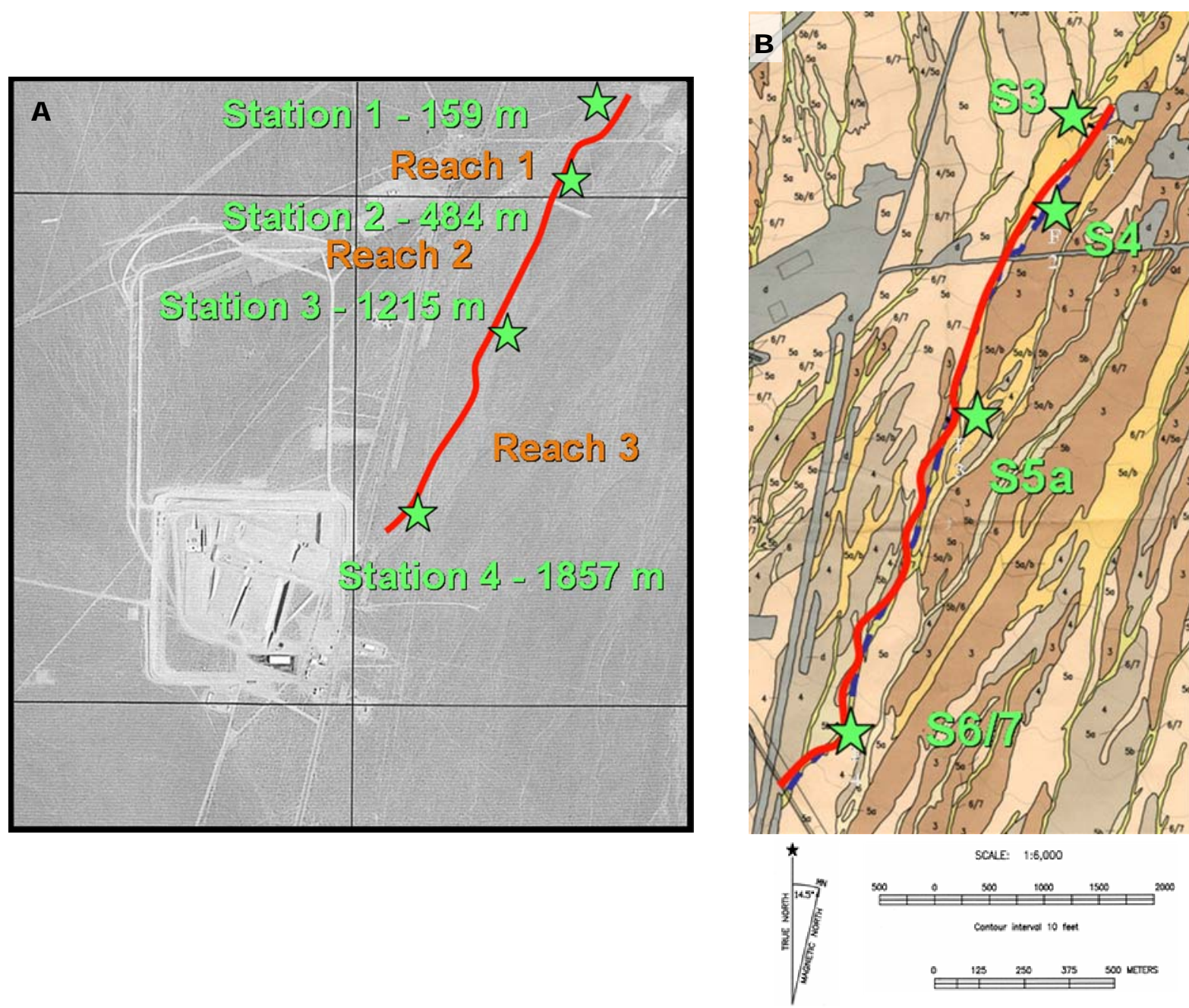

Figure 2.3. A. Aerial photograph showing locations of the flume stations on ER-5-3 Channel. B. Surficial geomorphic map showing locations of the flume stations on ER-5-3 Channel and the corresponding soils (see Table 2.1). 


\subsection{Cambric Ditch Experiment}

Cambric Ditch is an excavated channel constructed as part of a radionuclide-induced migration study initiated in 1975. During the induced migration experiment, water pumped from well RNM-2S was discharged to the upstream end of Cambric Ditch and transmitted to Frenchman Lake (playa) for disposal by evaporation and infiltration (Ross and Wheatcraft, 1994). The 1.6-km (1.1-mi) channel, constructed through alluvial soils, ranges in elevation from 952.7 to $938.7 \mathrm{~m}(3,125.0$ to $3,079.0 \mathrm{ft})$, resulting in an overall gradient of just less than one percent. Ponding on the playa may create a backwater effect in the lower $265.2 \mathrm{~m}(870.0 \mathrm{ft})$ of the channel. Water has flowed, only irregularly, in Cambric Ditch since completion of the induced migration experiment in the early 1990s.

Nearby drilling activities required that a pump test be performed at well RNM-2S during 2003, providing flow for the second transmission loss experiment. Instruments were installed at three stations, located at approximately 3.0, 442.1, and 1,006.1 $\mathrm{m}(10.0,1,450.0$, and 3,300.0 ft) downstream of the well outfall pond (Figure 2.4; Table 2.3). Fifteen cross sections were established to evaluate channel geometry.

Cambric Ditch is located on the alluvial basin floor of Frenchman Flat, at the far distal portions of the surrounding alluvial fans. Although geomorphic surfaces near Cambric Ditch have not been mapped, mapping within a distance of $3.2 \mathrm{~km}(2.0 \mathrm{mi})$ indicates that early Holocene age surfaces are likely to be predominant, suggesting that Cambric Ditch lies in surfaces composed of younger sediments, likely of middle- to late-Holocene age.

During excavation of instrumentation pits in Cambric Ditch, soil texture was noted to be fine loose sand with few particles of larger size. Visually, these soils appear similar to the middle- to late-Holocene soils in the lower reach of the ER-5-3 channel (Miller et al., 2003), which are characterized as (1) dominated by fine to coarse sand, (2) no underlying indurated surfaces present, (3) no desert pavement or varnish, and (4) vegetation and small animal burrows common. However, study results have since suggested that within the lower reach of Cambric Ditch, which is closer to the playa, an increased amount of fine material has been thoroughly intermixed with the sandy soil either by shoreline movement or eolian transport.

The Cambric Ditch experiment was conducted for 83 days between April 26 and July 18, 2003, while a pump test was conducted at well RNM-2S, near Cambric Ditch. Pump discharge was piped to a small upstream pond at the top of Cambric Ditch about $3.0 \mathrm{~m} \mathrm{(10.0} \mathrm{ft)}$ above Cambric station 1. After the first five to eight days, during which flow showed some variability, the flow at Cambric station 1 became nearly constant at a rate of approximately

$0.036 \mathrm{~m}^{3} / \mathrm{s}\left(1.3 \mathrm{ft}^{3} / \mathrm{s}\right)$. The RNM-2S pump was shut off on three occasions for maintenance; however, none of these shut-downs lasted long enough for the flow at Cambric station 1 to drop to zero. 


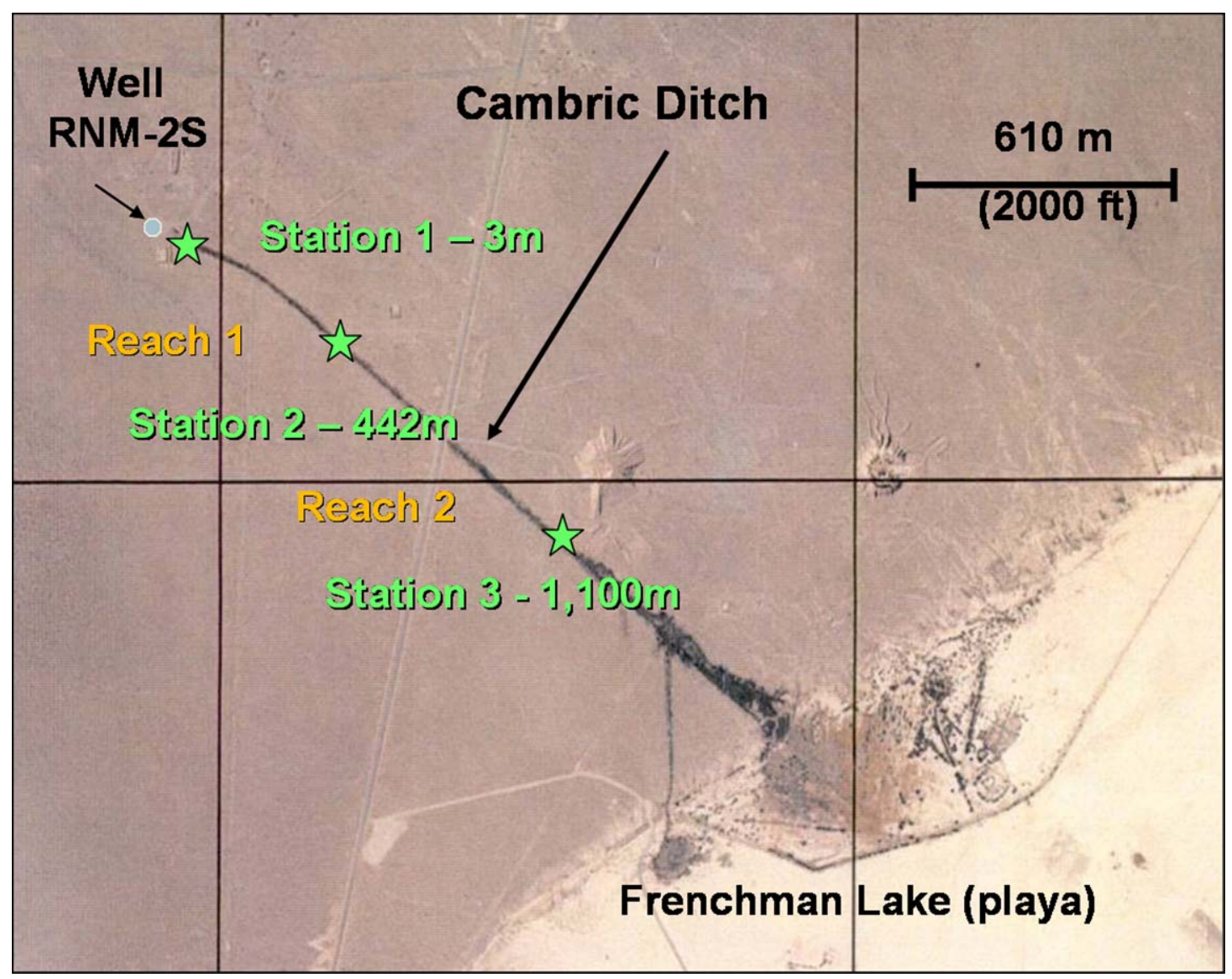

Figure 2.4. Aerial photograph showing locations of the flume stations on Cambric Ditch.

Table 2.3. Cambric experiment instrumentation and location.

\begin{tabular}{lccc}
\hline Instrumentation & Station & Depth $(\mathrm{cm})$ & Model/Manufacturer \\
\hline $\begin{array}{l}\text { flume } \\
\begin{array}{l}\text { pressure } \\
\text { transducer }\end{array}\end{array}$ & 1 to 3 & na 30,100 & Parshall flume, 6 in throat \\
$\begin{array}{l}\text { thermocouple } \\
\text { wire }\end{array}$ & 1 to 3 & $0,30,50,100$ & Campbell Scientific \\
$\begin{array}{l}\text { water content } \\
\text { reflectometer }\end{array}$ & 2 and 3 & $30,50,100$ type T, Omega Engineering \\
$\begin{array}{l}\text { heat dissipation } \\
\text { sensor }\end{array}$ & 2 and 3 & $30,50,100$ & CS615, Campbell Scientific \\
datalogger & 1 to 3 & na & 229, Campbell Scientific \\
\hline
\end{tabular}




\subsection{DIRECT MEASUREMENT RESULTS OF TRANSMISSION LOSS STUDIES}

Discharge measurements at several flumes located along the channels were used to directly measure transmission losses. Flume locations were chosen in relation to geomorphic surface types and ages, vegetative cover and types, subsurface indurated layers (calcrete), channel slopes, etc.

\subsection{ER-5-3 Experimental Results}

Data collection was initiated on March 30 and continued through May 14, 2001. Table 3.1 describes three flow events. Figure 3.1 contains hydrographs for each flow event at each flume. Data supporting Table 3.1 and Figure 3.1 are contained in Appendix A. Hydrographs reflect discharge variation during the well tests and indicate a diurnal pattern that may result from variation in aquifer pump test discharge, evaporation from holding ponds at the drill site, or increased infiltration due to the lower viscosity of warmed water. Average flow rate during each event decreased in the experimental reach from about $0.011 \mathrm{~m}^{3} / \mathrm{s}\left(0.39 \mathrm{ft}^{3} / \mathrm{s}\right)$ at ER-5-3 station 1 to $0.005 \mathrm{~m}^{3} / \mathrm{s}\left(0.18 \mathrm{ft}^{3} / \mathrm{s}\right)$ at ER-5-3 station 4 .

Timing of flow events at each downstream flume suggests transmission loss in the intervening reach. Flow events were generally delayed and of shorter duration at downstream flumes. During flow event 1, the upper three flumes recorded durations of similar magnitude and flume 4 exhibited a much shorter flow duration. During flow events 2 and 3, ER-5-3 station 1 recorded a significantly longer event than the lower three flumes, which exhibited similar event durations.

Table 3.1. 2001 flow experiment events at ER-5-3.

\begin{tabular}{|c|c|c|c|c|c|c|c|}
\hline & Station 1 & Reach 1 & Station 2 & Reach 2 & Station 3 & Reach 3 & Station 4 \\
\hline Event 1 & 4/7/20010500 & & 4/7/20010545 & & 4/7/2001 1015 & & 4/7/2001 1630 \\
\hline End & $4 / 10 / 20011545$ & & $4 / 10 / 20011730$ & & $4 / 10 / 20011715$ & & $4 / 10 / 20011400$ \\
\hline Average $\left(\mathrm{m}^{3} / \mathrm{s}\right)$ & 0.0096 & & 0.0082 & & 0.0071 & & 0.0034 \\
\hline Total vol $\left(\mathrm{m}^{3}\right)$ & $2,876.39$ & & 2448.22 & & $1,986.27$ & & 966.85 \\
\hline $\operatorname{Loss}\left(\mathrm{m}^{3}\right)$ & & 428.17 & & 461.96 & & $1,019.41$ & \\
\hline $\begin{array}{l}\text { Loss (percent } \\
\text { tot flow) }\end{array}$ & & 14.88 & & 16.06 & & 35.44 & \\
\hline Event 2 & $4 / 12 / 20010800$ & & $4 / 12 / 20012300$ & & 4/13/20010015 & & $4 / 13 / 20010215$ \\
\hline End & $4 / 19 / 20010545$ & & $4 / 19 / 20010445$ & & $4 / 19 / 20010145$ & & $4 / 19 / 20010045$ \\
\hline Average $\left(\mathrm{m}^{3} / \mathrm{s}\right)$ & 0.0085 & & 0.0074 & & 0.0059 & & 0.0034 \\
\hline Total vol $\left(\mathrm{m}^{3}\right)$ & $5,107.02$ & & $4,049.16$ & & $3,191.26$ & & $1,694.78$ \\
\hline $\operatorname{Loss}\left(\mathrm{m}^{3}\right)$ & & $1,057.86$ & & 857.90 & & $1,496.48$ & \\
\hline $\begin{array}{l}\text { Loss (percent } \\
\text { tot flow) }\end{array}$ & & 20.71 & & 16.80 & & 29.30 & \\
\hline Event 3 & $4 / 24 / 20011200$ & & $4 / 24 / 20012015$ & & $4 / 24 / 20012130$ & & $4 / 24 / 20012330$ \\
\hline End & $5 / 3 / 20012345$ & & $5 / 2 / 20011545$ & & $5 / 2 / 20011815$ & & $5 / 2 / 20011215$ \\
\hline Average $\left(\mathrm{m}^{3} / \mathrm{s}\right)$ & 0.0071 & & 0.0068 & & 0.0051 & & 0.0023 \\
\hline Total vol $\left(\mathrm{m}^{3}\right)$ & $5,741.05$ & & $4,678.18$ & & $3,460.20$ & & $1,539.40$ \\
\hline Loss $\left(\mathrm{m}^{3}\right)$ & & $1,062.87$ & & $1,217.99$ & & $1,920.79$ & \\
\hline $\begin{array}{l}\text { Loss (percent } \\
\text { tot flow) }\end{array}$ & & 18.51 & & 21.22 & & 33.46 & \\
\hline
\end{tabular}




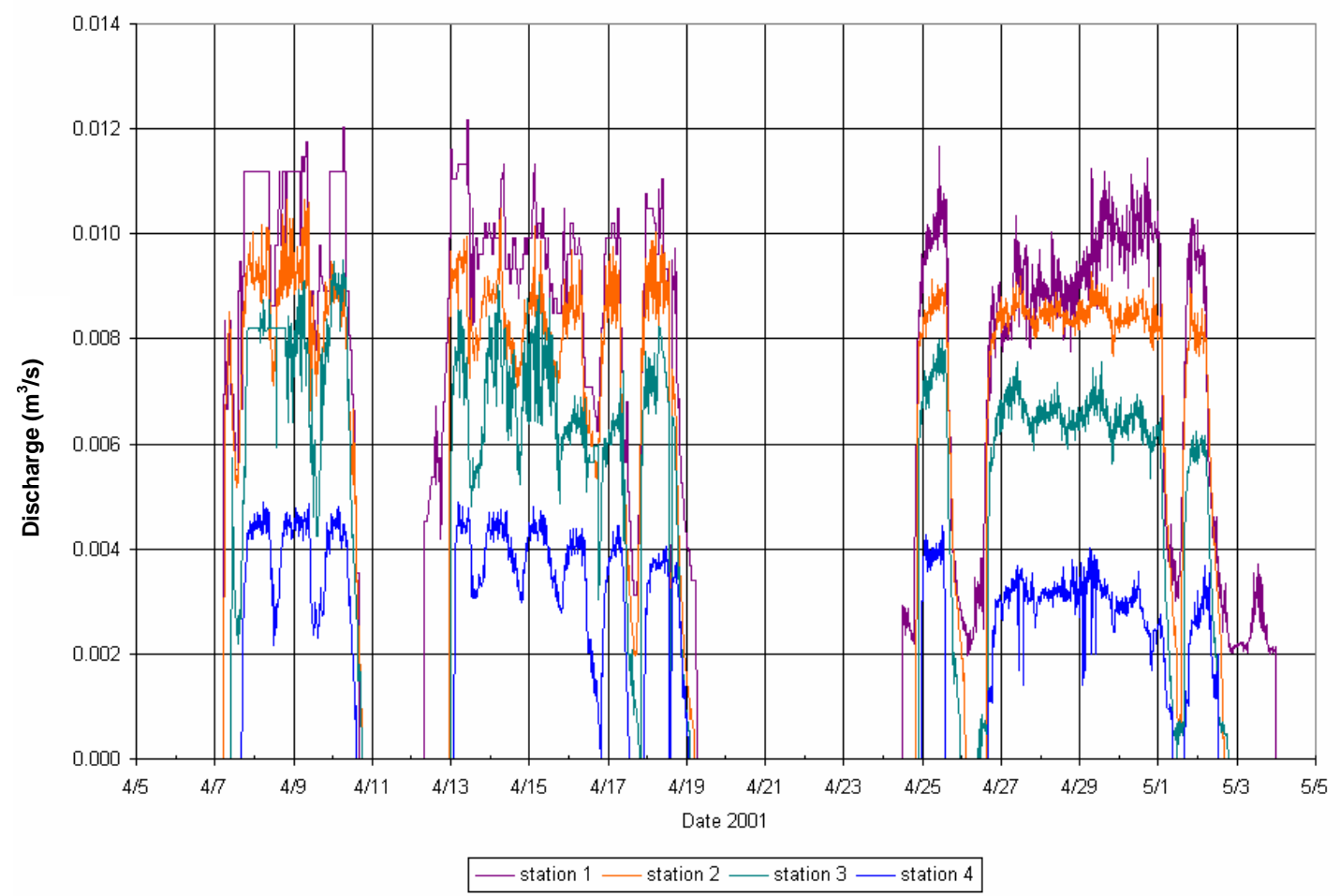

Figure 3.1. Hydrographs of channel transmission loss experiment flows at ER-5-3 Channel.

Loss of flow volume between the upstream and downstream flumes of each reach confirmed infiltration. Up to 70 percent of the flow was lost in reaches of 1,000 to 2,000 m (3,300 to 6,600 ft). Losses in ER-5-3 reaches 2 and 3 fell between 15 and 21 percent and 19 and 26 percent, respectively. ER-5-3 reach 3 had the greatest losses, between 47 and 56 percent of flow entering the reach. Losses in ER-5-3 reach 3 accounted for between 44 and 53 percent of all infiltration losses and up to 35 percent of the flow entering the experiment reach.

Dividing the total volume of loss for each flow event by the wetted area of the channel gives a loss per unit area. During flow event 1, ER-5-3 reach 3 had the largest loss rate per unit area, $1.9 \mathrm{~m}(6.2 \mathrm{ft})$, and ER-5-3 reach 2 the smallest, $0.8 \mathrm{~m}(2.6 \mathrm{ft})$. For flow events 2 and 3 , reach 1 exhibited the largest loss rate, 4.69 and $4.72 \mathrm{~m}$ (15.38 and $15.48 \mathrm{ft})$; reach 2 showed the smallest, 1.46 and $2.10 \mathrm{~m}$ (4.69 and $6.89 \mathrm{ft})$. The upper and lower reaches had a higher rate of loss per unit area than the middle reach.

The greatest loss of flow occurs in ER-5-3 reach 3, which is on the youngest soil surface. This reach is characterized by smaller particle size distribution of bed material, almost no calcrete, and no indication of long-term stability.

\section{$\underline{3.1 .1 \quad \text { Soil Temperature }}$}

Thermocouples were used to determine temperature changes associated with infiltration. Figures 3.2 and 3.3 present soil temperature and discharge data (see Appendix A Part 2). The most obvious feature of these data is the diurnal character of the ground surface $[0 \mathrm{~cm}(0 \mathrm{ft})]$ temperature. Diurnal oscillation ranges up to $40{ }^{\circ} \mathrm{C}$ (see late May, Figure 3.2). The range of diurnal oscillation is significantly damped with depth. 
Diurnality during flow varies with depth as a function of infiltration. At ER-5-3 station 1, where soils are formed on an older pediment and varnish and calcrete are present, the diurnal range is about $5{ }^{\circ} \mathrm{C}$. The diurnal range is about $20{ }^{\circ} \mathrm{C}$ at ER-5-3 station 4, where the soil is younger and contains coarser material with no evidence of aging. Lower infiltration rates lead to smaller diurnal ranges because temperature propagation is diffusion dominated. Higher infiltrations rates (i.e., ER-5-3 station 4) indicate heat is advectively transported with water.

With the exception of response to flow event 1, subsurface temperatures at ER-5-3 station 1 decrease with increasing depth when flow is present in the channel and after sufficient time for the post-flow temperatures to equilibrate to atmospheric temperature (Figure 3.2). In response to the onset of flow event 1, the temperature at all three probes dropped; the rate of decrease diminished at each deeper probe. The thermocouples appear to be just coming into equilibrium with the infiltrating water when flow event 1 ends. Onset of flow event 1 coincided with the arrival of a cold front and the temperature variations may reflect response to the cold front as well as arrival of water. Between flow events and immediately after cessation of flow event 3 , the temperature profile is reversed, with the $100-\mathrm{cm}(3.3-\mathrm{ft})$ probe the warmest and the $30-\mathrm{cm}$ $(1.0-\mathrm{ft})$ probe the coolest. It also appears that all responses to temperature change are damped with depth.

At ER-5-3 station 4, buried sensors indicated approximately the same temperature as the ground surface probe when water was present (Figure 3.3), suggesting rapid infiltration in the lower reach. Otherwise, the temperature response at ER-5-3 station 4 is similar to that observed at ER-5-3 station 1. These responses indicate advectively dominated heat transfer as warmer water rapidly percolates through the younger, more permeable soil. Temperature change at ER-5-3 station 4 preceded detection of flow in the flume at onset of flow event 1, perhaps as a result of flow bypassing the flume.

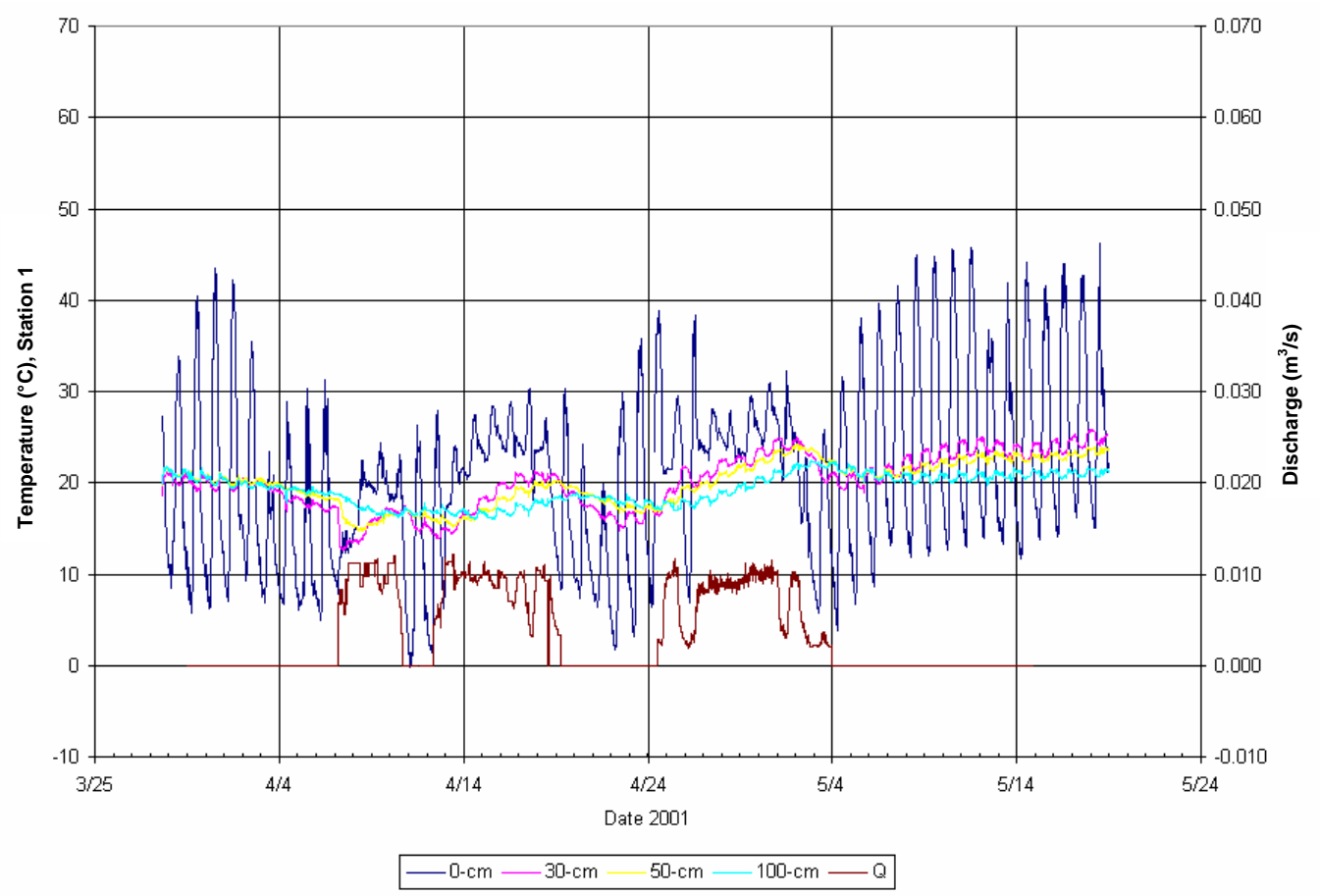

Figure 3.2. Soil temperature and discharge (Q) for ER-5-3 station 1. 


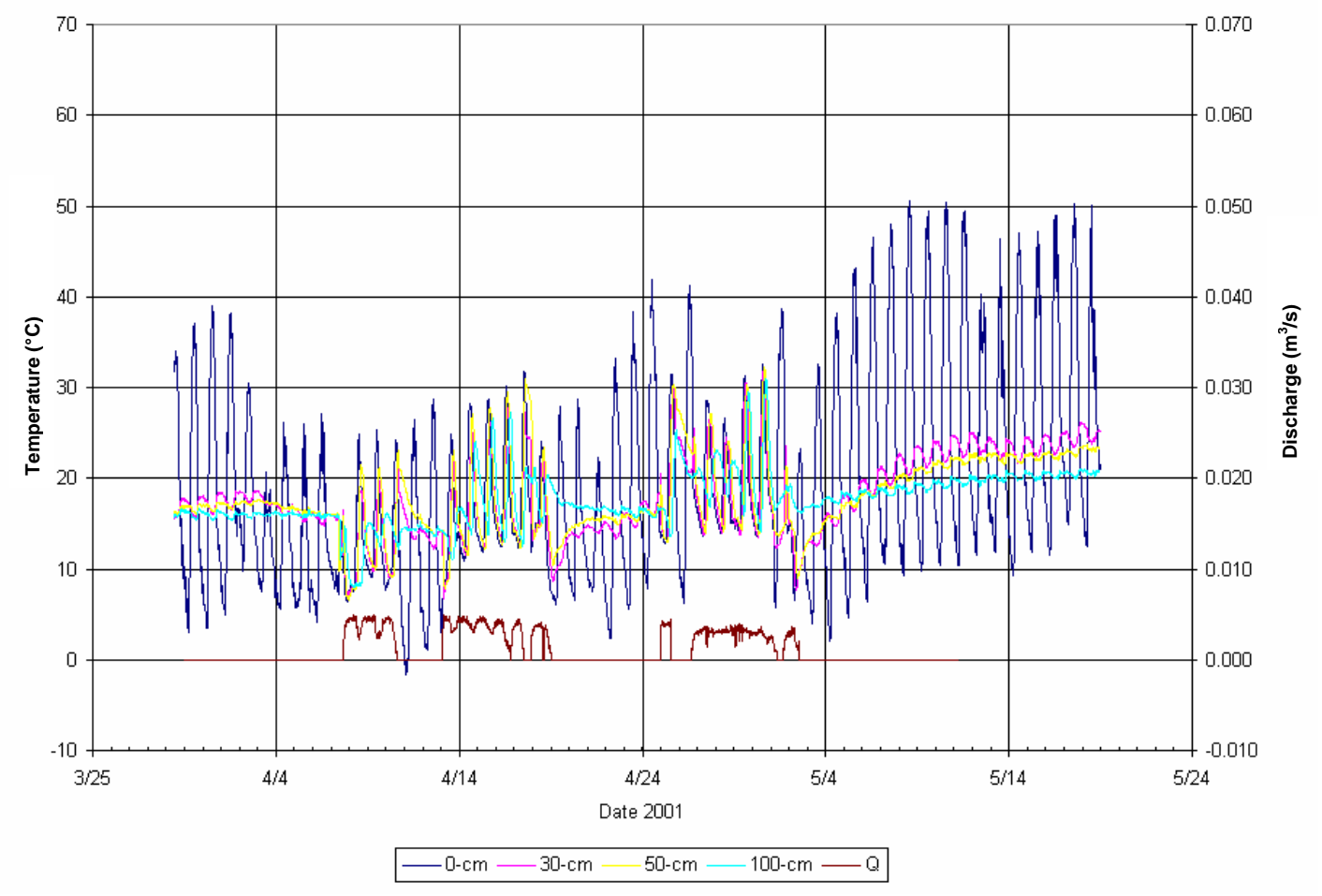

Figure 3.3. Soil temperature and discharge (Q) for ER-5-3 station 4.

\subsubsection{Water Content}

The WCR probes at both ER-5-3 stations 1 and 4 exhibit an abrupt, large magnitude change in moisture content with the arrival of flow. The three probes at each station responded similarly to the presence of water in the channel (Figures 3.4, Figure 3.5 and Appendix A Part 2), although it is clear that the variability of flow recorded at ER-5-3 station 4 led to greater variation in water content.

At ER-5-3 station 1, moisture content during flow event 1 displays an initial spike followed by a steep decline (Figure 3.4). The 30-cm (1.0-ft) probe responded first to the onset of flow, rising from about 0.26 to 0.40 . Response at each deeper probe was delayed, illustrating the travel time of the wetting front. Similar response is seen at the onset of the later flow events. During flow event 2 , moisture content declined at a much slower rate than during event 1 . For event 3 , moisture content was almost constant, except for response to variations in flow, showing that the system had reached dynamic equilibrium. Prior to flow event 1 , moisture content at $30 \mathrm{~cm}(1 \mathrm{ft})$ was lowest and the 50- and 100-cm (1.6- and 3.3-ft) probes indicated similar moisture content. Upon arrival of flow, moisture content at $30 \mathrm{~cm}(1.0 \mathrm{ft})$ rose first and increased the most. Only near the end of the longer no-flow interval between events 2 and 3 did the moisture content at $30 \mathrm{~cm}(1.0 \mathrm{ft})$ drop below that at either of the deeper probes. During the period of flow, moisture content at the $100-\mathrm{cm}(3.3-\mathrm{ft})$ probe remained above that at the $50-\mathrm{cm}(1.6-\mathrm{ft})$ probe. In the post-flow data, the $30-\mathrm{cm}(1.0-\mathrm{ft})$ probe indicates the driest soil condition at ER-5-3 station 1, whereas the two deeper probes indicate about the same moisture content.

In response to flow event 1, all three WCR probes at ER-5-3 station 4 exhibited a spike at about the same time, just before the flume recorded flow (Figure 3.5). This may have happened 
because flow bypassed the flume and rapidly infiltrated. During flow events 2 and 3, the initial spike appeared later for each deeper probe. Moisture content at all depths appears to respond to variations in flow, though responses were damped for the deeper probes. Moisture contents decreased immediately on cessation of flow. Eventually, the 30-cm (1.0-ft) probe became the driest, the $100-\mathrm{cm}(3.3-\mathrm{ft})$ probe indicated intermediate moisture contents, and the $50-\mathrm{cm}(1.6-\mathrm{ft})$ probe showed the highest values, reflecting both differences in soil texture and higher surface soil evaporation.

\section{$\underline{\text { 3.1.3 Soil Water Tension }}$}

Heat dissipation sensors were installed to evaluate soil water tension. All probes reflected the diurnal atmospheric temperature variation (Figure 3.6, Figure 3.7 and Appendix A Part 2). Sensor sensitivity is quite poor for this range of soil wetness; thus, readings may not represent actual soil conditions.

At ER-5-3 station 1, the 100-cm (3.3-ft) probe indicated the lowest water tension (wettest conditions) (Figure 3.6). It exhibited a continuous decline in tension throughout the data record. A slight rise in tension, which continues through the end of the data record (not shown in graph), is evident after flow stops. The $30-\mathrm{cm}(1.0-\mathrm{ft})$ probe exhibits the highest tension (driest conditions) at ER-5-3 station 1 under no-flow conditions. However, when water is present in the channel, the 30-cm (1.0-ft) probe shows a rapid decline in tension, dropping from 400 to $200 \mathrm{~cm}$ $(1.2$ to $0.6 \mathrm{ft}$ ) with the onset of flow event 1 . The no-flow interval between flow events 1 and 2 appears to have been too short to generate a significant increase in tension, even through water contents were declining. During events 2 and 3, the 30- and 50-cm (1.0- and 1.6-ft) probes indicated approximately the same tension. Both the $30-$ and $50-\mathrm{cm}(1.0-$ and $1.6-\mathrm{ft})$ probes also

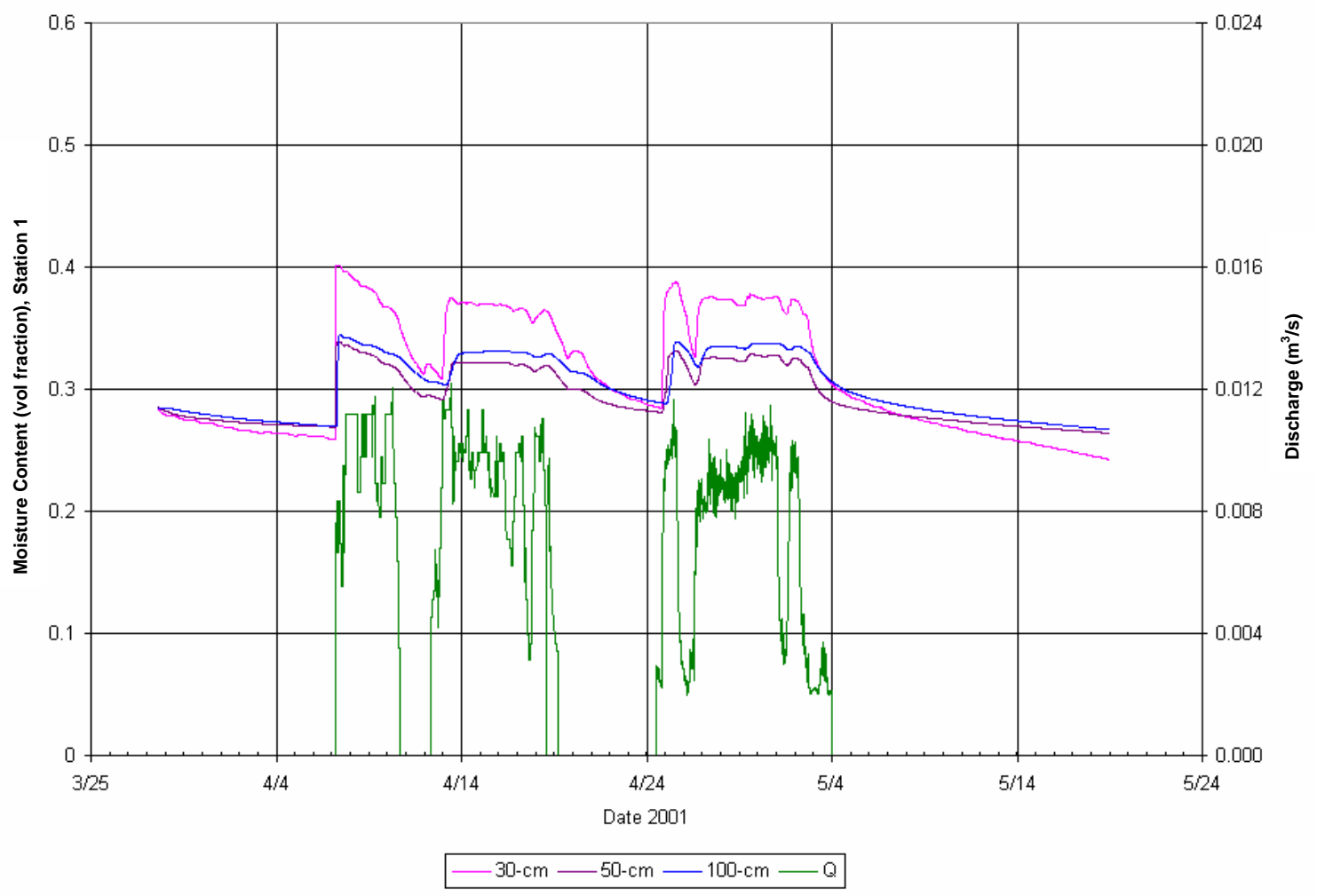

Figure 3.4. Moisture content and discharge (Q) for ER-5-3 station 1. 


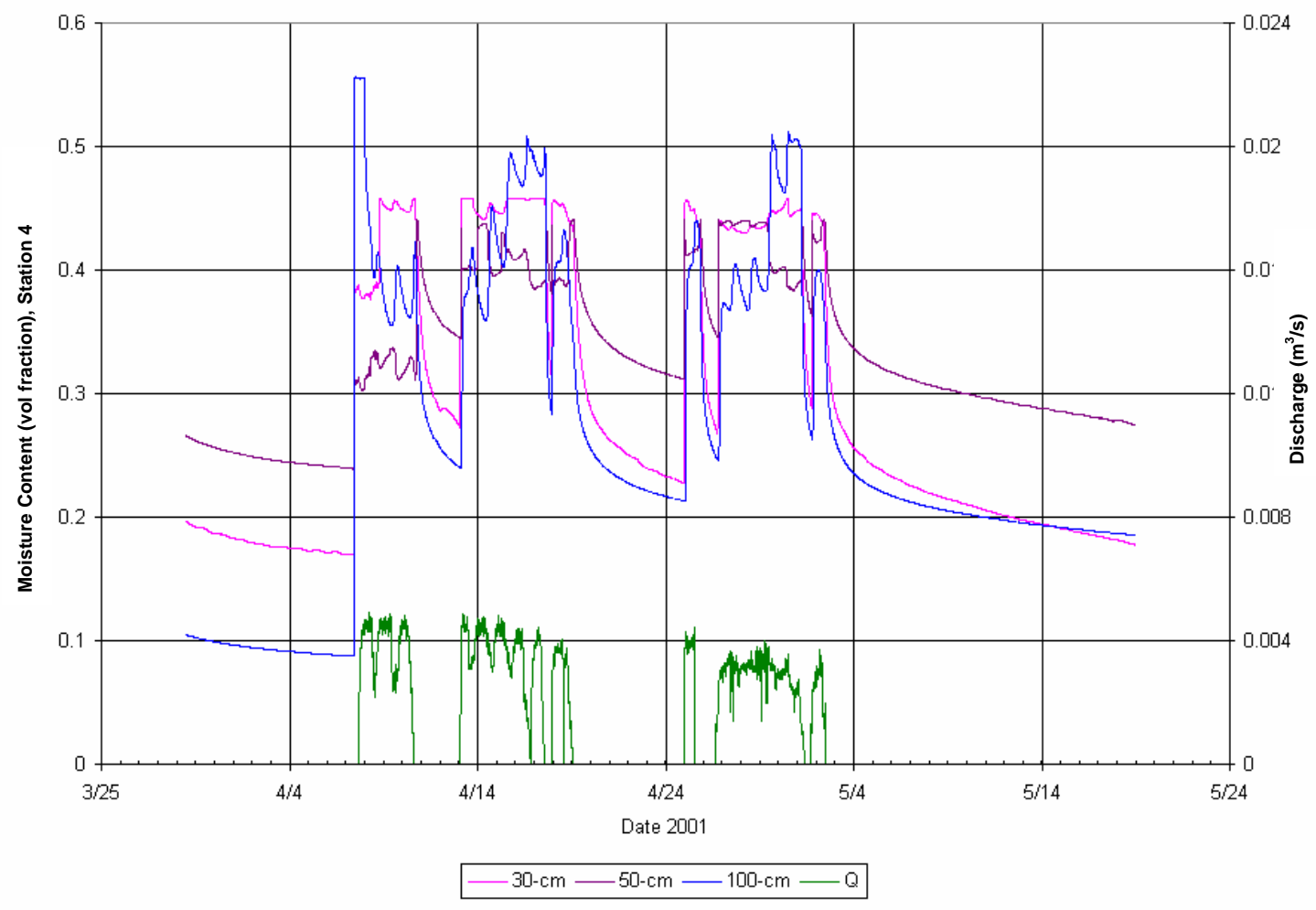

Figure 3.5. Moisture content and discharge (Q) for ER-5-3 station 4.

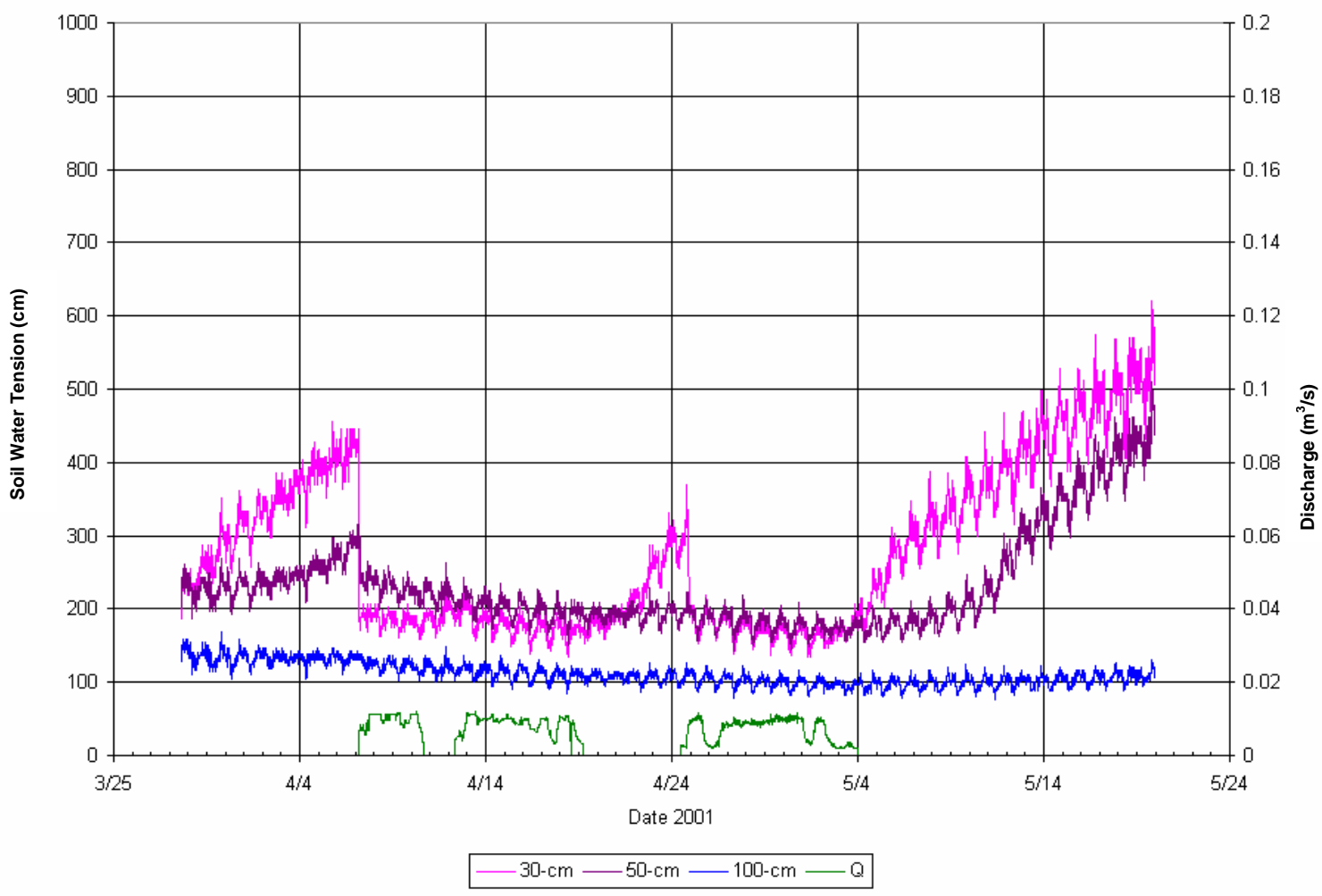

Figure 3.6. Soil water tension and discharge (Q) for ER-5-3 station 1. 


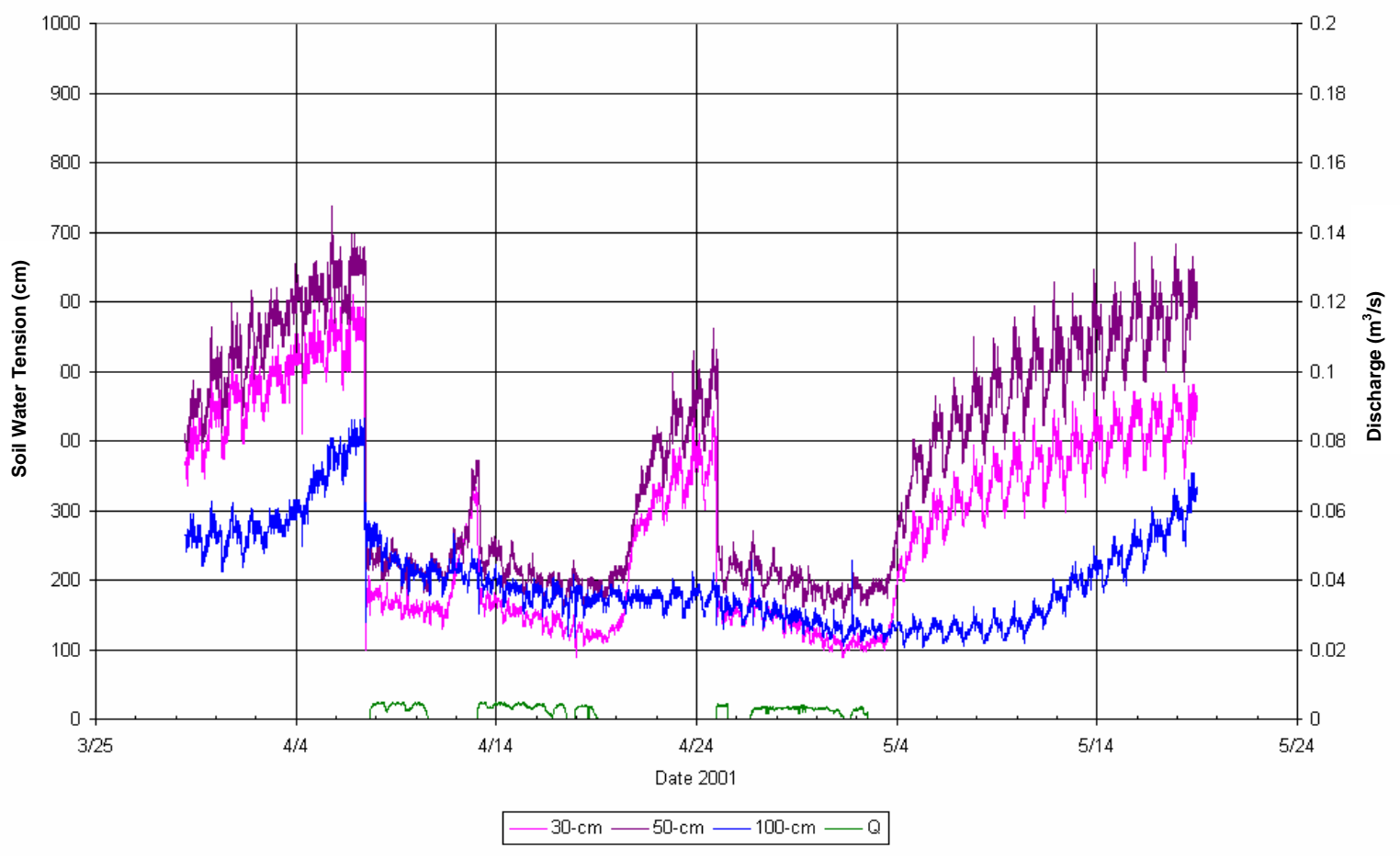

Figure 3.7. Soil water tension and discharge (Q) for ER-5-3 station 4.

show a general trend of declining tension in response to the cumulative effects of the three events. At cessation of flow, the two shallower probes exhibited a rapid increase in tension; the $30-\mathrm{cm}(1.0-\mathrm{ft})$ probe responded several days quicker than the $50-\mathrm{cm}(1.6-\mathrm{ft})$ probe.

Soil water tension response at ER-5-3 station 4 (Figure 3.7) was more extreme due to low, erratic flow in the wash (Figure 3.1). Overall sensor responses were similar to those at ER-5-3 station 1, except that the response times are nearly identical. The similar response times illustrate the rapid infiltration at this station due to the relative lack of an impeding layer, as seen further up the channel. Sensors at 30- and 50-cm (1.0- and 1.6-ft) depths responded almost immediately to cessation of flow in the channel, but the response for the $100-\mathrm{cm}(3.3-\mathrm{ft})$ sensor was muted. This is likely because the probe is at its lower operational limit and responding to pre-existing soil moisture conditions.

\subsection{Cambric Ditch Experimental Results}

Because of uncertainties in the drilling and pump test schedules, data collection activities occurred throughout all of 2003 (Appendix A Part 1). However, the actual pump test used for the experimental flow began on April 21, 2003 [julian date (jd) 111] and continued until July 17, 2003 (jd198) (Appendix A Part 2). The discharge record from this pump test was divided into four separate flow events for this study (Figure 3.8; Table 3.2). The pump failed within a few hours of the initial startup, and repairs, with pumping intermittent during this time, continued through jd115. Although flow did reach Cambric station 1, this initial event is not included in this discussion. On April 26 (jd116), the pump test began again (first flow event), and continued until a power failure on April 29 (jd119) interrupted flow for about 1.5 hours. The second event began when power was restored on jd119, and continued until power again failed for about 1.5 hours on May 13 (jd133). The third event began when power was restored on jd133, and continued until pumping was again interrupted for three or four hours on June 6 
(jd157). The fourth event began when pumping restarted on jd157 and continued until the end of the pump test on July 17 (jd198); however, during this last event, a flow data measurement instrumentation error occurred at Cambric station 2 (Figure 3.8).

Hydrographs for these events (Figure 3.8) reflect discharge variation during the pump tests and indicate a diurnal pattern that may result from variation in aquifer pump test discharge, evaporation from the upstream outfall pond at well RNM-2S, or increased infiltration due to the lower viscosity of warmed water. The flow measurement error at Cambric station 2 is shown as the spike beginning near jd175, and is assumed to continue through jd198. Average flow rate during each event decreased between Cambric stations 1 to 3 , from 0.036 to $0.024 \mathrm{~m}^{3} / \mathrm{s}(1.3$ to $0.09 \mathrm{ft}^{3} / \mathrm{s}$ ). Timing of flow events at each downstream flume also suggests transmission losses in the intervening reach. Flow events were delayed at downstream stations, generally with longer delays seen in the lower reach between Cambric stations 2 and 3. Although some of the delay could be accounted for by the increased lower reach length (56 percent of total length), it is probably more indicative of a slower infiltration rate at this reach. Flow durations for each event were generally the same at each station.

Loss of flow volume between the upstream and downstream flumes of each reach confirmed infiltration (Table 3.2). Losses in the upper and lower reaches fell between 12 and 32 percent and 6 and 14 percent, respectively. Total infiltration losses throughout the entire channel length were generally approximately 40 percent of the entire flow measured at the upstream station.

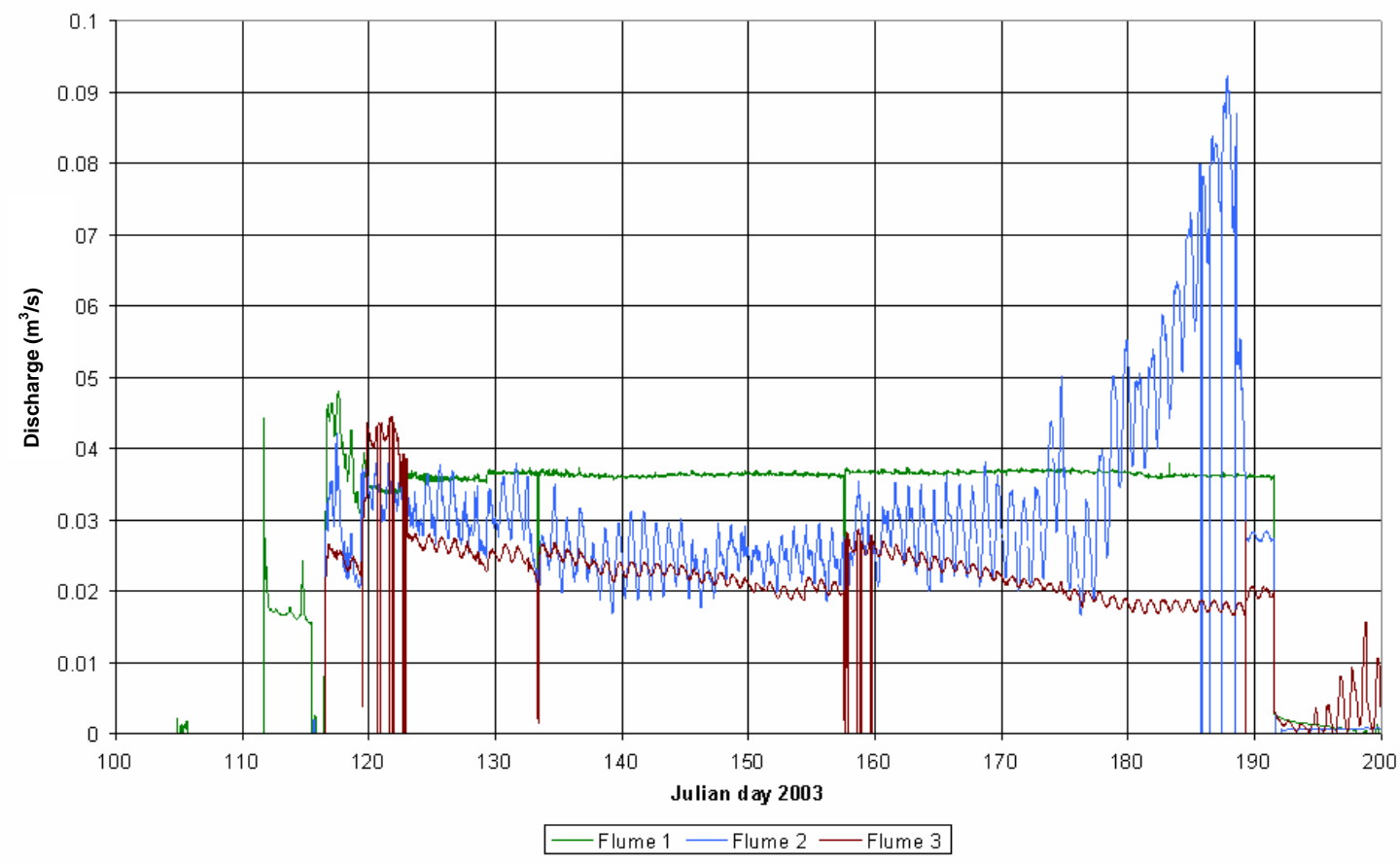

Figure 3.8. Hydrographs of channel transmission loss experiment flow events at Cambric Ditch. Flume 2 shows an error between jd157 and jd198. 
Table 3.2. 2003 Cambric Ditch flow experiment event statistics.

\begin{tabular}{|c|c|c|c|c|c|c|}
\hline & Station 1 & Reach 1 & Station 2 & Reach 2 & Station 3 & $\begin{array}{l}\text { Reach } 1 \\
\text { through } 3\end{array}$ \\
\hline \multicolumn{7}{|l|}{ Event 1: d116 to d119 } \\
\hline Start & 4/26/20031130 & & $4 / 26 / 2003$ & & 4/26/2003 1230 & \\
\hline End & 4/29/20031200 & & $4 / 29 / 2003$ & & 4/29/2003 1245 & \\
\hline Average $\mathrm{m}^{3} / \mathrm{s}$ & 0.039 & & 0.028 & & 0.024 & \\
\hline Total volume $\mathrm{m}^{3}$ & $10,279.473$ & & $7,264.049$ & & $6,262.763$ & \\
\hline Loss $\mathrm{m}^{3}$ & & $3,015.425$ & & $1,001.285$ & & $4,016.710$ \\
\hline $\begin{array}{l}\text { "loss/inflow to reach, } \\
\text { percent" }\end{array}$ & & 29.334 & & 13.784 & & 39.075 \\
\hline \multicolumn{7}{|l|}{ Event 2: d119 to d133 } \\
\hline Start & 4/29/20031215 & & $4 / 29 / 2003$ & & 4/29/20031300 & \\
\hline End & 5/13/20030900 & & $5 / 13 / 2003$ & & 5/13/20030945 & \\
\hline Average $\mathrm{m}^{3} / \mathrm{s}$ & 0.036 & & 0.031 & & 0.029 & \\
\hline Total volume $\mathrm{m}^{3}$ & $42,871.333$ & & $37,545.251$ & & $35,104.513$ & \\
\hline Loss $\mathrm{m}^{3}$ & & $5,326.082$ & & $2,440.737$ & & $7,766.820$ \\
\hline $\begin{array}{l}\text { "loss/inflow to reach, } \\
\text { percent" }\end{array}$ & & 12.423 & & 6.501 & & 18.117 \\
\hline \multicolumn{7}{|l|}{ Event 3: d133 to d157 } \\
\hline Start & $5 / 13 / 20030915$ & & $5 / 13 / 2003$ & & 5/13/20031000 & \\
\hline End & $6 / 6 / 20031430$ & & $6 / 6 / 20031445$ & & $6 / 6 / 20031515$ & \\
\hline Average $\mathrm{m}^{3} / \mathrm{s}$ & 0.036 & & 0.025 & & 0.022 & \\
\hline Total volume $\mathrm{m}^{3}$ & $75,778.125$ & & $51,673.162$ & & $46,499.053$ & \\
\hline Loss $\mathrm{m}^{3}$ & & $24,104.96$ & & $5,174.11$ & & $29,279.072$ \\
\hline $\begin{array}{l}\text { "loss/inflow to reach, } \\
\text { percent" }\end{array}$ & & 31.810 & & 10.013 & & 38.638 \\
\hline \multicolumn{7}{|l|}{ Event 4: d157 to d198 } \\
\hline Start & $6 / 6 / 20031445$ & & N/A & & 6/6/20031530 & \\
\hline End & $7 / 17 / 20030145$ & & N/A & & 7/13/20030600 & \\
\hline Average $\mathrm{m}^{3} / \mathrm{s}$ & 0.031 & & N/A & & 0.020 & \\
\hline Total volume $\mathrm{m}^{3}$ & $108,122.586$ & & N/A & & $62,107.109$ & \\
\hline Loss $\mathrm{m}^{3}$ & & N/A & & N/A & & $46,015.48$ \\
\hline $\begin{array}{l}\text { "loss/inflow to reach, } \\
\text { percent" }\end{array}$ & & N/A & & N/A & & 42.560 \\
\hline
\end{tabular}




\subsubsection{Soil Temperature}

Thermocouples, installed at 30-, 50-, and 100-cm (1.0-, 1.6-, and 3.3-ft) depths at Cambric stations 1, 2, and 3, were used to determine soil temperature changes associated with infiltration (Figures 3.9, 3.10, 3.11, 3.12, and Appendix A Part 2). Temperature clearly indicates the beginning and ending of the experimental flow events. Short-term diurnal fluctuations, most visible in the ground surface $(0 \mathrm{~cm}[0 \mathrm{ft}])$ measurements, ranged up to $20^{\circ} \mathrm{C}$, similar to those measured in the lower reach of ER-5-3, where the range was about $20^{\circ} \mathrm{C}$ in the younger soils there, compared to $5^{\circ} \mathrm{C}$ in the older soils in the upper reach (Miller et al., 2003). The higher infiltration rates measured in the younger soils at both experimental sites indicate heat is advectively transported with water, rather than diffusion dominated as in the older soils of the upper reaches of ER-5-3.

The diurnality during flow varies with depth as a function of infiltration. At Cambric station 1, located just downstream of the producing well, the soil temperature data are overwhelmed by the discharging groundwater temperature, and although a diurnal effect is visible, there is little variability in temperature with depth (Figure 3.9). However, an enlarged detail of the Cambric station 1 temperature record (Figure 3.10) indicates a damping effect with depth, with a few hours delay at each successive depth. At Cambric station 2, the probes at all depths indicated approximately the same temperature as the ground surface sensor, with a slight delay at each deeper sensor (Figure 3.11). The 30- , 50- and 100-cm (1.0-, 1.6-, and 3.3-ft) temperature sensors at Cambric station 2 indicate more variability than those at Cambric station 3, which suggests faster drainage through the soils at Cambric station 2.

At Cambric station 3, the deeper sensors indicated much less temperature variability than the ground surface sensor, with the 30- and 50-cm (1.6- and 3.3-ft) sensors showing an approximately 12-hour delay, and the 100-cm (3.3-ft) sensor showing an approximately 24-hour delay (Figure 3.12). Temperature data from Cambric stations 1 and 2 substantiate the corresponding flow data, suggesting more rapid infiltration rates in the upper reach than at Cambric station 3 . This is most likely because of playa fines being mixed into the Cambric station 3 soil profile. However, neither the flow nor temperature data sets indicate defined layers within the Cambric station 3 soil profile. The responses at all stations indicate advectively dominated heat transfer as warmer water rapidly percolates through the young permeable soil.

\subsubsection{Water Content}

The WCR probes were installed at 30-, 50-, and 100-cm (1.0-, 1.6-, and 3.3-ft) depths at Cambric stations 2 and 3 (Figures 3.13, Figure 3.14, and Appendix A Part 2). Data collection at the Cambric Ditch was undertaken assuming that the calibration conducted for the ER-5-3 experiment (Miller et al., 2003) would be sufficient. However, probe readings obtained at Cambric Ditch exceeded the calibration range used for ER-5-3; as a result, it is not currently possible to convert the probe values to water content values. Therefore, in the following discussion, it was tacitly assumed that water content is directly proportional to probe values.

At the onset of the first flow event (jd116), the moisture content at Cambric station 2 increased sharply at all depths, and then began a slight decline (Figure 3.13). The 30-cm (1.0-ft) probe, which recorded the highest reading of 1.4, responded first to the onset of flow, with response at each deeper probe delayed, illustrating the travel time of the wetting front. Similar response is seen at the onset of the later flow events. 
At Cambric station 2, the initial declining moisture content at all depths between jd120 and jd124 may reflect a possible trend of declining flow rate indicated in the flow data. Although there is a very slight increasing trend in water content at $30 \mathrm{~cm}(1.0 \mathrm{ft})$ on jd124, it immediately reverses. Water content at 50 and $100 \mathrm{~cm}(1.6$ and $3.3 \mathrm{ft})$ began to increase on jd124 about 22 days before an increasing trend was clearly evident at $30 \mathrm{~cm}$. The trend of increasing water content at all three depths continued during a period when the trend in flow was slightly declining to slightly increasing. Moisture content shows no response to the steep flow rate increase late in the experiment (jd175 to jd191), which indicates a measurement error in the flow data. Moisture content, at all depths, appears to have had only a slight response to the flow interruption on jd119; an apparent response at the 50- and 100-cm (1.6- and 3.3-ft) depths to the jd133 flow interruption; and a notable, although otherwise negligible, response to the jd157 interruption at all depths.

In response to onset of the first flow event (jd116), the moisture content at Cambric station 3 increased at all three depths, although the increase at $100 \mathrm{~cm}(3.3 \mathrm{ft})$ was delayed about one day and was more gradual than the $30-$ and $50-\mathrm{cm}(1.0-$ and $1.6-\mathrm{ft})$ depth responses (Figure 3.14). The sharp increase at all three depths was followed by a brief decline that lasted about one day. At $30 \mathrm{~cm}(1.0 \mathrm{ft})$, the moisture content continued to increase until jd128, then began to decline until jd141. Between jd141 and jd157, moisture content at $30 \mathrm{~cm}(1.0 \mathrm{ft})$ was nearly constant. Between jd121 and jd157, moisture content at $50 \mathrm{~cm}(1.6 \mathrm{ft})$ increased very slowly until the flow interruption on jd133, when it dropped a small amount before continuing the gradual increase, which continued until jd142, when the increase became greater. During this same period, moisture content at $100 \mathrm{~cm}(3.3 \mathrm{ft})$ increased above the $50 \mathrm{~cm}(1.6 \mathrm{ft})$ level and varied gradually around a near constant level until about jd142 when it too began to rise. On jd157, moisture content at 50 and $100 \mathrm{~cm}(1.6$ and $3.3 \mathrm{ft})$ was about the same.

At Cambric station 3, the jd157 flow interruption produced a sharp initial drop in moisture content at all three probe depths. Following this flow interruption, moisture content at $100 \mathrm{~cm}$ $(3.3 \mathrm{ft})$ appears to be higher than at 30 or $50 \mathrm{~cm}(1.0$ or $1.6 \mathrm{ft})$. After jd163, moisture content at 30 and $50 \mathrm{~cm}$ (1.0 and $1.6 \mathrm{ft})$ depths was identical. At the cessation of experimental flow, moisture content dropped sharply at all three depths. The precipitous drop continued for about 24 hours, after which the loss of moisture was more gradual. Following the experimental flow event, the 50- and 100-cm (1.6- and 3.3-ft) probes indicated nearly identical moisture content and the $30-\mathrm{cm}(1.0-\mathrm{ft})$ probe showed the lowest moisture content, reflecting the higher surface soil evaporation.

\subsubsection{Soil Water Tension}

Heat dissipation sensors were installed at Cambric stations 2 and 3 to evaluate soil water tension. As sensor sensitivity is quite poor for this range of soil wetness, readings may not represent actual soil conditions. All probes reflected the diurnal atmospheric temperature variation (Figure 3.15, Figure 3.16, and Appendix A Part 2). At Cambric station 2, throughout the experimental flow period, soil water tension at $50 \mathrm{~cm}$ (1.6 ft) was higher (driest condition) than at 30 and $100 \mathrm{~cm}$ (1.0 and $3.3 \mathrm{ft}$ ), where these two probes indicated about the same tension condition throughout the flow event (Figure 3.15). Initial response to the experimental flow was a sharp decline (wetting) in soil moisture tension, lasting about 24 hours, at all three probe depths. 
Tension continued to decline at Cambric station 2 through jd135. Between jd135 and jd191, moisture tension at the $30-$ and $50-\mathrm{cm}(1.0-$ and $1.6-\mathrm{ft})$ depths was approximately constant, whereas tension at the $100-\mathrm{cm}(3.3-\mathrm{ft})$ depth was continuously declining at a slow rate. Soil water tension appears to be unresponsive to flow interruptions or changes in flow rate during the experiment. After the experimental flow, soil water tension increased.

At the onset of the experimental flow event, soil water tension at Cambric station 3 dropped sharply at the $100-\mathrm{cm}(3.3-\mathrm{ft})$ depth and only slightly at the 30 - and $50-\mathrm{cm}(1.0-$ and $1.6-\mathrm{ft})$ depths (Figure 3.16). The gradual decrease in tension continued until about jd157, after which tension was constant until about jd198. Throughout the experimental flow event, tension at 30 and $100 \mathrm{~cm}(1.0$ and $3.3 \mathrm{ft})$ were about equal and slightly greater than tension at $50 \mathrm{~cm}(1.6 \mathrm{ft})$ (wettest condition). About 10 days after the cessation of experimental flow, soil tension at all three depths again began to increase. Soil water tension at Cambric station 3 appears to be unresponsive to either interruptions or variations in flow rate in the channel; as long as sufficient water is present in the channel, the soil tension is stable.

Soil water tension at $30 \mathrm{~cm}(1.0 \mathrm{ft})$ appears to be approximately the same at both Cambric stations 2 and 3; however, the $100-\mathrm{cm}$ (3.3-ft) tension at Cambric station 3 is slightly higher than at Cambric station 2, again suggesting a lower infiltration rate at Cambric station 3.

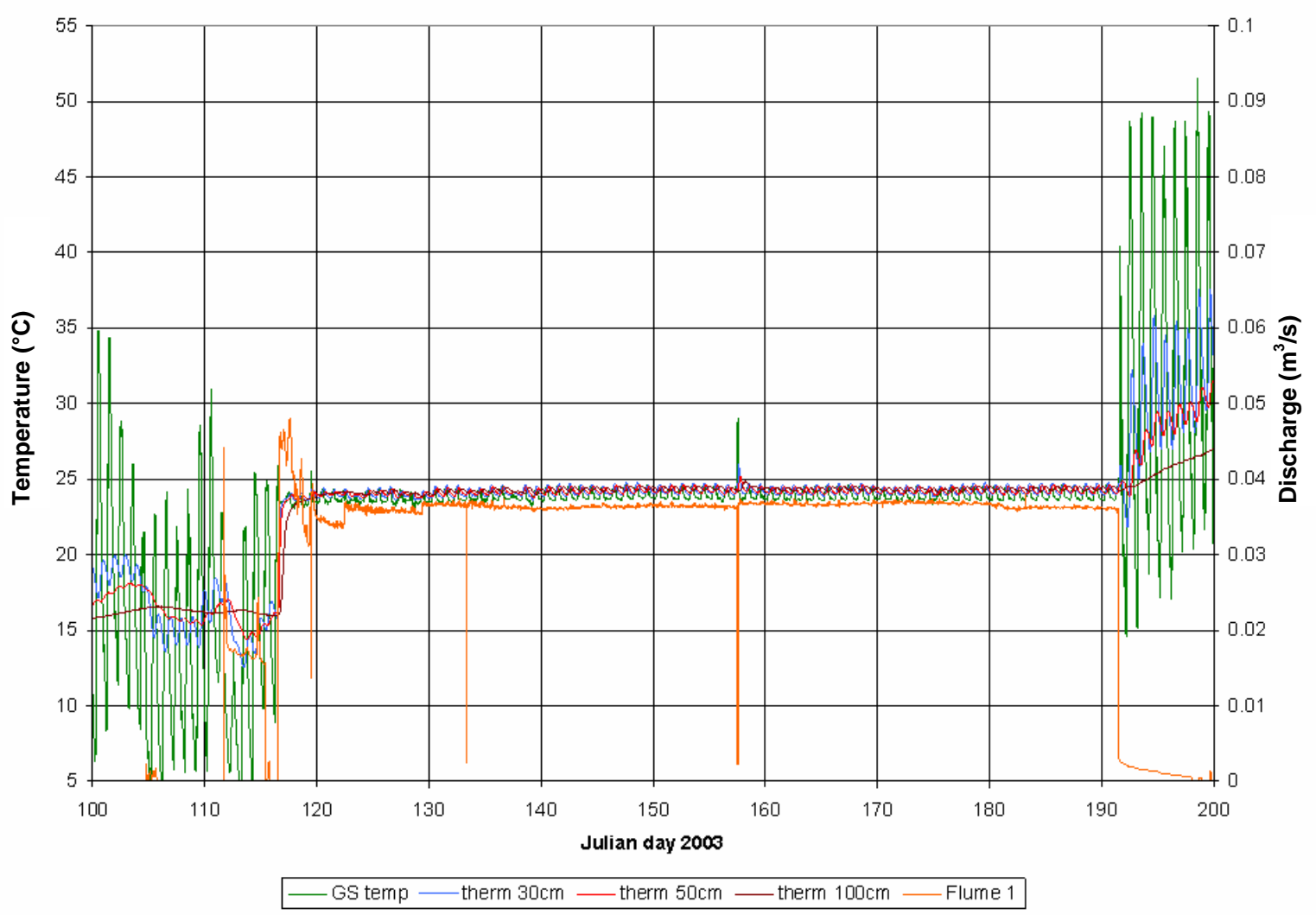

Figures 3.9 Soil temperature and discharge for Cambric station 1. 


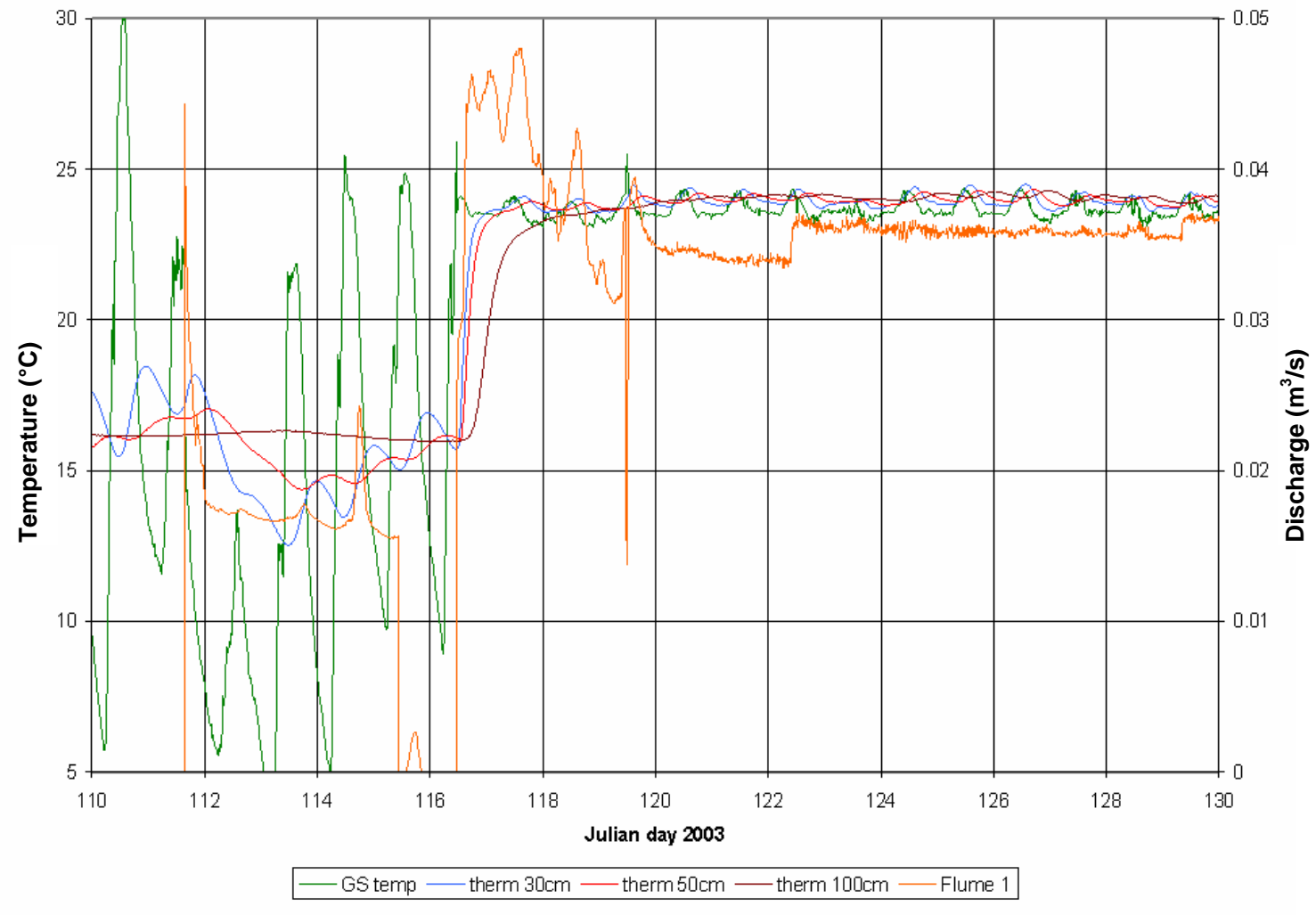

Figures 3.10 Soil temperature and discharge for Cambric station 1 detail.

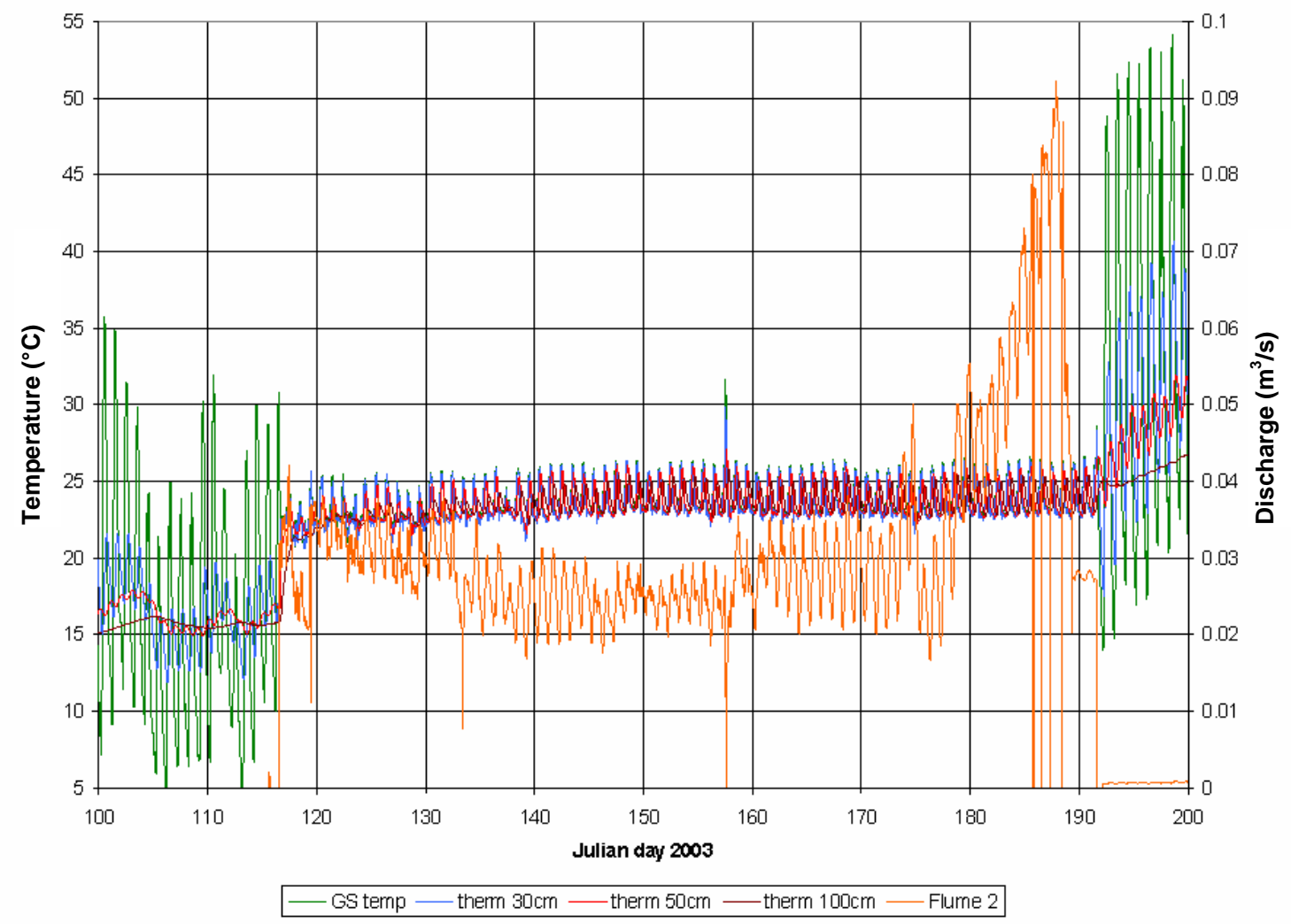

Figures 3.11 Soil temperature and discharge for Cambric station 2. 


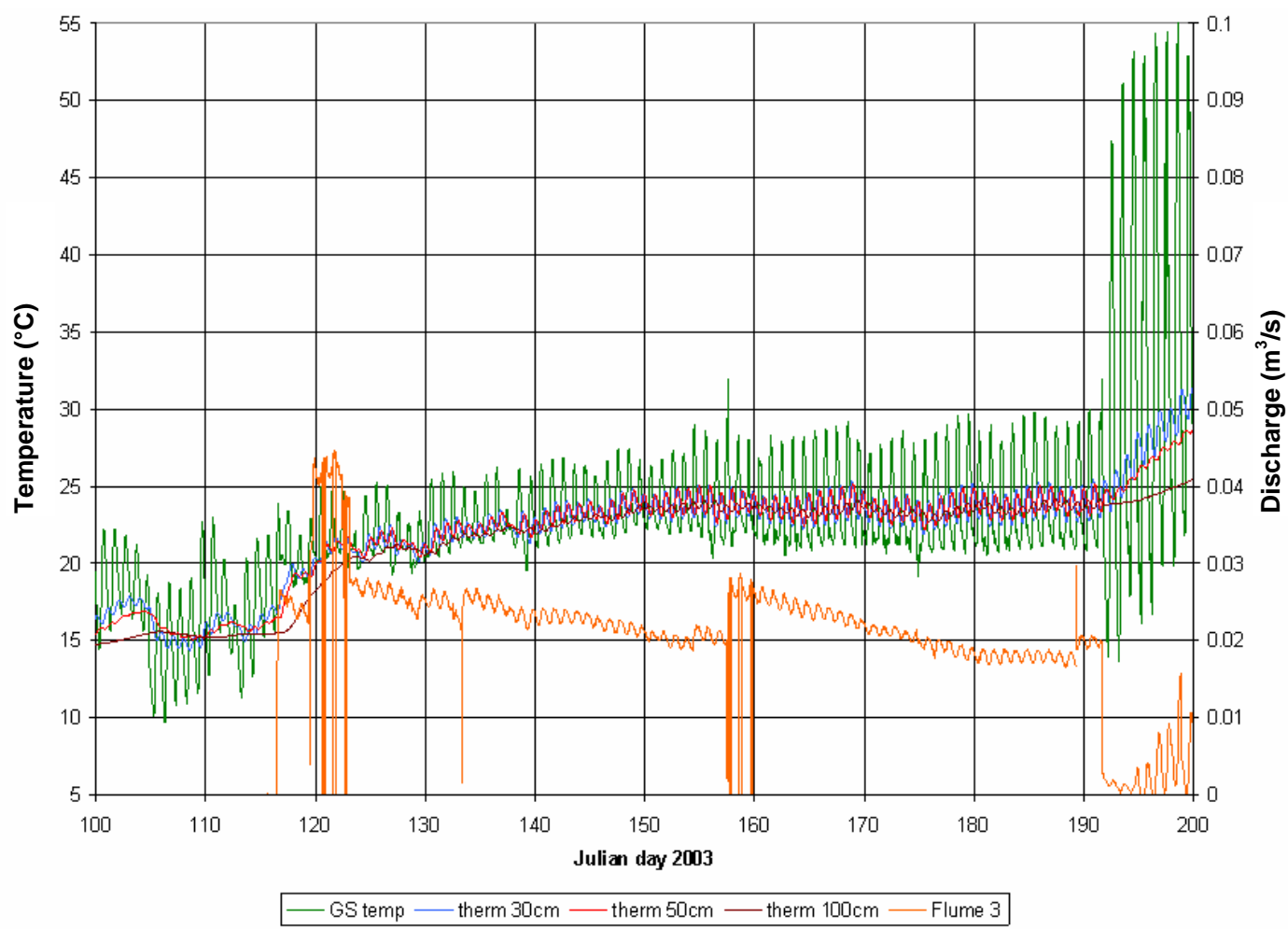

Figures 3.12. Soil temperature and discharge for Cambric station 3.

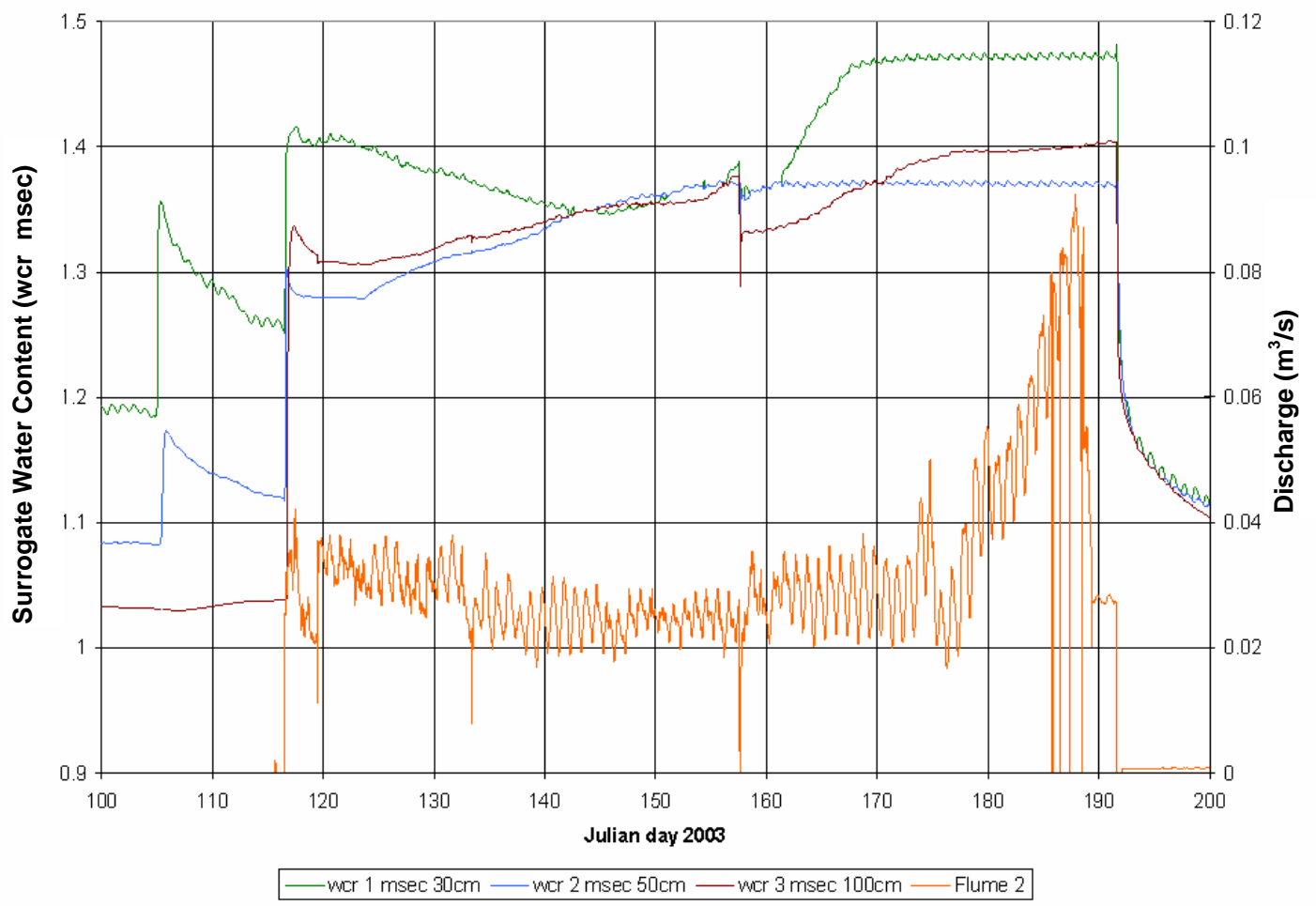

Figures 3.13 Soil water content with discharge for Cambric station 2. 


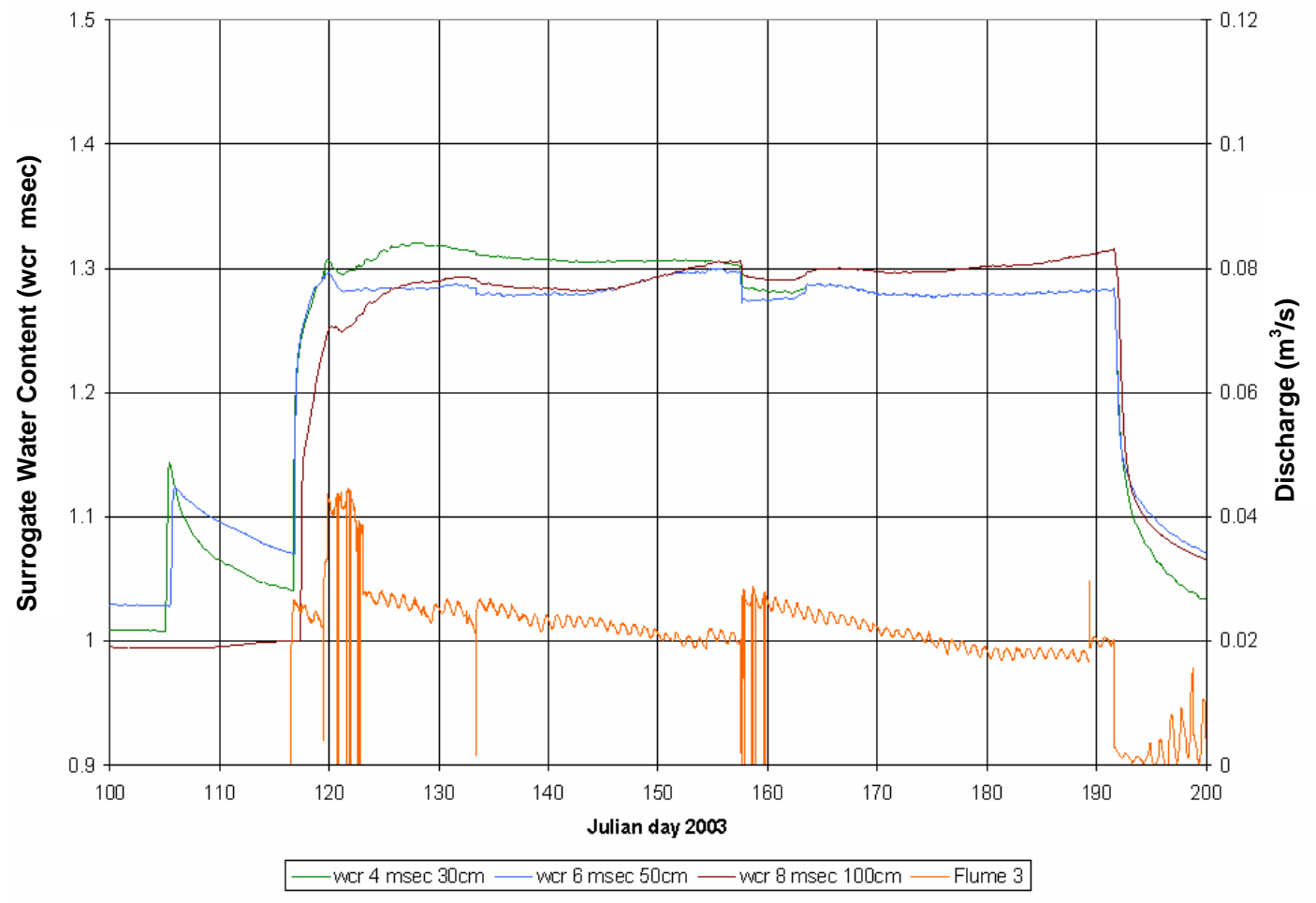

Figures 3.14 Soil water content with discharge for Cambric station 3.

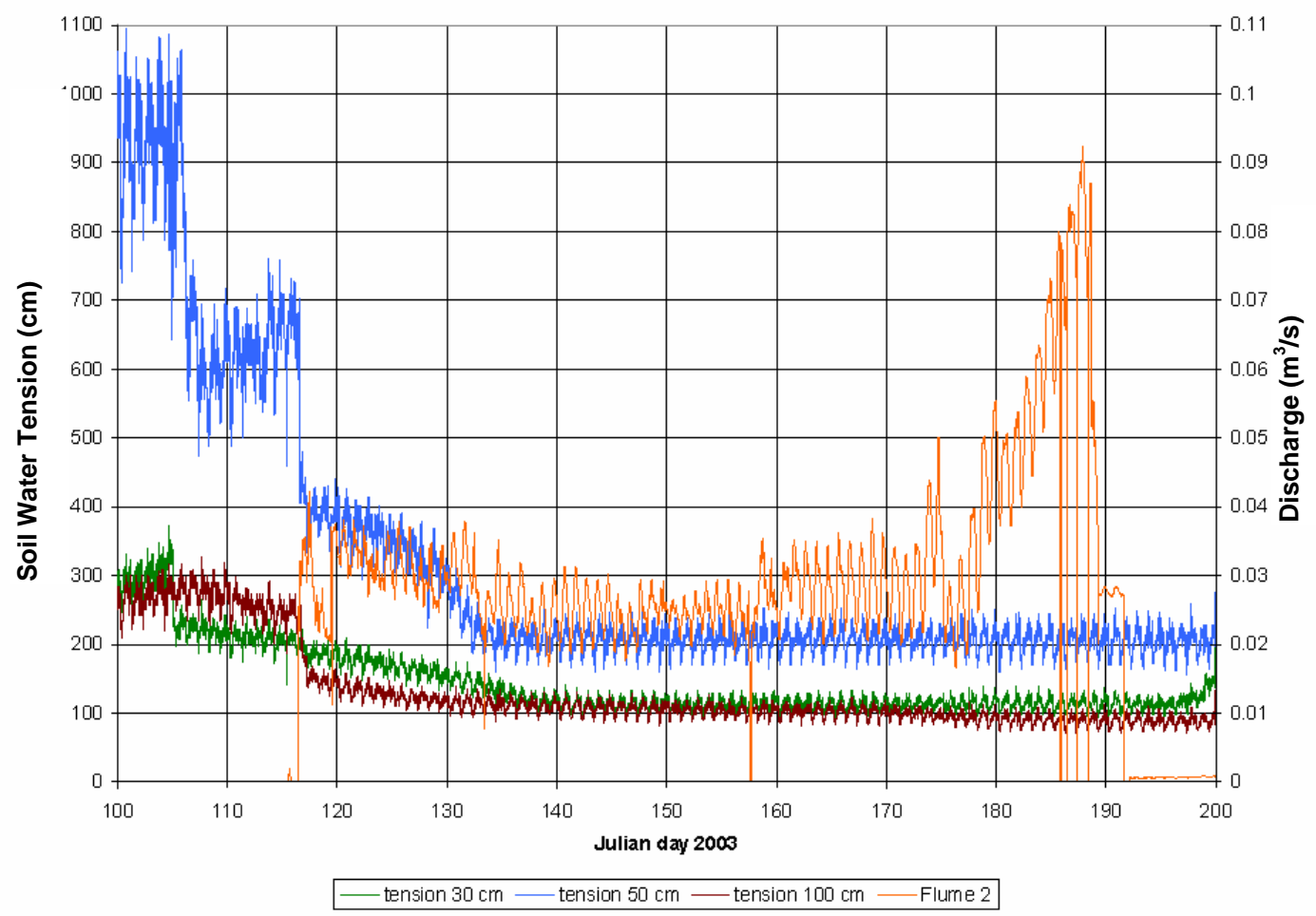

Figures 3.15. Soil water tension with discharge for Cambric station 2. 


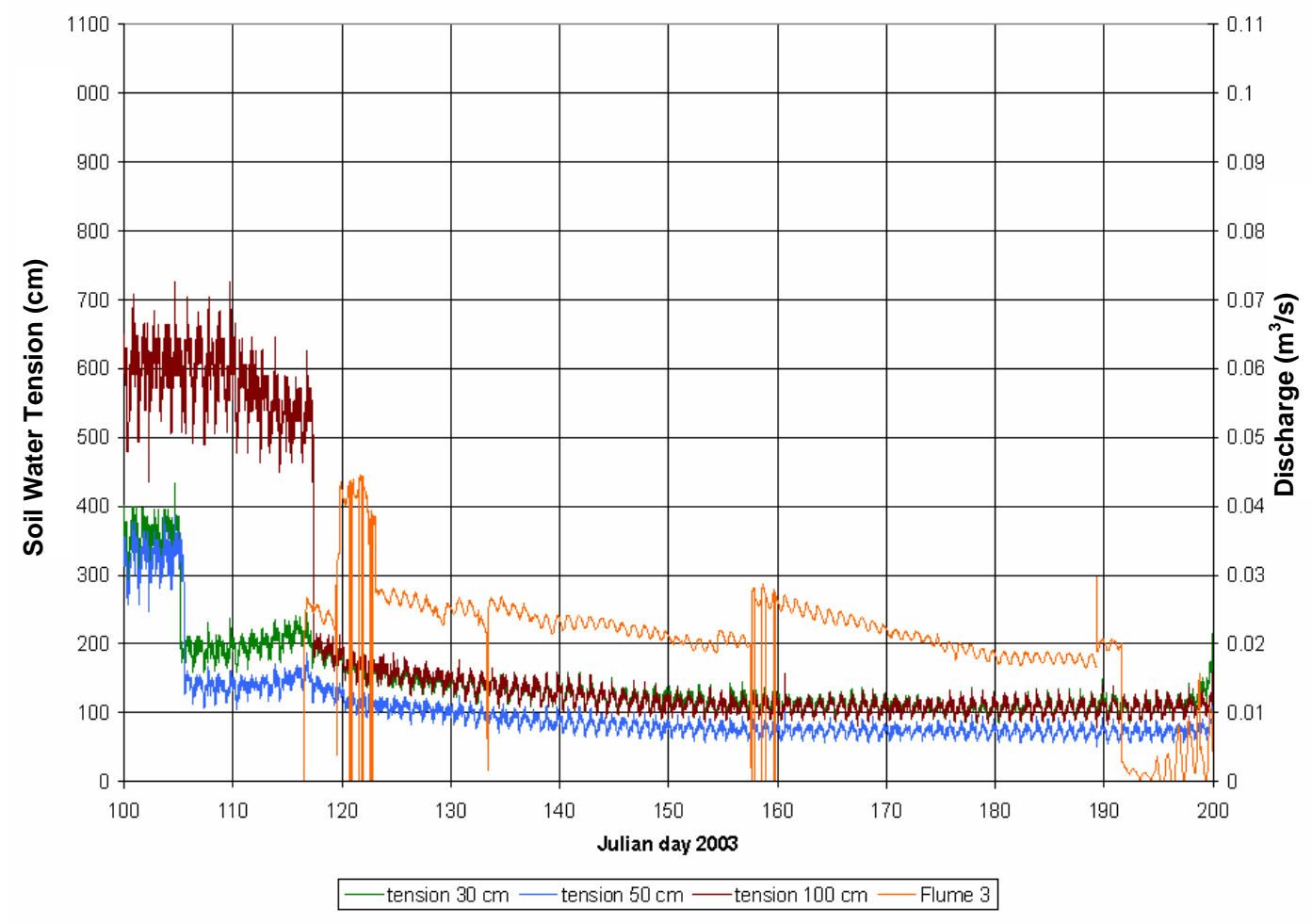

Figures 3.16. Soil water tension with discharge for Cambric station 2. 


\subsection{TRANSMISSION LOSS QUANTIFICATION ANALYSES}

Transmission losses are quantified using three different analysis methods. Method 1 uses Lane's Method (Lane, 1983) for estimating flood magnitude in ephemeral channels. Method 2 uses heat as a subsurface tracer for infiltration. Numerical modeling, using HYDRUS-2D (Simunek et al., 1999), a finite-element-based flow and transport code, is applied to estimate infiltration from soil temperature data. Method 3 uses hydraulic gradient and water content in a Darcy's Law approach (Freeze and Cherry, 1979) to calculate one-dimensional flow rates. Heat dissipation and water content data were collected for this analysis.

\subsection{Lane's Method of Transmission Loss Estimates}

Lane (1983) describes a method ("Lane's Method") for estimating flood magnitudes on ungaged ephemeral channels that compensates for transmission losses as a result of infiltration through the channel bed, banks, and floodplain. Coefficients of the Lane's Method estimating equations can be evaluated for channels of known geometry when measured inflow-outflow data are available. Also, a procedure is described by which the coefficients for a known channel can be used to estimate the coefficients for a similar channel where inflow-outflow data are unavailable.

Lane's Method (Lane, 1983) was developed using inflow-outflow data for natural flood events that occurred on three ephemeral channels in the southwest and on the Great Plains. It uses a regression equation to predict outflow from a given channel reach based upon measured inflow to the reach for a discreet runoff event. If measured inflow to the channel reach is not available, the inflow can be estimated as the runoff from a precipitation or storm event. The method recognizes that water storage in the channel bed and banks must be satisfied ("threshold volume") before runoff from the reach can occur. Assumptions of the method include:

1. Water is lost in the channel: no gains occur in the channel of interest.

2. Infiltration characteristics of the channel bed and banks are uniform with length and width or can be represented by an average.

3. Variations in sediment concentration and temperature in the runoff and antecedent flow can be represented by average conditions.

4. Average width and average duration represent the width and duration of flow for the entire channel reach.

5. Outflow volumes are a linear function of inflow volumes after the threshold volume has been satisfied.

6. Peak rates of outflow are a linear function of peak rates of inflow after the threshold volume is exceeded and the average loss rate is subtracted.

The equations for estimating outflow volume from Lane (1986) are

$$
\mathrm{Q}= \begin{cases}0 & \mathrm{P}<=\mathrm{Po} \\ \mathrm{a}(\mathrm{x}, \mathrm{w})+\mathrm{b}(\mathrm{x}, \mathrm{w}) \mathrm{P} & \mathrm{P}>\mathrm{Po}\end{cases}
$$


where $\mathrm{P}$ is the inflow to the modeled reach; Po is the inflow volume required to satisfy transmission loss; $\mathrm{Q}$ is the outflow from the modeled reach; and $\mathrm{a}(\mathrm{x}, \mathrm{w})$ and $\mathrm{b}(\mathrm{x}, \mathrm{w})$ are the regression equation coefficients.

$$
\text { Po }=-a(x, w) / b(x, w)
$$

To satisfy the physics of flow, the parameters of Equation (4-1) must be constrained: $\mathrm{a}(\mathrm{x}, \mathrm{w})<0$ and $0 \leq \mathrm{b}(\mathrm{x}, \mathrm{w}) \leq 1$. If these constraints are not met, the predictive equation is physically unrealistic. Constraining the intercept, $\mathrm{a}(\mathrm{x}, \mathrm{w})$, of the regression equation to be less than zero is necessary because the initial inflow volume goes to satisfy initial abstraction (transmission loss), or storage capacity, in the channel bed and bank. The more negative $\mathrm{a}(\mathrm{x}, \mathrm{w})$, the greater the transmission loss in the channel. Coefficient $\mathrm{b}(\mathrm{x}, \mathrm{w})$ must be greater than zero because a negative slope in the estimation equation would imply that outflow was decreasing as the inflow was increasing, a physically unrealistic condition. Additionally, a coefficient $\mathrm{b}(\mathrm{x}, \mathrm{w})$ greater than one would imply that the reach was gaining water, an impossible situation in a reach where lateral inflow is assumed to be zero.

\subsubsection{Results of Lane's Method Application}

Data for the four flumes on ER-5-3 allow the experimental channel to be divided into six reaches for analyses. Reach 1 lies between flumes 1 and 2; reach 2 lies between flumes 2 and 3; reach 3 lies between flumes 3 and 4; reach 4 lies between flumes 1 and flume 3; reach 5 lies between flume 2 and flume 4; and reach 6 lies between flume 1 and flume 4. Inflow-outflow data for each reach was used to evaluate the coefficients of Equation (4-1). Data from the flumes internal to the longer reaches described is ignored when those longer reaches are analyzed.

The ER-5-3 transmission loss experiment consisted of three flow events (Figure 3.1) providing three inflow-outflow data points on each reach. A linear regression equation was fitted to the data for each reach (Appendix B). The intercept and slope coefficients for the fitted regression equations (Table 4.1) are equivalent to the $\mathrm{a}(\mathrm{x}, \mathrm{w})$ and $\mathrm{b}(\mathrm{x}, \mathrm{w})$ coefficients of Lane's Method Equation (4-1). Only in ER-5-3 reach 3 did the intercept coefficient, $a(x, w)$, satisfy the constraint that $a(x, w)<0$. For ER-5-3 reach 3, $a=-0.0154$. This value is extremely close to zero and may not reflect a reasonable transmission loss condition.

The Cambric Ditch transmission loss experiment consisted of one flow event, although there were two occasions during the experiment when the pump supporting the experiment was shut down. Inflow-outflow volumes were calculated for the intervals during which the pump was operating. Additionally, a small precipitation event in the early spring produced flow at each of the flumes. As a group, these inflow-outflow data provided four to six flow events on each reach; however, not all events could be evaluated on all reaches. These data were regressed to evaluate the coefficients of the Lane's Method estimation equations (Appendix B). Table 4.1 presents the results of the regression analyses. Again, only one reach, Cambric reach 2, produced the required negative value for $\mathrm{a}(\mathrm{x}, \mathrm{w})$. 
Table 4.1. Parameters for the Lane's Method estimation equation developed by regression of ER-5-3 and Cambric Ditch transmission loss inflow-outflow data.

\begin{tabular}{lllllll}
\hline \multicolumn{7}{c}{ ER-5-3 Reaches } \\
\hline Parameter & 1 & 2 & 3 & 4 & 5 & 6 \\
$\mathrm{a}(\mathrm{x}, \mathrm{w})$ & 0.1847 & 0.2816 & -0.0154 & 0.3940 & 0.1489 & 0.1914 \\
$\mathrm{~b}(\mathrm{x}, \mathrm{w})$ & 0.7626 & 0.6800 & 0.5039 & 0.5222 & 0.3352 & 0.2609 \\
Po & -0.2435 & -0.4141 & 0.0306 & -0.7545 & -0.4442 & -0.7336 \\
$\mathrm{R} 2$ & 0.9956 & 0.9883 & 0.9620 & 0.9982 & 0.9100 & 0.9442 \\
\hline & & & Cambric Ditch Reaches & & \\
\hline Parameter & 1 & 2 & 3 & & & \\
$\mathrm{a}(\mathrm{x}, \mathrm{w})$ & 0.4891 & -0.0384 & 0.7518 & & \\
$\mathrm{~b}(\mathrm{x}, \mathrm{w})$ & 0.7181 & 0.9125 & 0.6209 & & \\
Po & -0.6811 & 0.0421 & -1.2110 & & \\
$\mathrm{R} 2$ & 0.9690 & 0.9992 & 0.9932 & & \\
\hline
\end{tabular}

It is not clear why the $\mathrm{a}(\mathrm{x}, \mathrm{w})$ coefficient of the Lane's Method regression equation did not meet the constraint $\mathrm{a}(\mathrm{x}, \mathrm{w})<0$. However, it may be that the conditions of the NTS transmission loss experiments were not sufficiently similar to conditions underlying the data Lane used in deriving his methodology. For example, the ER-5-3 flow events were four, six, and nine days in duration and the Cambric Ditch events lasted from a few hours to 75 days. Intuitively, ephemeral flood events are unlikely to continue as long as the ER-5-3 flow events. During a shorter flood event, the transmission loss would constitute a larger portion of the total volume of flow. Additionally, the time between the ER-5-3 flow events when there was no flow in the channel may have been too short to allow the channel bed and bank to return to ambient water content levels. Because the pump producing water for the Cambric Ditch flows was shut off for only a few hours at a time there was no period when water was absent from the Cambric Ditch. Under these conditions, transmission loss during most of the flow period used in the regressions would reflect higher antecedent soil moisture levels than would likely be present prior to a natural ephemeral flood event.

Only two reaches, ER-5-3 reach 3 (between ER-5-3 stations 3 and 4) and Cambric reach 2 (between Cambric stations 2 and 3), produced an intercept and slope for the Lane's Method estimating equation that satisfied the constraints of the method. Outflow from these two reaches was estimated using Equation (4-1) and the appropriate equation coefficients from Table 4.1. The outflow estimates for each flow event on these two reaches are presented in Table 4.2.

For the ER-5-3 reach 3 estimates (Table 4.2), Lane's Method slightly over-estimates the measured outflow for the reach in 2 of the 3 events (a negative error indicates that the Lane's Method is over-estimating the measured outflow); however, the percent error of the over-estimated outflow ranges between 1.5 and 4.2 percent. For the second event at 
ER-5-3 reach 3, the method under-estimates the measured outflow, but again the percent error is relatively small, at less than 6.0 percent. For the Cambric reach 2 estimates (Table 4.2), again Lane's Method slightly over-estimates the measured outflow for this reach in two of the three events; however, the percent error only ranges between 1.3 and 4.6 percent. For the second event at Cambric reach 2, the method slightly underestimates the measured outflow, with a percent error of 2.5 percent. These results suggest that Lane's Method is a good estimator of discharge from a reach when the regression equation coefficients are within proper constraints.

\subsection{Temperature Modeling}

HYDRUS-2D (Simunek et al., 1999) was used to model the temperature data from the two instrumented stations on the ER-5-3 channel and three instrumented stations on the Cambric Ditch. The software simulates two-dimensional water, heat, and solute movement in saturated to variably saturated porous media. Water flow is simulated through numerical solution of the Richards' equation in two dimensions

$$
\frac{\partial \theta}{\partial t}=\frac{\partial\left[K\left(K_{i j}^{A} \frac{\partial h}{\partial x_{j}}+K_{i z}^{A}\right)\right]-S}{\partial x_{i}}
$$

Table 4.2. Outflow for ER-5-3 reach 3 and Cambric reach 2 estimated by Lane's Method.

\begin{tabular}{|c|c|c|c|c|c|c|c|c|c|}
\hline \multicolumn{10}{|c|}{ ER-5-3 station 3 and station 4 flows } \\
\hline & \multicolumn{4}{|c|}{ Measured flows } & \multicolumn{2}{|c|}{ Estimated flows } & & & \\
\hline \multirow{3}{*}{ Event } & \multicolumn{2}{|c|}{ Inflow } & \multicolumn{2}{|c|}{ Outflow } & \multicolumn{2}{|c|}{ Estimated } & \multirow{2}{*}{\multicolumn{3}{|c|}{ Error }} \\
\hline & \multicolumn{2}{|c|}{ Station 3} & \multicolumn{2}{|c|}{ Station 4} & \multicolumn{2}{|c|}{ Outflow } & & & \\
\hline & (af) & $\left(\mathrm{m}^{3}\right)$ & (af) & $\left(\mathrm{m}^{3}\right)$ & (af) & $\left(\mathrm{m}^{3}\right)$ & (af) & $\left(\mathrm{m}^{3}\right)$ & $(\%)$ \\
\hline 1 & 1.60 & $1,980.0$ & 0.78 & 963.4 & 0.79 & 978.7 & -0.012 & -15.34 & -1.59 \\
\hline 2 & 2.58 & $3,189.7$ & 1.36 & $1,673.6$ & 1.29 & $1,588.3$ & 0.069 & 85.30 & 5.97 \\
\hline 3 & 2.80 & $3,455.6$ & 1.34 & $1,652.4$ & 1.40 & $1,722.3$ & -0.057 & -69.89 & -4.22 \\
\hline \multicolumn{10}{|c|}{ Cambric station 2 and station 3 flows } \\
\hline & \multicolumn{4}{|c|}{ Measured flows } & \multicolumn{2}{|c|}{ Estimated flows } & & & \\
\hline & \multicolumn{2}{|c|}{ Inflow } & \multicolumn{2}{|c|}{ Outflow } & \multicolumn{2}{|c|}{ Estimated } & & & \\
\hline \multirow[t]{2}{*}{ Event } & \multicolumn{2}{|c|}{ Station 2} & \multicolumn{2}{|c|}{ Station 3} & \multicolumn{2}{|c|}{ Outflow } & \multicolumn{3}{|c|}{ Error } \\
\hline & (af) & $\left(\mathrm{m}^{3}\right)$ & (af) & $\left(\mathrm{m}^{3}\right)$ & (af) & $\left(\mathrm{m}^{3}\right)$ & (af) & $\left(\mathrm{m}^{3}\right)$ & $(\%)$ \\
\hline d116-d119 & 5.89 & $7,264.0$ & 5.08 & $6,262.8$ & 5.31 & $6,548.3$ & -0.232 & -285.6 & -4.56 \\
\hline d119-d133 & 30.44 & $37,545.2$ & 28.46 & $35,104.5$ & 27.73 & $34,206.8$ & 0.728 & 897.6 & 2.56 \\
\hline d133-d157 & 41.89 & $51,673.2$ & 37.70 & $46,499.0$ & 38.19 & $47,111.1$ & -0.496 & -612.1 & -1.32 \\
\hline
\end{tabular}


where $\theta$ is the volumetric water content $\left(\mathrm{L}^{3} \mathrm{~L}^{-3}\right), \mathrm{h}$ is the pressure head $(\mathrm{L}), \mathrm{t}$ is time $(\mathrm{T}), \mathrm{x}_{i}$ are spatial coordinates, $\mathrm{S}\left(\mathrm{T}^{-1}\right)$ is a sink term, $\mathrm{K}_{i j}{ }^{\mathrm{A}}$ comprise the anisotropy tensor $\mathbf{K}^{\mathrm{A}}$, and $\mathrm{K}$ is the unsaturated hydraulic conductivity function $\left(\mathrm{LT}^{-1}\right)$, which is

$$
K(h, x, z)=K_{s}(x, z) K_{r}(h, x, z) .
$$

$\mathrm{K}_{\mathrm{s}}$ is the saturated hydraulic conductivity $\left(\mathrm{LT}^{-1}\right)$ and $\mathrm{K}_{\mathrm{r}}$ is the relative hydraulic conductivity.

The equation of heat transport is described by Sophocleous (1979)

$$
C(\theta) \frac{\partial T}{\partial t}=\frac{\partial\left[\lambda_{i j}(\theta) \frac{\partial T}{\partial x_{j}}\right]}{\partial x_{i}}-C_{w} q_{i} \frac{\partial T}{\partial x_{i}}
$$

where $\mathrm{T}$ is temperature $(\mathrm{K}), \mathrm{q}_{\mathrm{i}}$ is water flux $\left(\mathrm{LT}^{-1}\right), \lambda_{i j}(\theta)$ is the apparent thermal conductivity $\left(\mathrm{MLT}^{-3} \mathrm{~K}^{-1}\right)$, and $\mathrm{C}(\theta)$ and $\mathrm{C}_{\mathrm{w}}$ are volumetric heat capacities $\left(\mathrm{ML}^{-1} \mathrm{~T}^{-2} \mathrm{~K}^{-1}\right)$ of the media and water, respectively. The first term on the right side of Equation (4-5) represents transport of heat by conduction, whereas the second term represents convection of heat by flowing water. The transport of latent heat due to water vapor movement is not considered. HYDRUS-2D (Simunek et al., 1999) uses a finite-element approach in the numerical solution of the governing equations.

\section{$\underline{4.2 .1 \quad \text { Model Domain }}$}

Each instrumented site on the ER-5-3 and Cambric Ditch channels was modeled as a two-dimensional vertical cross section, and as a rectangular channel shape with the channel dimensions known from previous survey data. In the horizontal direction, the model was symmetrical about the center of the channel. The model domain extended approximately $20 \mathrm{~m}(66 \mathrm{ft})$ on either side of the channel center so that model boundaries did not affect the simulation results. In the vertical direction, the model extended to a

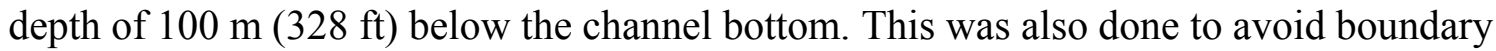
effects on the simulated flow.

HYDRUS-2D (Simunek et al., 1999) discretizes the model domain into a mesh of triangular elements (Figure 4.1 A and B). Discretization was fine $[10$ to $20 \mathrm{~cm}(0.3$ to $0.6 \mathrm{ft}$ ) from base to apex of the triangular elements] near the channel bottom and became coarser farther from the channel. Observation nodes were placed in the model at 30, 50, and $100 \mathrm{~cm}(1.0,1.6$, and $3.3 \mathrm{ft})$ below the channel bottom so that the simulated results could be compared with the thermocouple data from the field. Simulations were run for the time that water was in the channel. Whenever possible, domains were constructed as a homogeneous soil unit (i.e., no soil layering). 


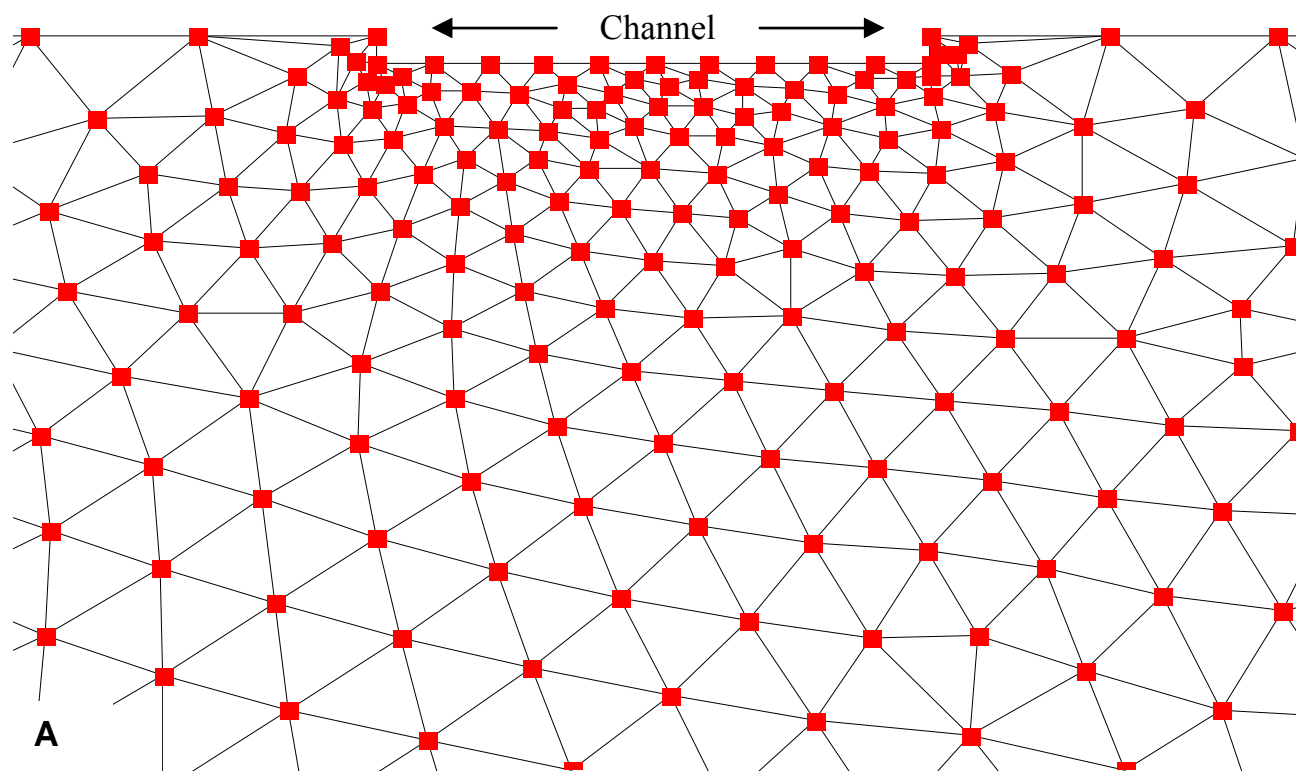

Channel

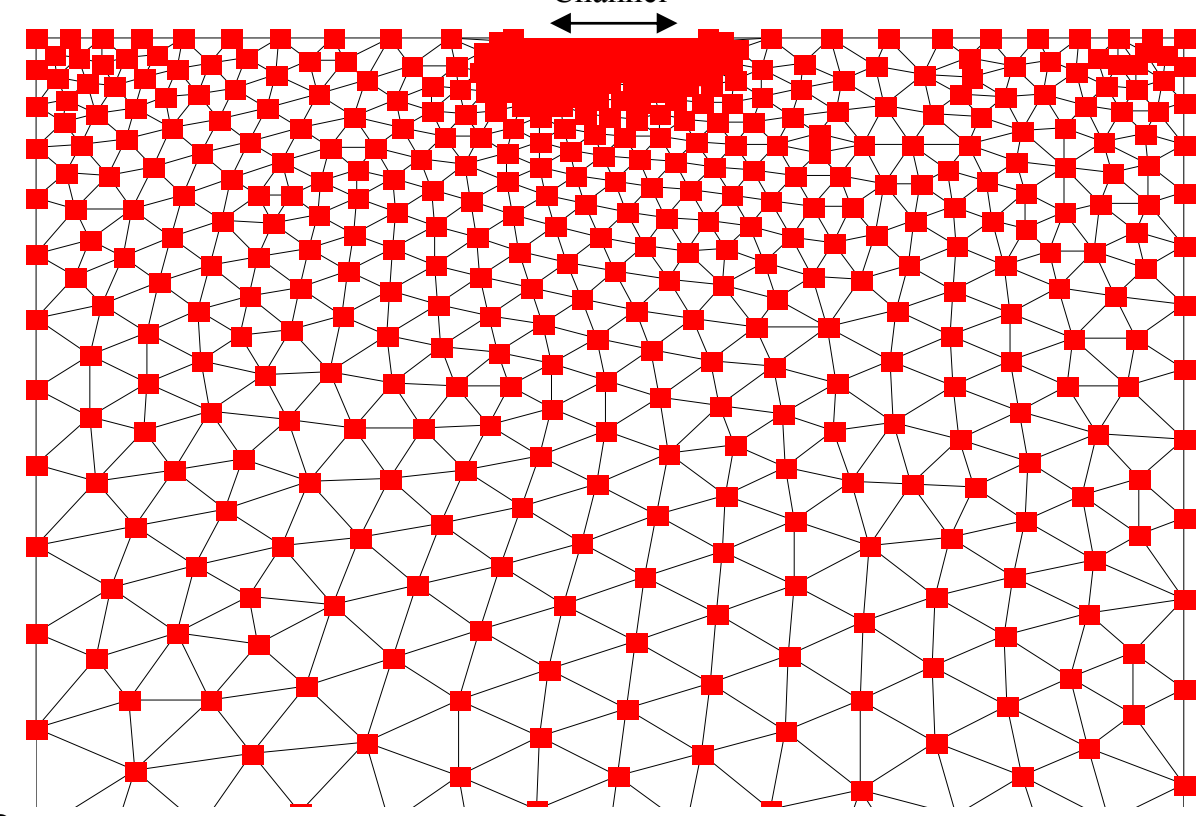

B

Figure 4.1. A) Close-up of the model domain showing the finite-element mesh. B) Extended view of the model domain. 


\subsubsection{Initial and Boundary Conditions}

The initial condition for water content was set to $0.11 \mathrm{~cm}^{3} \mathrm{~cm}^{-3}$ at the channel bottom. From the channel bottom to a depth of approximately $2 \mathrm{~m}(6.6 \mathrm{ft})$, the initial moisture was linearly interpolated between 0.11 to $0.2 \mathrm{~cm}^{3} \mathrm{~cm}^{-3}$. Depths deeper than $2 \mathrm{~m}(6.6 \mathrm{ft})$ below the channel bottom were assigned an initial water content of $0.2 \mathrm{~cm}^{3} \mathrm{~cm}^{-3}$. These values are considered reasonable given the field situation. Initial temperature conditions were determined from thermocouple readings immediately prior to the period of simulation.

A time-dependent variable head boundary condition was assigned to the channel bottom. The head was varied every hour based on stage data collected at the flumes. The channel bottom was also designated time-dependent prescribed temperature boundaries. This boundary was also varied every hour based on the temperature recorded by the thermocouple on the channel bottom. The bottom boundary of the model was designated a free drainage boundary. This boundary assumes only gravity-driven flow, a unit vertical gradient. A prescribed temperature boundary was also ascribed to the bottom of the model. The temperature for this boundary was set to $16.7^{\circ} \mathrm{C}$, which is the approximate average annual temperature and represents the groundwater table.

\subsubsection{Hydraulic and Thermal Properties}

The van Genuchten parameterization (1980) of the water retention curve was used in the numerical simulations

$$
\Theta=\frac{\theta-\theta_{r}}{\theta_{s}-\theta_{r}}=\frac{1}{\left(1+|\alpha h|^{n}\right)^{m}}
$$

where $\Theta$ is the relative volumetric water saturation, $\theta_{r}$ and $\theta_{s}$ are residual and saturated volumetric water contents, respectively, $\alpha\left(\mathrm{L}^{-1}\right)$ and $n$ are fitting parameters, $h(\mathrm{~L})$ is the soil water pressure head, and $m$ is $(1-1 / n), 0<m<1$. The van Genuchten (1980) equation is combined with the Mualem model (Mualem, 1976) of unsaturated hydraulic conductivity to produce a convenient, closed-form expression of hydraulic conductivity as a function of soil water pressure head

$$
K(h)=K_{s}\left(\frac{\left(1-(\alpha h)^{n-1}\left(1+(\alpha h)^{n}\right)^{-m}\right)^{2}}{\left(1+(\alpha h)^{n}\right)^{m / 2}}\right)
$$

where $\mathrm{K}_{\mathrm{s}}\left(\mathrm{LT}^{-1}\right)$ is the saturated hydraulic conductivity. Because surface tension $(\sigma)\left(\mathrm{MT}^{-2}\right)$, water density $(\rho)\left(\mathrm{ML}^{-3}\right)$, and viscosity $(\mu)\left(\mathrm{ML}^{-1} \mathrm{~T}^{-1}\right)$ are all temperature dependent, the hydraulic functions vary with temperature. This dependence in the water retention function is accounted for by the following equation:

$$
h_{T}=\frac{\sigma_{T}}{\sigma_{r e f}} * h_{r e f}
$$


where $h_{\mathrm{T}}$ and $h_{\text {ref }}\left(\sigma_{\mathrm{T}}\right.$ and $\left.\sigma_{\text {ref }}\right)$ are the soil water pressure heads (surface tensions) at temperature $\mathrm{T}$ and a reference temperature, respectively. Temperature dependence in the hydraulic conductivity function is accounted for by

$$
K_{T}(\theta)=\frac{\mu_{r e f}}{\mu_{T}} * \frac{\rho_{T}}{\rho_{r e f}} * K_{r e f}(\theta)
$$

where $\mathrm{K}_{\mathrm{T}}$ and $\mathrm{K}_{\text {ref }}$ are the hydraulic conductivities at a specific temperature and a reference temperature, respectively, and $\mu_{\mathrm{T}}$ and $\mu_{\mathrm{ref}}\left(\rho_{\mathrm{T}}\right.$ and $\left.\rho_{\mathrm{ref}}\right)$ are the dynamic viscosities (water densities) at a given temperature and a reference temperature, respectively (Constantz, 1982).

To simulate the movement of heat, the thermal conductivity of the media must be known. Thermal conductivity of soil is largely dependent on the soil water content. HYDRUS-2D (Simunek et al., 1999) uses the parameterization of the thermal conductivity function developed by Chung and Horton (1987)

$$
\lambda(\theta)=b_{1}+b_{2} \theta+b_{3} \theta^{0.5}
$$

where $b_{1}, b_{2}$, and $b_{3}$ are coefficients that change with soil texture.

The hydraulic and thermal properties were adjusted to match the temperature data recorded by the thermocouples at the three depths below the channel and water content data, when available (Appendix C). Tables 4.3 and 4.4 list the final thermal and hydraulic properties, respectively, used to produce the modeled results. A sensitivity analysis shows that model results are most sensitive to the value of $\mathrm{K}_{\mathrm{s}}$. Appendix $\mathrm{C}$ lists all model input and output data.

Table 4.3. Heat transport parameters. $b$ values are coefficients in the thermal conductivity function (Chung and Horton, 1987). $\mathrm{c}_{\mathrm{w}}$ and $\mathrm{c}_{\mathrm{s}}$ are the volumetric heat capacities of the liquid and solid phases, respectively.

\begin{tabular}{lrcccc}
\hline & $b_{1}$ & $b_{2}$ & $b_{3}$ & $\mathrm{c}_{\mathrm{w}}$ & $\mathrm{c}_{\mathrm{s}}$ \\
& & & & $\mathrm{J} \mathrm{m}^{-3}{ }^{\circ} \mathrm{C}^{-1}$ & $\mathrm{~J} \mathrm{~m}^{-3}{ }^{\circ} \mathrm{C}^{-1}$ \\
\hline Cambric 1 & $2.43 \mathrm{E}-6$ & $3.93 \mathrm{E}-6$ & $1.534 \mathrm{E}-5$ & $4.18 \mathrm{E}+6$ & $1.92 \mathrm{E}+6$ \\
Cambric 2 & $2.28 \mathrm{E}-6$ & $2.406 \mathrm{E}-5$ & $4.909 \mathrm{E}-5$ & $4.18 \mathrm{E}+6$ & $1.92 \mathrm{E}+6$ \\
Cambric 3 & $2.28 \mathrm{E}-6$ & $2.406 \mathrm{E}-5$ & $4.909 \mathrm{E}-5$ & $4.18 \mathrm{E}+6$ & $1.92 \mathrm{E}+6$ \\
ER-5-3-1 & $2.43 \mathrm{E}-6$ & $3.93 \mathrm{E}-6$ & $1.534 \mathrm{E}-5$ & $4.18 \mathrm{E}+6$ & $1.92 \mathrm{E}+6$ \\
ER-5-3-4 & $2.28 \mathrm{E}-6$ & $2.406 \mathrm{E}-5$ & $4.909 \mathrm{E}-5$ & $4.18 \mathrm{E}+6$ & $1.92 \mathrm{E}+6$ \\
\hline
\end{tabular}


Table 4.4. Unsaturated hydraulic properties used to produce model results.

\begin{tabular}{cccccc}
\hline Location & $\begin{array}{c}\theta_{\mathrm{r}} \\
\mathrm{cm}^{3} \mathrm{~cm}^{-3}\end{array}$ & $\begin{array}{c}\theta_{\mathrm{s}} \\
\mathrm{cm}^{3} \mathrm{~cm}^{-3}\end{array}$ & $\begin{array}{c}\alpha \\
\mathrm{m}^{-1}\end{array}$ & $\begin{array}{l}n \\
-\end{array}$ & $\begin{array}{c}\mathrm{K}_{\mathrm{s}} \\
\mathrm{m} \mathrm{d}^{-1}\end{array}$ \\
\hline Cambric 1 & 0.045 & 0.380 & 10.000 & 2.500 & 1.000 \\
Cambric 2 & 0.057 & 0.390 & 12.000 & 2.500 & 1.500 \\
Cambric 2 (50, 100) & 0.057 & 0.350 & 12.000 & 2.500 & 1.500 \\
Cambric 3 (30) & 0.065 & 0.370 & 7.500 & 1.890 & 0.400 \\
Cambric 3 (50) & 0.065 & 0.350 & 12.000 & 2.500 & 4.000 \\
Cambric 3 (100) & 0.065 & 0.350 & 12.000 & 2.500 & 4.000 \\
ER-5-3-1 (30) & 0.057 & 0.375 & 10.000 & 1.900 & 0.080 \\
ER-5-3-1 (50) & 0.057 & 0.320 & 5.000 & 1.450 & 0.040 \\
ER-5-3-1 (100) & 0.057 & 0.350 & 6.000 & 1.450 & 0.400 \\
ER-5-3-4 (30) & 0.057 & 0.450 & 9.000 & 1.900 & 2.100 \\
ER-5-3-4 (50) & 0.045 & 0.430 & 5.500 & 1.400 & 2.000 \\
ER-5-3-4 (100) & 0.057 & 0.450 & 9.000 & 1.900 & 3.500 \\
\hline
\end{tabular}

\subsubsection{Results of Temperature Modeling}

Flow and transport of heat were simulated for ER-5-3 stations 1 and 4. Modeling of the ER-5-3 channel was complicated because the channel was dry at times during the modeled period. HYDRUS-2D (Simunek et al., 1999) is incapable of handling the changing nature of the top boundary condition from a variable head to an atmospheric condition with evaporation. To more accurately simulate this flow period in HYDRUS-2D (Simunek et al., 1999), it would have to be done in sections as separate models; however, as an alternative to making many individual simulations, an approximation to the actual field conditions was used, which allowed the use of a single simulation. To keep water from entering the model during the dry periods, the upper boundary was set to a high negative value $[\sim-0.2 \mathrm{~m}(-0.7 \mathrm{ft})]$. Although this does not account for evaporation at the surface, it does keep water from entering the model, thereby allowing moisture to drain from the domain.

The model was able to fit the measured temperature data for ER-5-3 station 1 relatively well (Figure 4.2). Figure 4.3 shows the water content and discharge for ER-5-3 station 1. The model predicts the water content at the $30 \mathrm{~cm}(1.0 \mathrm{ft})$ depth reasonably well. The trend in water content at the $50-\mathrm{cm}(1.6-\mathrm{ft})$ depth is roughly matched, but the water content at the $100-\mathrm{cm}$ (3.3-ft) depth is poorly replicated. This is likely a result of increasing heterogeneity as the flowpath lengthens. The most notable inconsistency between the water content data and predictions is the time necessary for the probes at depth to sense the moisture. All of the probes respond almost immediately once there is water in the flume. However, the low values of $\mathrm{K}_{\mathrm{s}}$ that were used in the model to match the temperature data and that correspond to laboratory analyses result in the wetting front propagating much more slowly in the model. This inconsistency most likely results from preferential flow, with water bypassing the low conductivity zones and reaching the deeper probes more quickly than the actual wetting front, which travels through the fine-grained matrix. The mechanism for preferential flow may have originated during probe installation, as the surface was disturbed and backfilled. 

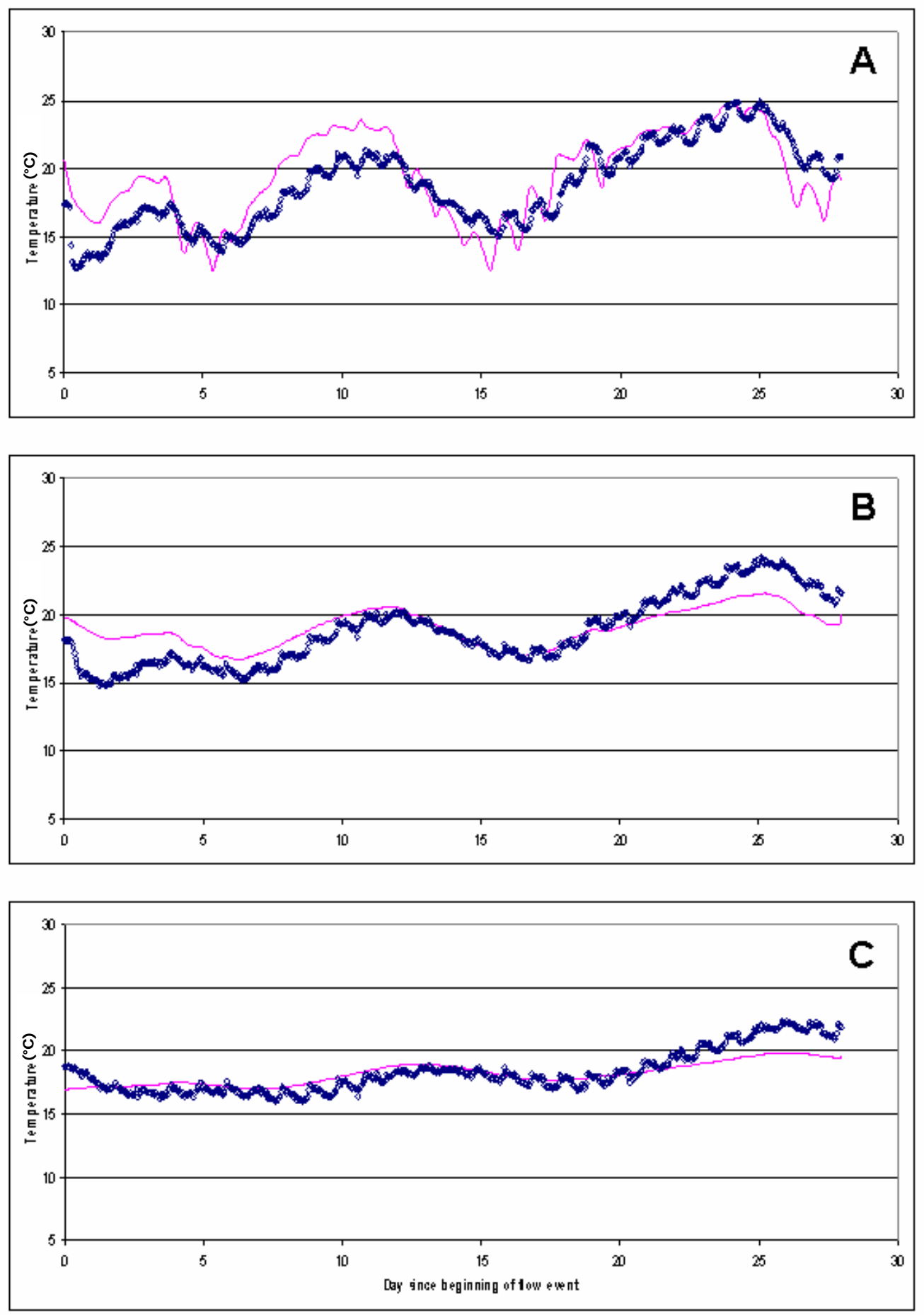

Figure 4.2. Comparison of modeled (solid line) and field (symbol) temperature data at ER-5-3 station 1 at A) $30-\mathrm{cm}$, B) $50-\mathrm{cm}$, and C) $100-\mathrm{cm}$ depth. 


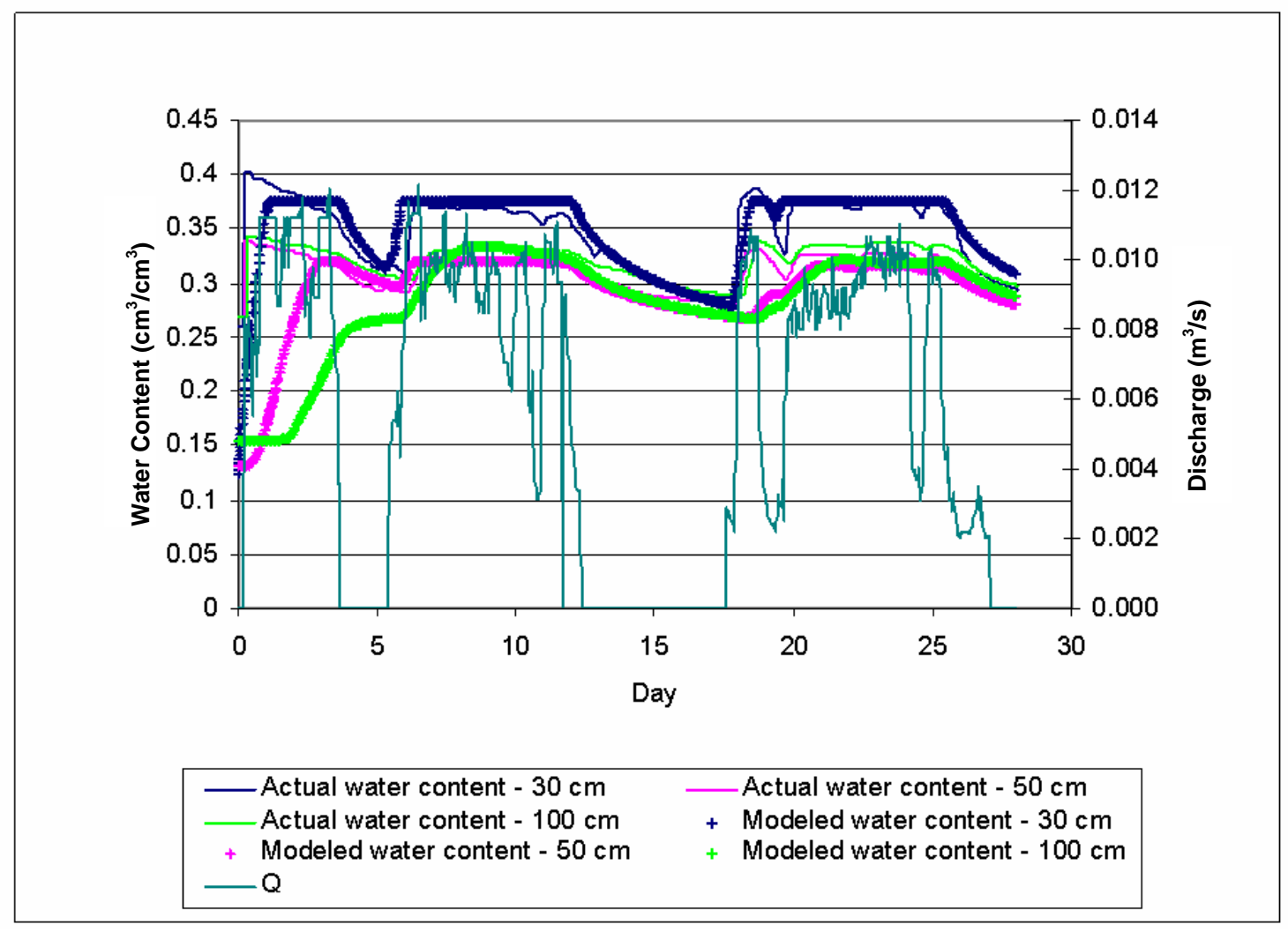

Figure 4.3. Comparison of modeled (symbols) and field (solid) temperature data and discharge at ER-5-3 station 1 for the flow period.

The model for ER-5-3 station 1 predicted a cumulative infiltration of approximately $3.0 \mathrm{~m}^{3}$ per meter ( $32.3 \mathrm{ft}^{3}$ per foot) of channel during the entire flow period, and the flux was approximately $0.3 \mathrm{~m} / \mathrm{d}(1.0 \mathrm{ft} / \mathrm{d})$ when water was in the channel. Although the general temperature trends are replicated in the simulations, the diurnal fluctuation is not captured for ER-5-3 station 1, which is another indication that there may be water bypassing the lower conductivity layers (Figure 4-2).

For ER-5-3 station 4, the model predicts the temperature fluctuations fairly well (Figure 4.4). The model, however, overpredicts temperature at the 30-cm (1.0-ft) depth and underpredicts temperatures at the 50- and 100-cm (1.6- and 3.3-ft) depth. This inconsistency is a result of the inability of the model to capture the temperature inversion recorded by the thermocouples. The recorded temperatures show a temperature reversal, which only occurs when water is in the channel, with higher temperatures at the $50-\mathrm{cm}(1.6-\mathrm{ft})$ depth than the $30-\mathrm{cm}$ $(1.0-\mathrm{ft})$ depth. Further investigation is needed to identify the cause of the temperature inversion. The periods of minimal temperature fluctuation correspond to times when water was not in the channel. Figure 4.5 shows stage data at ER-5-3 station 4. During dry periods, the only mechanism of heat transport is through conduction, which is considerably less efficient. 

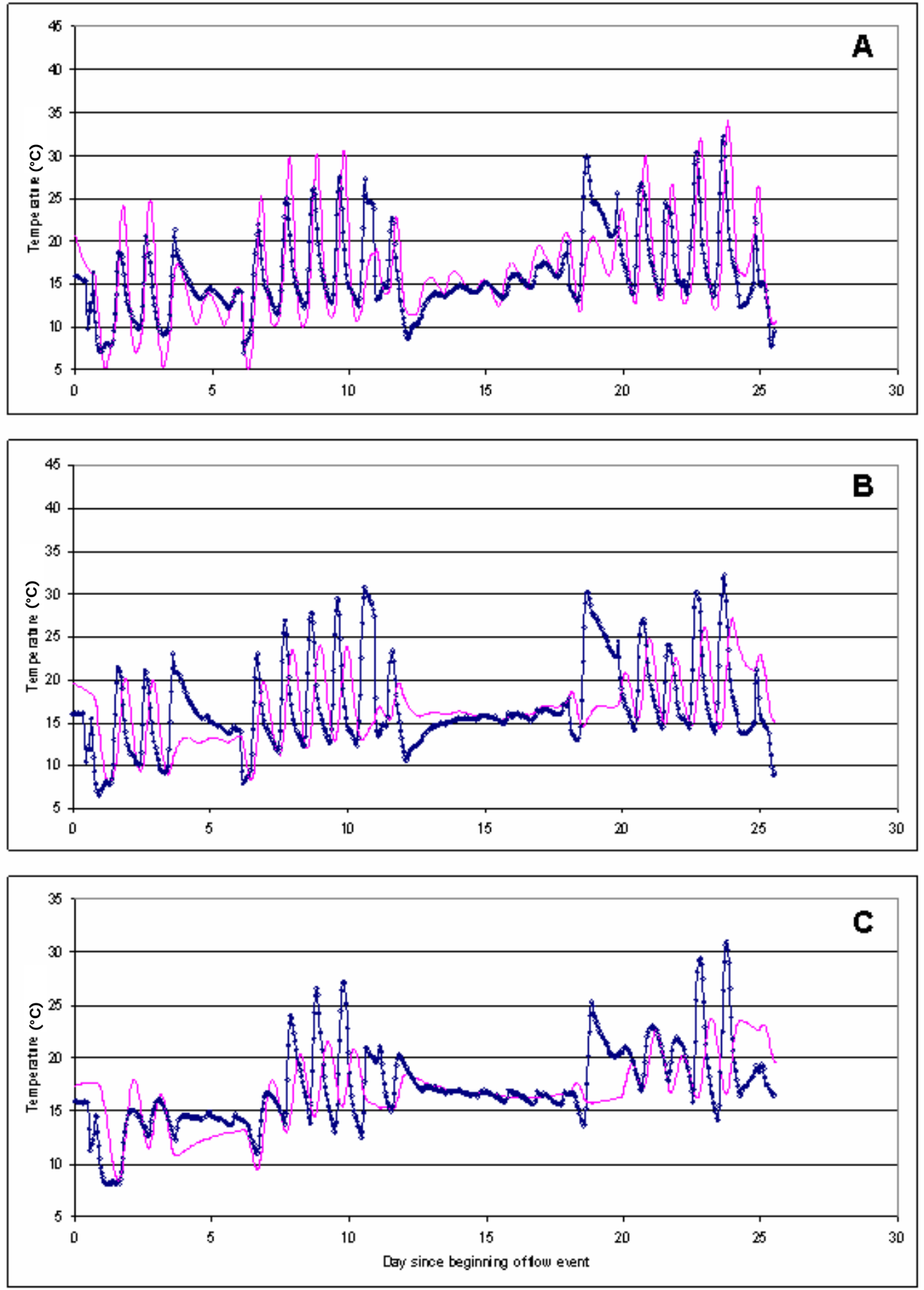

Figure 4.4. Comparison of modeled (solid line) and field (symbol) temperature data at ER-5-3 station 4 at A) 30-cm, B) 50-cm, and C) 100-cm depth. 
The ER-5-3 model matches the water content data well near the boundary at the $30-\mathrm{cm}$ (1.0-ft) depth (Figure 4.6). However, model fits to the data worsen with depth, probably because heterogeneity increases as the flowpath lengthens. The model captures the large decreases in water content, when there was no water in the channel and soil water began to drain. There are, however, small fluctuations in the measured water content that the model could not capture. Temperature effects on the sensors could cause these smaller changes in water content, for instance, dielectric permittivity is widely known to be temperature dependent (Wraith and Or, 1999.

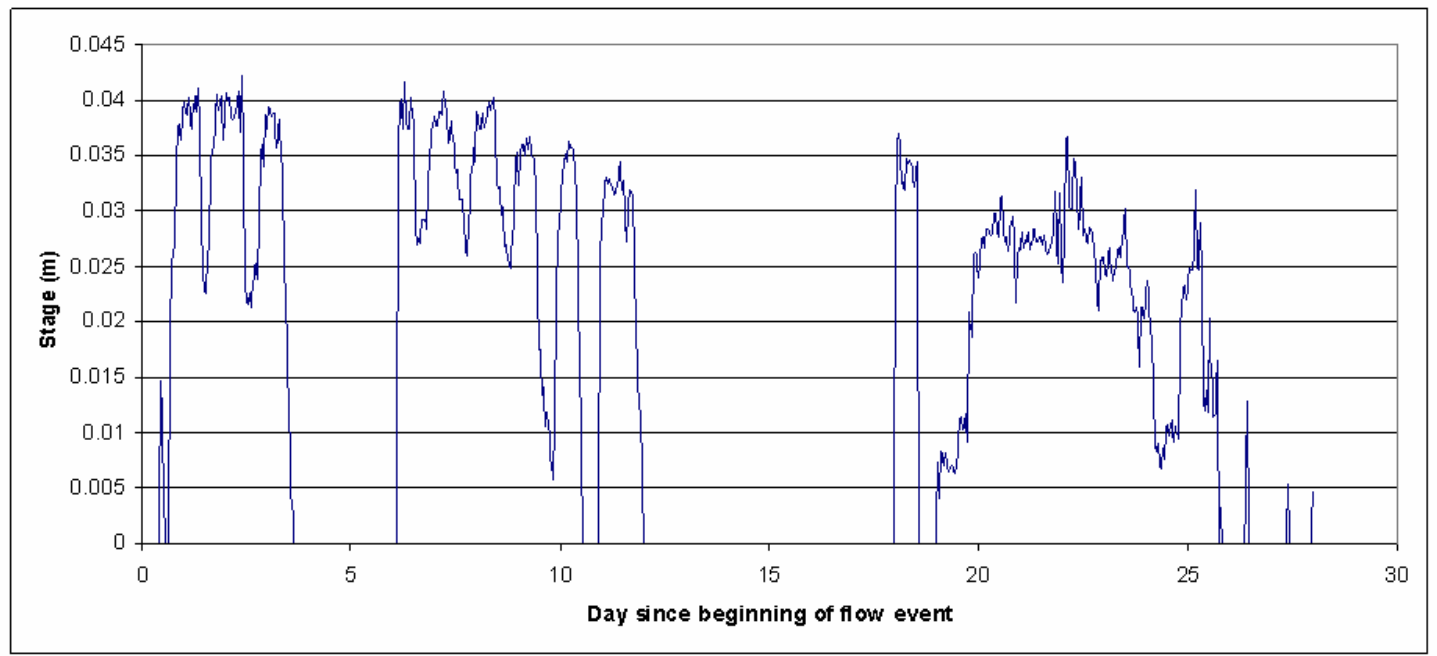

Figure 4.5. Stage data at ER-5-3 station 4.

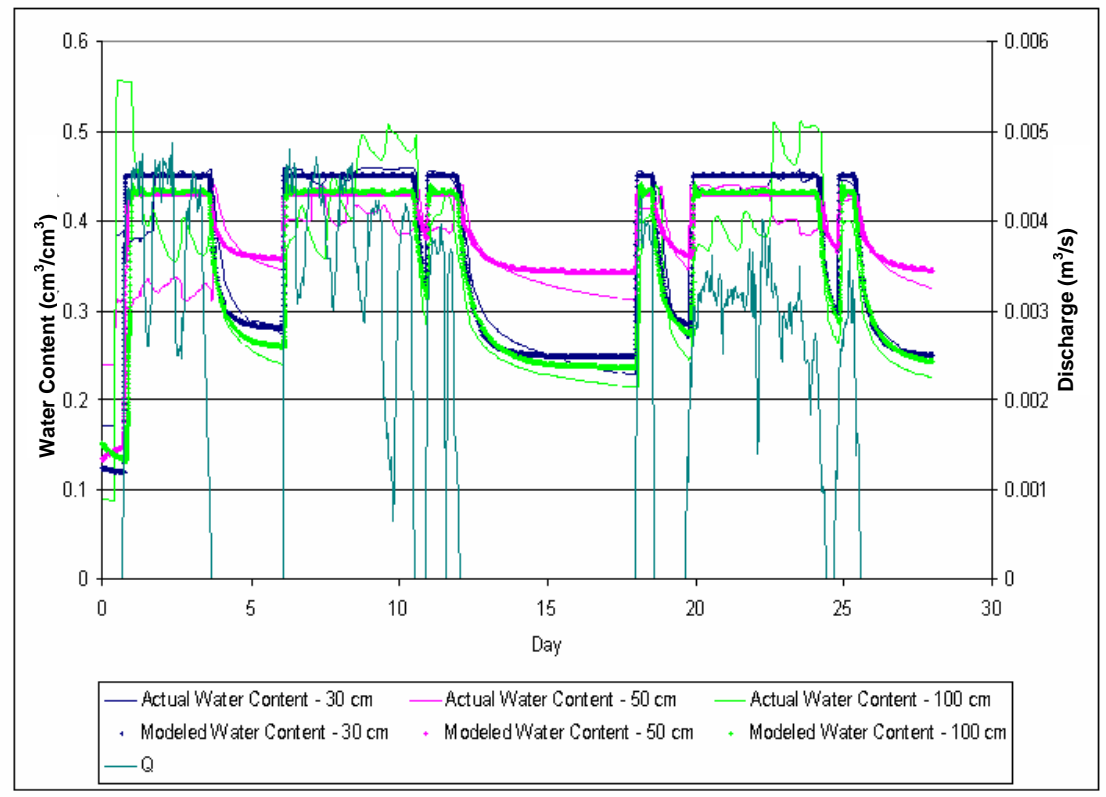

Figure 4.6. Comparison of modeled (symbols) and field (solid) temperature data and discharge for ER-5-3 station 4 for the flow period. 
The ER-5-3 modeled water content at the 50-cm (1.6-ft) depth is offset slightly with regard to time, which could result from small differences between the actual probe location in the field and its location within the model domain. The water content at the 50-cm (1.6-ft) depth decreases much less than at the other two measured depths, which indicates a finer soil texture at $50 \mathrm{~cm}(1.6 \mathrm{ft})$. Lower values of laboratory determined $\mathrm{K}_{\mathrm{s}}$ corroborate this transition. The model predicts a cumulative flux of approximately $32 \mathrm{~m}^{3}$ per meter $\left(344.3 \mathrm{ft}^{3}\right.$ per foot) of channel over the flow period and an average flux of approximately $4.2 \mathrm{~m} / \mathrm{d}(13.8 \mathrm{ft} / \mathrm{d})$ at ER-5-3 station 4 for the times when water is flowing in the channel.

Flow and transport of heat were simulated for stations 1, 2, and 3 in the Cambric Ditch. Modeling of the Cambric Ditch was not as complicated as that of ER-5-3 because the channel was never dry during the modeled period.

Figure 4.7 shows the model results for Cambric station 1. The model results are able to capture the correct temperature amplitude and diurnal periodicity; however, the model results are slightly offset from the measured data. Data from Cambric station 1 are the only data that exhibit this unknown offset. Also, the amplitude of the diurnal temperature fluctuation is much lower at Cambric station 1 than at Cambric stations 2 and 3. The total range of temperature oscillation at the Cambric station $130-\mathrm{cm}(1.0-\mathrm{ft})$ depth is less than $1{ }^{\circ} \mathrm{C}$, indicating that heat is not being efficiently transported in this section of the channel.

As previously described, there is no water content data for Cambric station 1 . The model predicts a cumulative infiltration over the flow period of $500 \mathrm{~m}^{3}$ per meter $\left(5,379.2 \mathrm{ft}^{3}\right.$ per foot) of channel with an average flux of $1.8 \mathrm{~m} / \mathrm{d}(5.9 \mathrm{ft} / \mathrm{d})$.

The model results of Cambric station 2 match the temperature data very well (Figure 4.8); although the match to the field data is slightly worse for the $100-\mathrm{cm}(3.3-\mathrm{ft})$ depth, where the model overpredicts the temperature fluctuation at the beginning of the simulation. The model fit is best at the shallowest depth and worsens with depth, most likely due to material heterogeneity.

Because of an incomplete calibration of the WCR used at Cambric station 2, values of volumetric water content are unreliable. However, Figure 4.9 shows the actual probe response (i.e., pre-calibration data), and although these data cannot be used quantitatively, they do illustrate the field situation. Once the flow period begins, water is constantly maintained in the channel; a positive head is maintained. Therefore, the subsurface should remain at near-saturated conditions. The probe response at all three depths reflects this near-saturated condition

(Figure 4.9). Figure 4.9 also shows that $\theta_{\mathrm{s}}$ is slightly higher near the surface than at depth. Based on the hydraulic and thermal properties shown in Tables 4.3 and 4.4, the model predicts a cumulative infiltration over the flow period of $740 \mathrm{~m}^{3}$ per meter $\left(7,961.2 \mathrm{ft}^{3}\right.$ per foot $)$ of channel with an average flux of $2.0 \mathrm{~m} / \mathrm{d}(6.6 \mathrm{ft} / \mathrm{d})$.

The model is also able to fit the temperature data for Cambric station 3, particularly for the two shallower depths (Figure 4.10). The model overpredicts temperatures at the $100-\mathrm{cm}(3.3-\mathrm{ft})$ depth for the first half of the simulation, which is most likely caused by material heterogeneity that is unaccounted for in the model. Thus, the advectively transported heat is delayed. Because of an incomplete calibration of the WCR used at Cambric station 3, only the raw instrument response is shown in Figure 4.11. The data show that once water is in the channel, the subsurface 

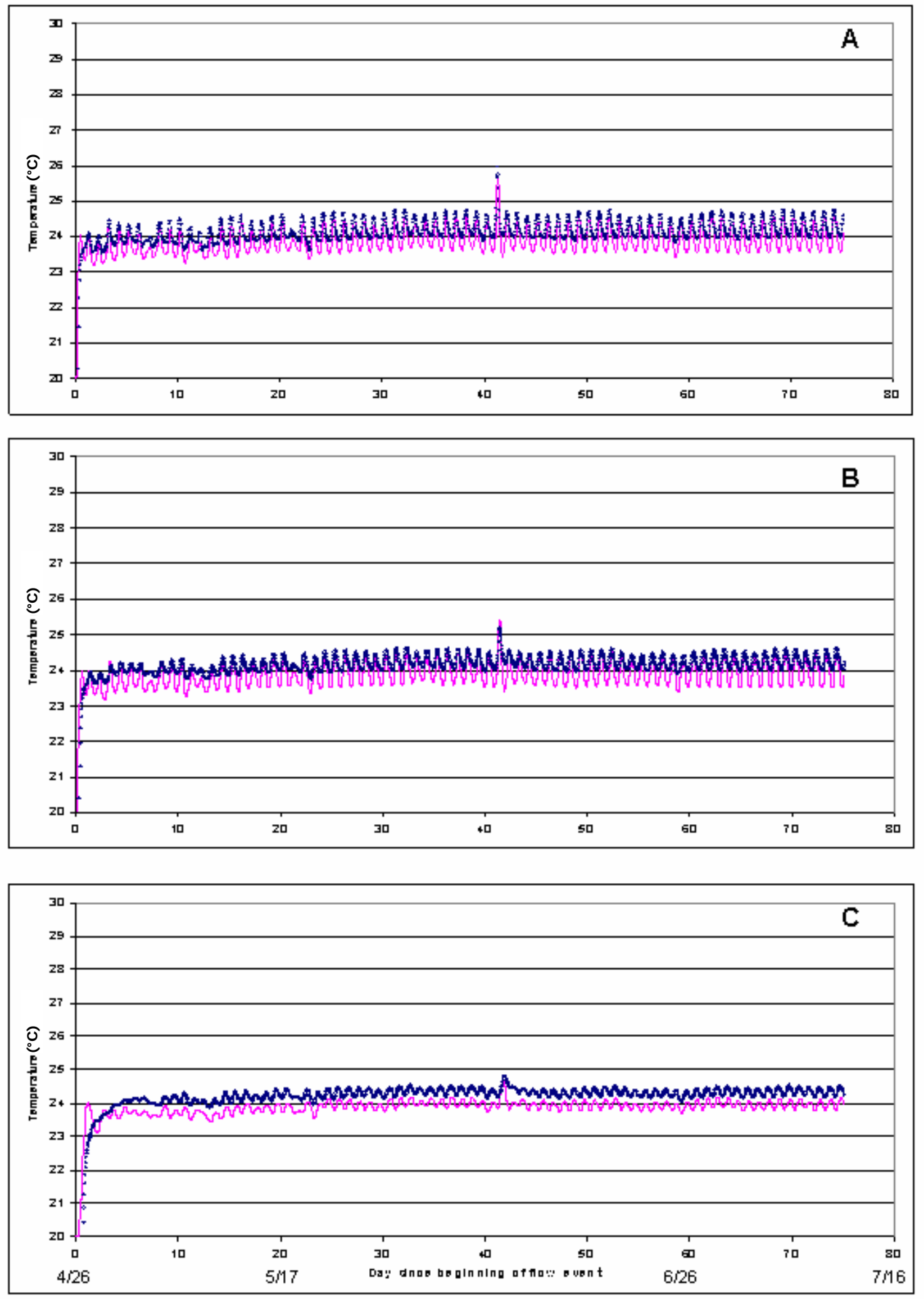

Figure 4.7. Comparison of modeled (solid line) and field (symbol) temperature data at Cambric station 1 at A) $30-\mathrm{cm}$, B) $50-\mathrm{cm}$, and C) $100-\mathrm{cm}$ depth. 

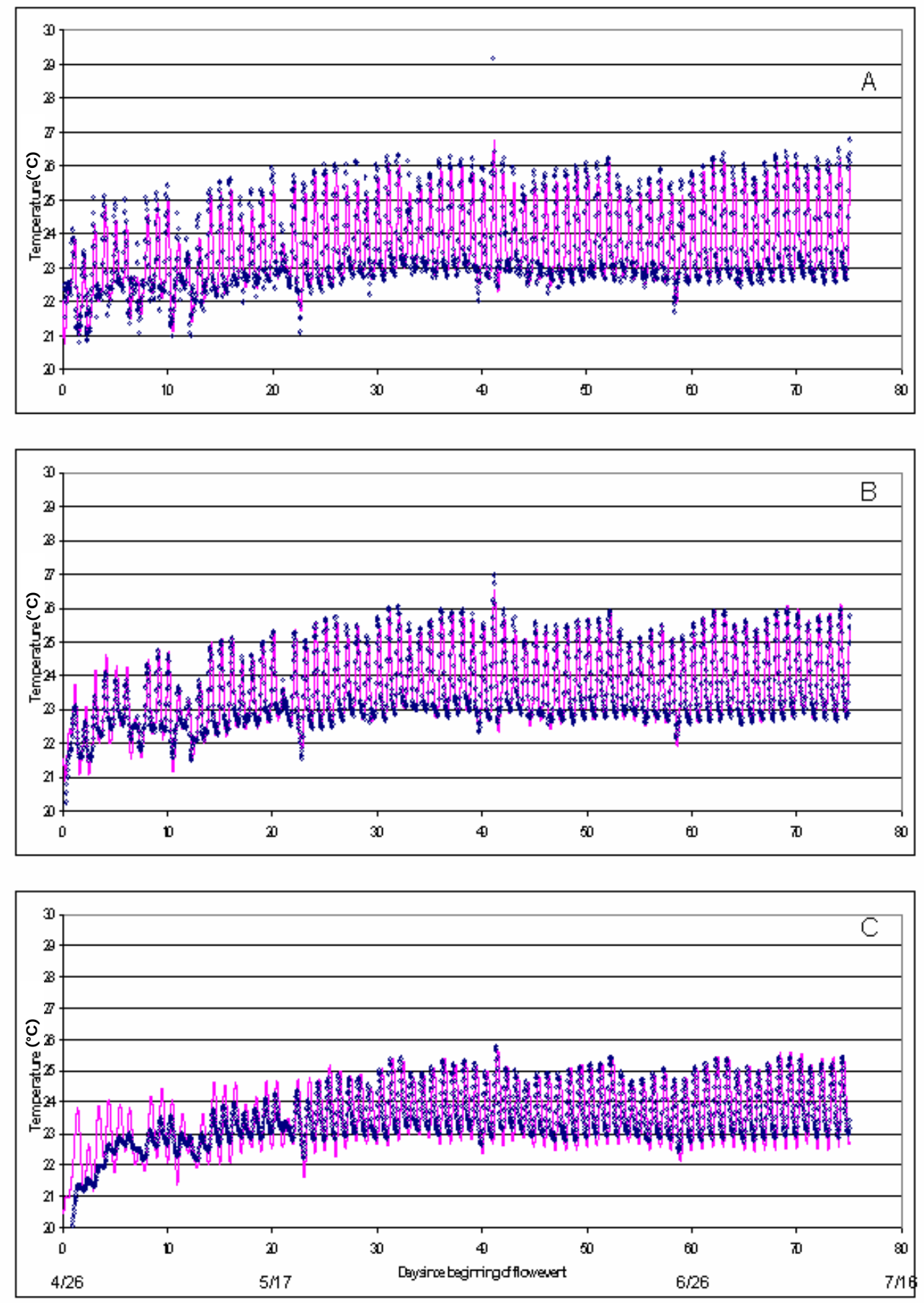

Figure 4.8. Comparison of modeled (solid line) and field (symbol) temperature data at Cambric station 2 at A) $30-\mathrm{cm}, \mathrm{B}) 50-\mathrm{cm}$, and C) $100-\mathrm{cm}$ depth. 
remains at a near-constant water content, assumed to approximate $\theta_{\mathrm{s}}$, throughout the monitored depth. The model predicts a cumulative infiltration for the flow period of $320 \mathrm{~m}^{3}$ per meter $\left(3,442.7 \mathrm{ft}^{3}\right.$ per foot $)$ of channel with an average flux of $0.6 \mathrm{~m} / \mathrm{d}(2.0 \mathrm{ft} / \mathrm{d})$.

The models for the Cambric Ditch were produced based on the fit to the temperature data alone. There were no hydraulic physical property data on the in-situ soils to support the parameters used in the model. To fit the temperature data, all parameters were in the range of those typical of coarse-textured soils.

The exceptions to this are the parameters used for ER-5-3 station 1, where the parameters used were more typical of a finer-grained substrate. This is reflected in the low values of predicted cumulative infiltration and the flux values. The ER-5-3 modeling results also agree with previously reported laboratory determined values of $\mathrm{K}_{\mathrm{s}}$, which show much lower values at ER-5-3 station 1 than at ER-5-3 station 4.

The HYDRUS-2D (Simunek et al., 1999) analyses indicate that temperature can be used to make relatively good estimates of soil water content, which correlate to infiltration, or in this case, to channel transmission loss estimates.

\subsection{One-Dimensional Darcian Flow Estimate}

The third method used to quantify transmission losses uses hydraulic gradient and water content in a Darcy's Law Approach (Freeze and Cherry, 1979) to calculate one-dimensional flow rates. Heat dissipation and water content data were collected from the subsurface for this analysis (Appendix A). Darcy's Law describes the movement of water through a porous media such as a soil or sediments in a stream channel. Darcy's Law is given (Freeze and Cherry, 1979) as

$$
\mathrm{Q}=\mathrm{KiA}
$$

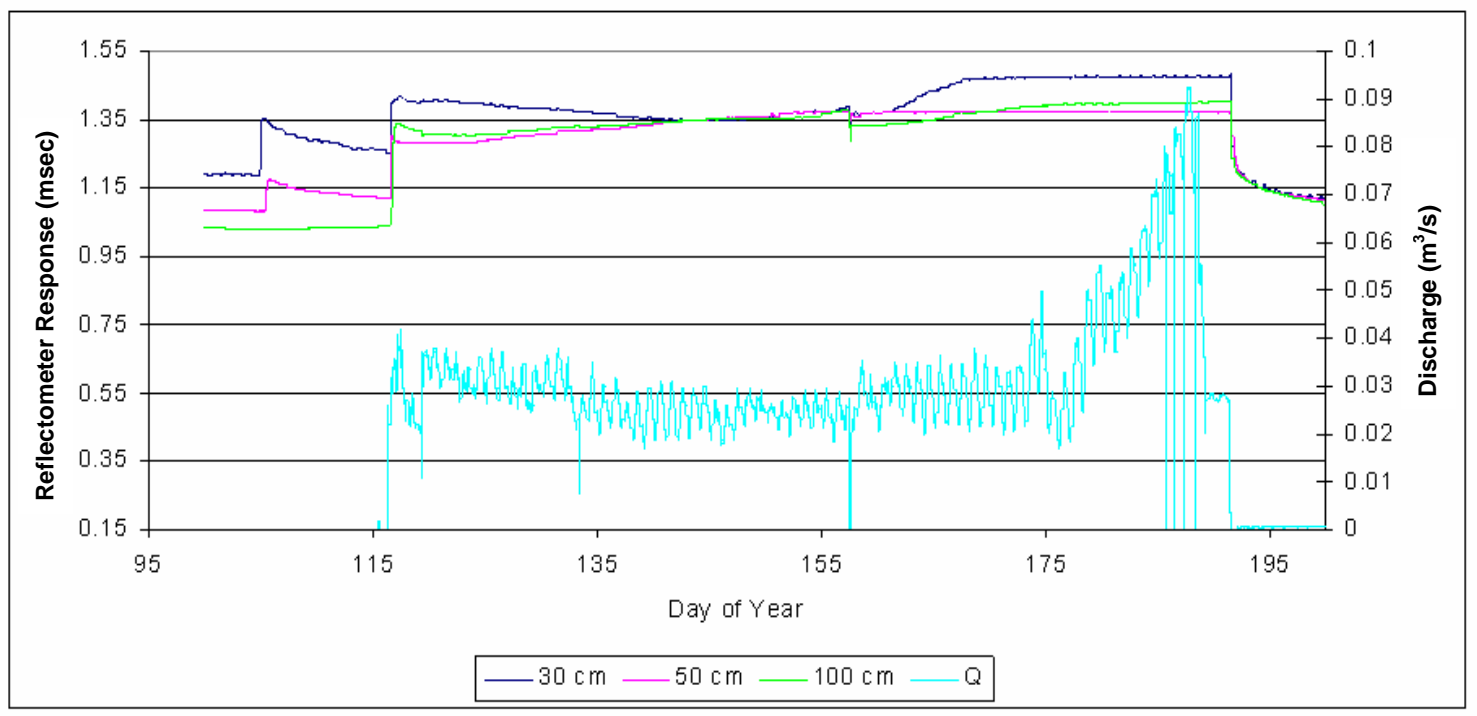

Figure 4.9. Raw data from WCR and discharge data collected at Cambric station 2. 

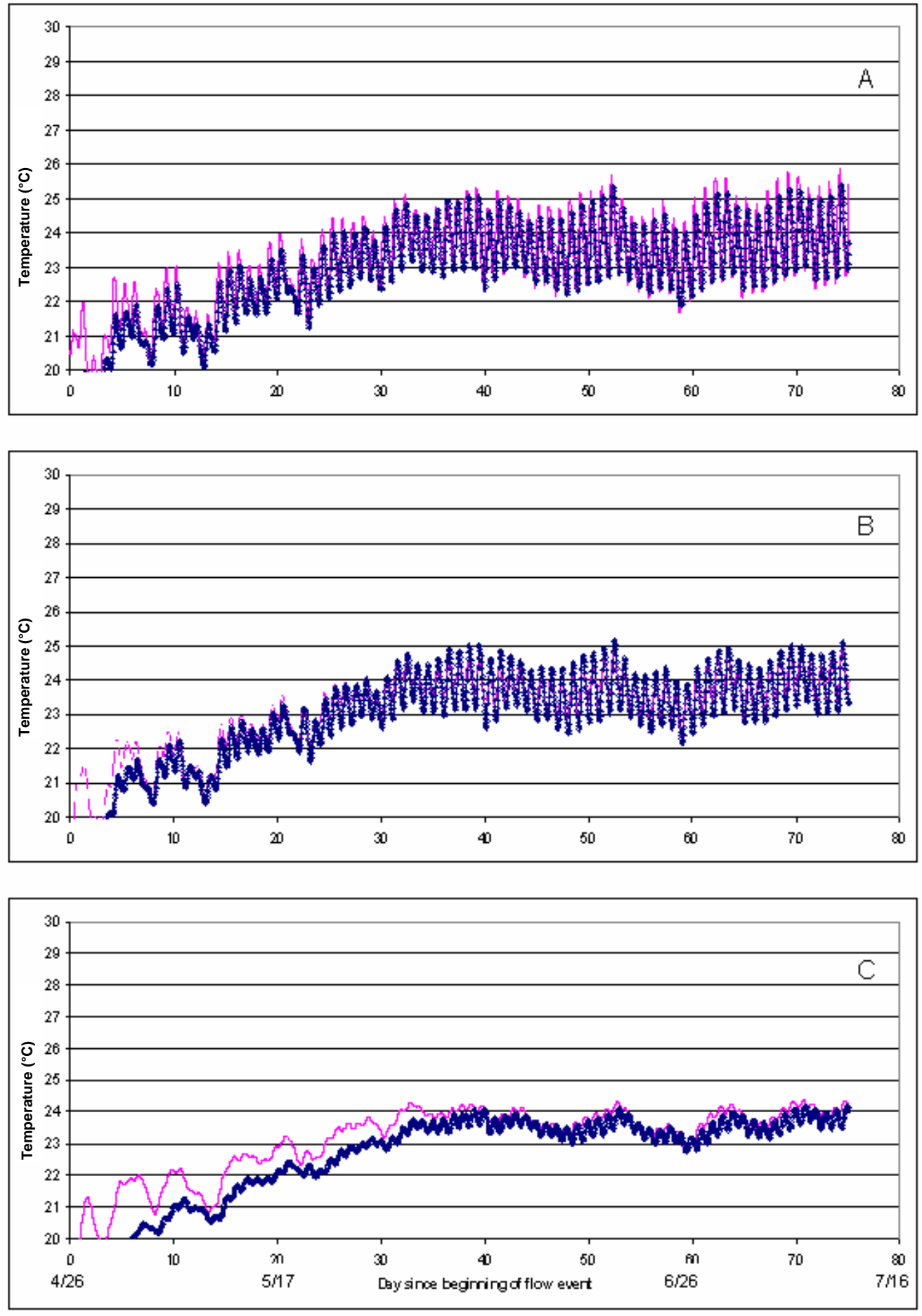

Figure 4.10. Comparison of modeled (solid line) and field (symbol) temperature data at Cambric station 3 at A) $30-\mathrm{cm}$, B) $50-\mathrm{cm}$, and C) $100-\mathrm{cm}$ depth. 


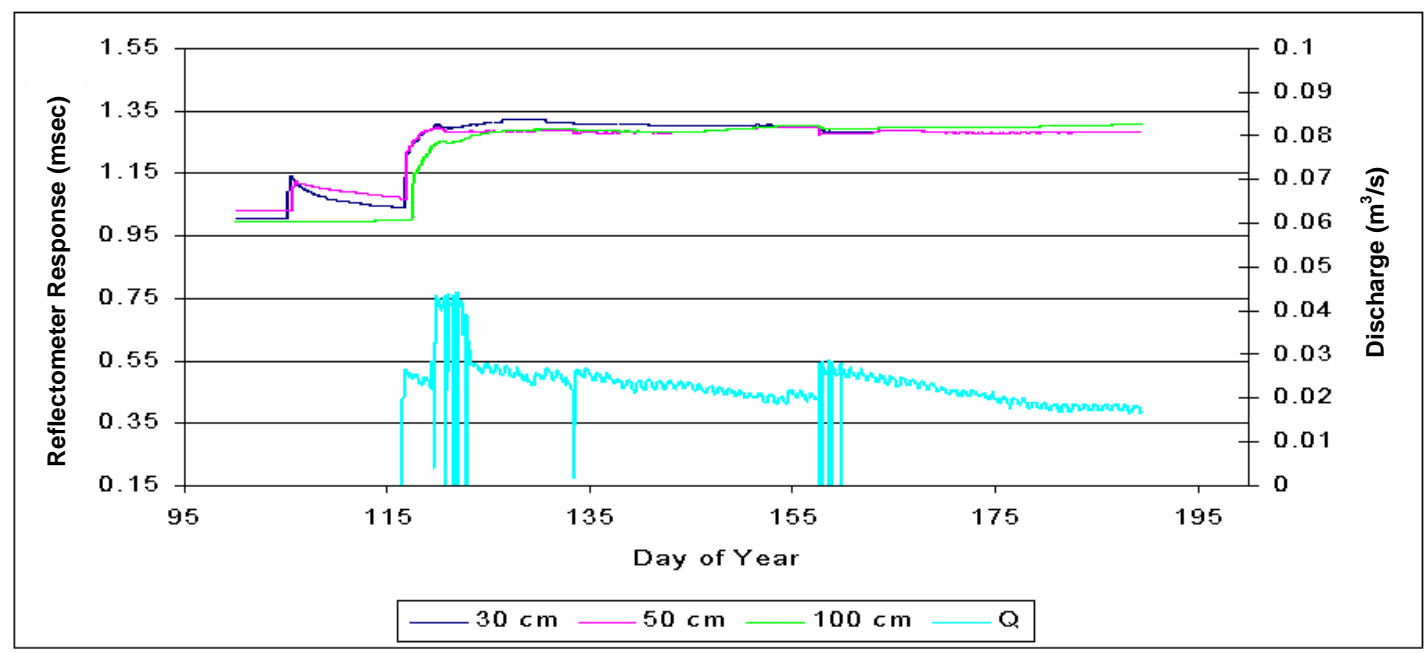

Figure 4.11. Raw data from WCR and discharge data collected at Cambric station 3.

where $\mathrm{K}$ is the hydraulic conductivity, $\mathrm{i}$ is the gradient of hydraulic head, $\mathrm{A}$ is the cross-section area through which flow takes place, and Q is the volumetric flow through cross-section $\mathrm{A}$ under gradient " $i$ " in porous media defined by conductivity $\mathrm{K}$. Under saturated conditions, $\mathrm{K}$ is a single value referenced as $\mathrm{K}_{\text {sat }}$, which defines the ability of the media to transmit water. Under partially saturated conditions, hydraulic conductivity is a function of the degree of saturation of the media.

Hydraulic gradient, i, describes the magnitude and direction of the force driving the water movement. It is measured as the difference in hydraulic head at two points along the flowpath divided by the distance between the measured points. Hydraulic head is the sum of the pressure head and elevation head. Pressure head in the soil is negative, and is known as "soil water tension" when the soil is not fully saturated. At the streambed, pressure head is equivalent to the stage when water is present, and is zero when there is no water in the channel. During the ER-5-3 experiment, stage was measured in the channel at each station and soil water tension was measured at 30,50 , and $100 \mathrm{~cm}(1.0,1.6$, and $3.3 \mathrm{ft})$ below the streambed at ER-5-3 stations 1 and 4.

Physical dimensions of the channel were measured in the field under typical flow conditions at each cross section, including the downstream length between the cross sections and the wetted perimeter of each cross section. The product of the downstream length between channel cross sections and the wetted perimeter defines the surface area through which the flow infiltrates the streambed and enters the underlying soil. This assumes that the one-dimensional gradient data and the two-dimensional area data may be combined to estimate the volume of infiltrating water.

The HDS probes at ER-5-3 stations 1 and 4 were buried in the channel bed at depths of 30, 50 , and $100 \mathrm{~cm}(1.0,1.6$, and $3.3 \mathrm{ft})$, and were calibrated to indicate soil water tension. The hydraulic gradient was calculated between the channel bed $[0 \mathrm{~cm}(0 \mathrm{ft})]$ and the $100-\mathrm{cm}(3.3-\mathrm{ft})$ HDS. Stage measurements made at the ER-5-3 flumes determined the pressure head at the channel bed. Data were collected at five-minute increments, and the database was queried for 
each 15-minute value. It was the 15-minute data that were used in making the Darcy infiltration estimate.

Saturated conductivities were determined in the laboratory for soil cores collected from four depths at stations 1 and 4 on the ER-5-3 channel. The geometric mean of the four conductivity values at each respective station was assumed to represent the average conductivity in the upper $100 \mathrm{~cm}(3.3 \mathrm{ft})$ of the soil beneath the channel. Saturated conductivities were used to obtain a first approximation of the infiltration occurring when water was present in the channel.

Stage and soil water tension data are available from the electronic field data collection record at 15-minute intervals throughout the period of record. Only the intervals during which flow was present in the channel are included in the estimation of infiltration by Darcy flow. The step-wise process of calculating the infiltration rate proceeds as follows:

1. The average hydraulic gradient for the 15-minute interval is evaluated as the average of the value measured at the beginning and end of each interval;

2. The average hydraulic gradient is multiplied by the hydraulic conductivity $(\mathrm{cm} / \mathrm{s})$ to obtain the infiltration rate, q, for the 15-minute interval;

3. The total infiltration rate for the 15-minute interval is determined as the infiltration rate multiplied by 900 seconds (15 minutes);

4. The total infiltration rate for the flow event is determined as the sum of total infiltration for all of the 15-minute intervals included in the event duration; and

5. The average infiltration rate for the event is determined by dividing the event total infiltration rate by the duration of the event in days.

Table 4.5 shows the results of the Darcy infiltration estimation made using hydraulic head and saturated hydraulic conductivity at ER-5-3 stations 1 and 4 (Appendix D). To compare results of the Darcy infiltration estimation with measured transmission loss in the channel, it is necessary to assume that the infiltration rate at a particular station is representative of an identifiable channel reach. The significant difference between soil conditions (Table 2.1) and infiltration estimates (Table 4.5) at ER-5-3 station 1 and station 4 precludes taking an average to represent infiltration over the entire instrumented channel.

Channel length and average wetted perimeter for ER-5-3 reach 3 (between ER-5-3 stations 3 and 4) were developed from field surveys and are given in Table 4.6. These values are used in estimating total infiltration volume for the specific reach. The estimate of total infiltration volume over ER-5-3 reach 3 assumes the infiltration rate calculated at ER-5-3 station 4 is representative of the entire reach. Infiltration over ER-5-3 reach 3, estimated by the Darcy analysis, is 7,572.6, 12,420.1, and $11,931.2 \mathrm{~m}^{3}\left(267,423.8,438,611.7\right.$, and 421,346.4 $\left.\mathrm{ft}^{3}\right)$ for flow events 1,2 , and 3 , respectively.

\subsubsection{Results of Darcian Flow Estimate}

The Darcy infiltration estimation over-estimates observed transmission loss between ER-5-3 stations 3 and 4 for all three experimental flow events on the ER-5-3 channel. The error 
Table 4.5. Darcy infiltration rate estimates for ER-5-3 station 1 and station 4

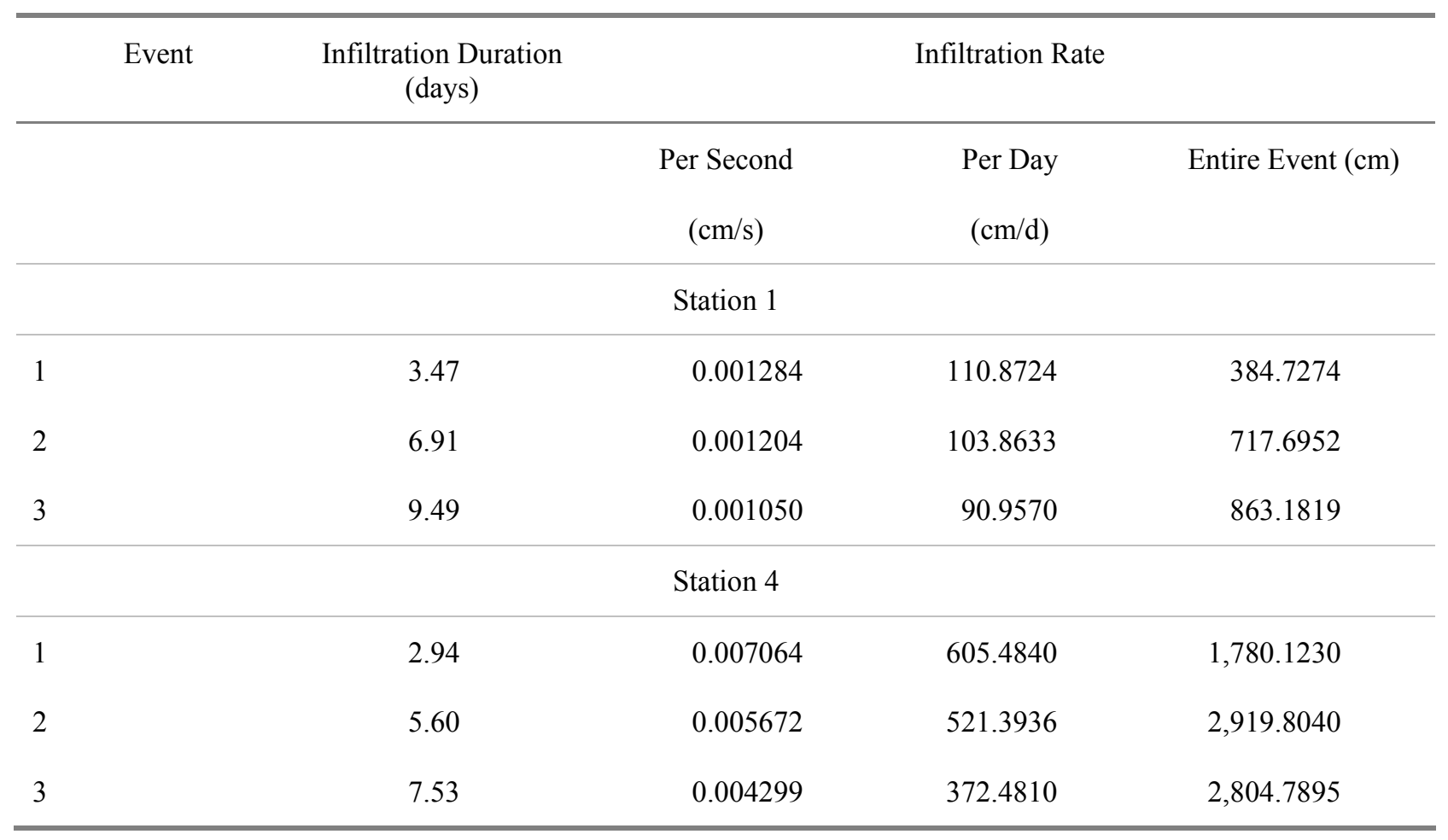

Table 4.6. ER-5-3 channel dimensions and infiltration between station 3 and 4 for each flow event.

\begin{tabular}{|c|c|c|c|}
\hline $\begin{array}{l}\text { Average wetted perimeter: } \\
\text { Range of wetted perimeters: } \\
\text { Length: } \\
\text { Wetted Area: }\end{array}$ & $\begin{array}{l}66.25 \mathrm{cn} \\
46 \text { to } 94 \\
642.2 \mathrm{~m} \\
425.4 \mathrm{~m}^{2}\end{array}$ & & \\
\hline & \multicolumn{2}{|c|}{ Infiltration by Darcy Estimation } & $\begin{array}{l}\text { Transmission Loss by } \\
\text { Flow Difference }\end{array}$ \\
\hline Event & Station $4(\mathrm{~cm})$ & Reach $3\left(\mathrm{~m}^{3}\right)$ & Reach 3-4 $\left(\mathrm{m}^{3}\right)$ \\
\hline 1 & $1,780.12$ & $7,572.6$ & $1,019.4$ \\
\hline 2 & $2,919.80$ & $12,420.8$ & $1,496.5$ \\
\hline 3 & $2,804.79$ & $11,931.6$ & $1,920.8$ \\
\hline
\end{tabular}

ranges from six to eight times the observed loss. The difference in the loss estimation is likely due to using saturated hydraulic conductivity in the calculation and assuming that soil characteristics and saturated hydraulic conductivity at ER-5-3 station 4 describe the entire reach. The upper half and lower half of ER-5-3 reach 3 are on different soil surfaces (Figure 2.1). The soil of the upper half commonly contains shrub and animal burrows (Table 2.1). In contrast, the soil of the lower half of the reach contains only sparse vegetation and no animal burrows (Table 2.1). These differences may represent a significant difference in biological disturbance of the soil and an associated increase in permeability. Thus, without more spatially detailed knowledge of the soil characteristics and hydraulics within a channel, it is unlikely that using Darcy's Law approach to estimate transmission losses is a valid approach. 
THIS PAGE INTENTIONALLY LEFT BLANK 


\subsection{CONCLUSIONS}

Transmission losses along ephemeral channels are an important, yet poorly understood, aspect of rainfall-runoff prediction. Losses occur as flow infiltrates channel bed, banks, and floodplains. This research was designed to improve understanding of the impact of transmission loss on ephemeral flood modeling and compare various methodologies for predicting runoff from rainfall events. Two channel transmission loss field experiments were performed on the NTS between 2001 and 2003: the first was conducted in the ER-5-3 channel, and the second was conducted in the Cambric Ditch. Both studies used water discharged from unrelated drilling activities during well development and aquifer pump tests.

Discharge measurements at several flumes located along the channels were used to directly measure flow from which transmission losses were calculated. Flume locations were chosen in relation to geomorphic surface types and ages, vegetative cover and types, subsurface indurated layers (calcrete), channel slopes, etc. At some of the flumes, instrument arrays, consisting of WCR, HDS, and thermocouples were installed in the subsurface to collect additional data for loss quantification analyses.

Transmission losses are quantified using three different analysis methods. Method 1 uses Lane's Method (Lane, 1983) for estimating flood magnitude in ephemeral channels. Method 2 uses heat as a subsurface tracer for infiltration. Numerical modeling, using HYDRUS-2D (Simunek et al., 1999), a finite-element-based flow and transport code, is applied to estimate infiltration from soil temperature data. Method 3 uses hydraulic gradient and water content in a Darcy's Law approach (Freeze and Cherry, 1979) to calculate one-dimensional flow rates. Heat dissipation and water content data were collected for this analysis.

In the ER-5-3 channel experiment, using the discharge measurements from the flumes, up to 70 percent of the flow was lost in reaches of 1,000 to $2,000 \mathrm{~m}(3,280$ to $6,560 \mathrm{ft})$. In Cambric Ditch, approximately 40 percent of the initial upstream flow was lost throughout the 1,000-m $(3,300-\mathrm{ft})$ experimental channel. The timing of flow events at each subsequent downstream

flume location within these experimental channels suggested transmission losses were occurring in the intervening reach. Flow events were generally delayed and of shorter duration at downstream flumes. Loss of flow volume between the upstream and downstream flumes of each reach confirmed transmission losses. The greatest losses were measured in the reaches with the youngest soils, characterized by unconsolidated sands, no calcrete, and no indication of long-term stability. Losses were less in the reaches where geomorphic surface ages were older and calcrete present.

Thermocouples, WCR probes, and HDS probes were buried just downstream of the flumes at the fully instrumented ER-5-3 stations 1 and 4 and at Cambric Ditch stations 1 (thermocouples only), 2, and 3. Thermocouples were used to determine temperature changes associated with infiltration. Temperature changes clearly indicated the beginning and end of each flow event. Thermal gradients correspond well with channel and surficial geomorphology and measured losses. Larger thermal gradients are measured on older geomorphic surfaces with buried calcrete, suggesting heat transfer by conduction, and thus lower infiltration rates. Smaller thermal gradients, suggesting advection-dominated heat transfer and higher infiltration rates, are observed in reaches on younger geomorphic surfaces. 
The WCR probes were used to measure water content in the soil. The WCR measured an abrupt, large-magnitude change in moisture content with the arrival of flow in the channel. The HDS probes were used to evaluate soil water tension. All probes reflected the diurnal atmospheric temperature variations, as well as measuring the lowest water tension in the wettest conditions. However, HDS sensor sensitivity is quite poor for the range of soil wetness typically found in arid environments; thus, readings may not represent actual soil conditions.

The transmission losses are quantified using three different analysis methods, the first being Lane's Method (Lane, 1983) for estimating flood magnitude in ephemeral channels that compensates for transmission losses. As inflow-outflow data for each reach within the experimental channels was known from flume measurements, Lane's Method was applied. The method uses a regression equation to predict outflow from a given channel reach based upon measured inflow to the reach for a discreet event. The predicted outflows could then be compared with the measured flume data.

In the regression equation, one of the required parameters, $\mathrm{a}(\mathrm{x}, \mathrm{w})$, should always be a negative value (Lane, 1983). However, evaluation of the measured inflow-outflow data from the experimental channels resulted in only one reach in each of the two channels producing the required negative value for the $\mathrm{a}(\mathrm{x}, \mathrm{w})$ parameter. It is not clear why this parameter did not meet the $\mathrm{a}(\mathrm{x}, \mathrm{w})<0$ constraint; however, it may be that the conditions of the transmission loss experiments were not sufficiently similar temporally or spatially to the conditions underlying the data Lane used in deriving his method.

Therefore, only two reaches, ER-5-3 reach 3 (between ER-5-3 stations 3 and 4) and Cambric reach 2 (between Cambric stations 2 and 3), produced an intercept and slope for the Lane's Method estimating equation that satisfied the constraints of the method.

For both the ER-5-3 reach 3 and Cambric reach 2, Lane's Method slightly over-estimates the measured outflow for each reach in two of the three flow events; however, the percent error of the over-estimated outflow only ranges between 1.3 and 5.1 percent. For the remaining flow event in each reach, the method under-estimates the measured outflow, but again the percent error is relatively small, ranging between 2.5 and 6.0 percent. These results suggest that the Lane's Method is a good estimator of discharge from a reach when the regression equation coefficients are within proper constraints.

The HYDRUS-2D (Simunek et al., 1999) finite-element-based flow and transport code was used to model the measured temperature data from the experimental channels. The modeling of the ER-5-3 channel was more complicated than that of the Cambric Ditch because the ER-5-3 channel was dry at times during the modeled period, as the pumps were shut off at well ER-5-3 for extended periods of time. Although the pumps were also turned off at well RNM-2S, they were never off long enough to prevent discharge to the Cambric Ditch during the respective model period.

The model was able to fit the measured temperature and water content data for ER-5-3 stations 1 and 4 relatively well; however, there were some inconsistencies between the measured water content and the modeled predictions at depth. These inconsistencies were most likely the 
result of increasing heterogeneity as the flowpath lengthens, and with the water travel time to the deeper probes.

The models for ER-5-3 stations 1 and 4 predicted cumulative infiltration of approximately $3.0 \mathrm{~m}^{3}$ per meter $\left(32.3 \mathrm{ft}^{3}\right.$ per foot) and $32 \mathrm{~m}^{3}$ per meter $\left(344.3 \mathrm{ft}^{3}\right.$ per foot $)$, respectively. The flux was $0.3 \mathrm{~m} / \mathrm{d}(1.0 \mathrm{ft} / \mathrm{d})$ and $4.2 \mathrm{~m} / \mathrm{d}(13.8 \mathrm{ft} / \mathrm{da})$ at ER-5-3 stations 1 and 4 , respectively.

The models for the Cambric Ditch were produced based upon the fit to the temperature data alone, as there were no hydraulic physical property data on the in-situ soils to support the parameters used in the model. Again, the model was able to fit the measured temperature data for Cambric Ditch stations 1, 2, and 3 relatively well. The models for Cambric Ditch stations 1, 2, and 3 predicted cumulative infiltration of approximately $500.0 \mathrm{~m}^{3}$ per meter $\left(5,379.2 \mathrm{ft}^{3}\right.$ per foot), $740.0 \mathrm{~m}^{3}$ per meter $\left(7,961.2 \mathrm{ft}^{3}\right.$ per foot $)$, and $320.0 \mathrm{~m}^{3}$ per meter $\left(3,442.7 \mathrm{ft}^{3}\right.$ per foot $)$, respectively. The flux was $1.8 \mathrm{~m} / \mathrm{d}(5.9 \mathrm{ft} / \mathrm{d}), 2.0 \mathrm{~m} / \mathrm{d}(6.6 \mathrm{ft} / \mathrm{d})$, and $0.6 \mathrm{~m} / \mathrm{d}(2.0 \mathrm{ft} / \mathrm{da})$ at Cambric stations 1, 2, and 3, respectively.

The HYDRUS-2D (Simunek et al., 1999) analyses indicate that temperature can be used to make relatively good estimates of soil water content, which correlates to infiltration, or in this case, to channel transmission loss estimates.

Method 3 uses hydraulic gradient and water content in a Darcy's Law approach (Freeze and Cherry, 1979) to calculate one-dimensional flow rates. Heat dissipation and water content data were collected for this analysis. Heat dissipation and water content data collected from ER-5-3 stations 1 and 4 were used for this analysis. As water content data were not collected in Cambric Ditch, no analysis was performed of this second experimental channel. To compare the results of the Darcy infiltration estimation with measured transmission losses in the ER-5-3 channel, it was necessary to assume that the infiltration rate at a particular station was representative of an identifiable channel reach. The significant difference between soil conditions and infiltration estimates at stations 1 and 4 precludes taking an average to represent infiltration over the entire length of the ER-5-3 channel.

The Darcy's Law approach estimate of total infiltration volume over the ER-5-3 reach 3 assumes the infiltration rate calculated at ER-5-3 station 4 is representative of the entire reach. Infiltration estimates, using the Darcy analysis, ranged from $7,572.6$ to $12,420.1 \mathrm{~m}^{3}(267,423.8$ to $438,611.7 \mathrm{ft}^{3}$ ) for the various flow events in the channel. These calculated loss estimates are six to eight times greater than the measured losses between ER-5-3 stations (flumes) 3 and 4 . The difference in the loss estimation is likely due to using saturated hydraulic conductivity in the calculation and assuming that soil characteristics and saturated hydraulic conductivity at station 4 describe the entire reach. Thus, without more spatially detailed knowledge of the soil characteristics and hydraulics within a channel, it is unlikely that using Darcy's Law approach to estimate transmission losses is a valid approach.

Although transmission losses measured through the entire length of both experimental channels ranged upwards between 40 and 70 percent, it is clear from the variation of transmission loss volumes measured in shorter reaches of the channels that these losses vary greatly along the length of a channel. The variation in volume of transmission losses in the shorter reaches demonstrates the important roles that geomorphic surface types and ages, 
vegetative cover and types, subsurface indurated layers (calcrete), channel slopes, soil hydraulic properties, etc., play in runoff prediction.

These studies indicate that there may be some validity in applying temperature modeling or Lane's Method (1983) to estimating transmission losses if the necessary detailed, specific, and accurate information regarding geomorphic surfaces, vegetation, subsurface conditions, and soils properties is available. However, without this site-specific information, it appears that it would be difficult to consistently estimate accurate transmission losses using any of the three methods evaluated in these studies. Thus, at this time, it is not recommended that DOE/NNSA, or any other entity, attempt to reduce any rainfall-runoff model-generated discharge value to account for transmission losses in any engineering analysis or design.

\subsection{REFERENCES}

Bechtel Nevada, 2000. Geomorphic Surface Map of Northern Frenchman Flat, Nevada Test Site, Nye County, Nevada. Bechtel Nevada, Las Vegas, Nevada.

Chung, S.O. and R. Horton, 1987. Soil heat and water flow with a partial surface mulch. Water Resources Research, 23:2175-2186.

Constantz, J., 1982. Temperature dependence of unsaturated hydraulic conductivity of two soils. Soil Science Society of America Journal, 46:466-470.

Freeze, R.A. and J.A. Cherry, 1979. Groundwater. Prentice-Hall, Inc., Englewood Cliffs, NJ, $604 \mathrm{pp}$.

Lane, L.J., 1972. A Proposed Model for Flood Routing in Abstracting Ephemeral Channels. Hydrology and Water Resources in Arizona and the Southwest, 2(2):439-453.

Lane, L.J., 1983. Transmission Losses. Chapter 19, Section 4, Hydrology, National Engineering Handbook, NEH-4, U. S. Department of Agriculture, Soil Conservation Service, Washington, D. C. pp $19.1-19.21$.

Miller, J.J., R.H. French, M.H. Young and S.A. Mizell, 2003. Effect of Soil Condition on Channel Transmission Loss During Ephemeral Flow Events. American Society of Civil Engineers, Environmental and Water Resources Institute, World Water and Environmental Congress, Conference Proceedings, June 23-27, 2003, Philadelphia, PA.

Mizell, S.A., J.J. Miller and R.H. French, 2005. Effect of Soil Condition on Channel Transmission Loss During Ephemeral Flow Events - Part 2. American Society of Civil Engineers, Environmental and Water Resources Institute, World Water and Environmental Congress, Conference Proceedings, May 15-19, 2005, Anchorage, AK.

Mualem, Y., 1976. A new model for predicting the hydraulic conductivity of unsaturated porous media. Water Resources Research, 12:513-522. 
Ross, W.C. and S.W. Wheatcraft, 1994. A Two-Dimensional Simulation of Tritium Transport in the Vadose Zone at the Nevada Test Site. Publication No. 45098, Water Resources Center, Desert Research Institute, Reno, Nevada.

Sharma, K.D. and J.S.R. Murthy, 1994. Estimating Transmission Losses in an Arid Region. Journal of Arid Environment, 26(3):209-219.

Simunek, J., M. Sejna and M.Th. van Genuchten, 1999. HYDRUS-2D/MESHGEN-2D software for simulating water flow and solute transport in two-dimensional variably saturated media. Version 2.0. IGWMC - TPS - 53C, International Ground Water Modeling Center, Colorado School of Mines, Golden, CO, 227 pp.

Sophocleous, M., 1979. Analysis of water and heat flow in unsaturated-saturated porous media. Water Resources Research, 15:1195-1206.

van Genuchten, M.T., 1980. A closed-form equation for predicting the hydraulic conductivity of unsaturated soils. Soil Science Society of America Journal, 44:892-898.

Wraith, J.M., D. Or, 1999. Temperature effects on soil bulk dielectric permittivity measured by time domain reflectometry: Experimental evidence and hypothesis development, Water Resource Research, 35(2):361-370. 
THIS PAGE INTENTIONALLY LEFT BLANK 


\section{DISTRIBUTION}

Jhon Carilli

Waste Management Division

Nevada Site Office

National Nuclear Security Administration

U.S. Department of Energy

P.O. Box 98518

Las Vegas, NV 89193-8518

Frank Di Sanza

Acting Deputy Assistant Manager

Office of Environmental Management

Nevada Site Office

National Nuclear Security Administration

U.S. Department of Energy

P.O. Box 98518

Las Vegas, NV 89193-8518

Russ Dyer

Office of Civilian Radioactive Waste

Management

Office of Repository Development

U.S. Department of Energy

1551 Hillshire Drive

Las Vegas, NV 89134

Dave Emme

Nevada Division of Environmental

Protection

Bureau of Waste Management

333 W. Nye Lane, Suite 138

Carson City, NV 89701-0851

Erwin Faqua, Contracting Officer

Acquisition and Financial Assistance

Department

Office of Business Services

National Nuclear Security Administration

Albuquerque Office

U.S. Department of Energy

P.O. Box 5400

Albuquerque, NM 87185-5400

Marjory Jones

Division of Hydrologic Sciences

Desert Research Institute

2215 Raggio Parkway

Reno, NV 89512-1095
Steve Lawrence, Assistant Manager

Site Operations

Nevada Site Office

National Nuclear Security Administration

U.S. Department of Energy

P.O. Box 98518

Las Vegas, NV 89193-8518

David Shafer

Division of Hydrologic Sciences

Desert Research Institute

755 E. Flamingo Road

Las Vegas, NV 89119-7363

Sandra Waisley, Director

Office of Cleanup Technologies (EM-21)

U.S. Department of Energy

19901 Germantown Road

Germantown, MD 20874

Terry Wallace, Assistant Manager

Technical Services

Nevada Site Office

National Nuclear Security Administration

U.S. Department of Energy

P.O. Box 98518

Las Vegas, NV 89193-8518

Nevada State Library and Archives

State Publications

100 North Stewart Street

Carson City, NV 8971-4285

Archives

Getchell Library

University of Nevada, Reno

DeLaMare Library/262

University of Nevada, Reno

Document Section, Library

University of Nevada, Las Vegas

4505 Maryland Parkway

Las Vegas, NV 89154 
Stoller-Navarro Joint Venture

Bldg. B-1

P.O. Box 93838, M/S 439

Las Vegas, NV 89193-3838

ATTN: Toni Miller, M/S 439

Library

Southern Nevada Science Center

Desert Research Institute

755 E. Flamingo Road

Las Vegas, NV 89119-7363

Public Reading Facility

c/o Nuclear Testing Archive

Nevada Site Office

National Nuclear Security Administration

U.S. Department of Energy

P.O. Box 98521

Las Vegas, NV 89193-8521
Technical Library

Nevada Site Office

National Nuclear Security Administration

U.S. Department of Energy

P.O. Box 98518

Las Vegas, NV 89193-8518

Office of Scientific and Technical Information

U.S. Department of Energy

P.O. Box 62

Oak Ridge, TN 37831-9939

(electronic copy) 